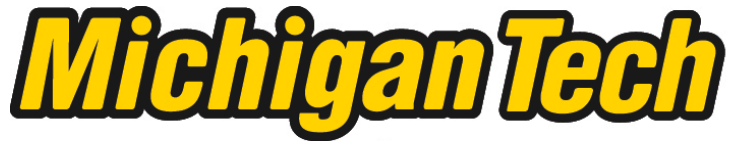 \\ Michigan Technological University Create the Future Digital Commons @ Michigan Tech
}

Dissertations, Master's Theses and Master's Reports - Open

Dissertations, Master's Theses and Master's

Reports

2008

\section{High cycle fatigue of AA6082 and AA6063 aluminum extrusions}

Nicholas E. Nanninga

Michigan Technological University

Follow this and additional works at: https://digitalcommons.mtu.edu/etds

Part of the Engineering Science and Materials Commons

Copyright 2008 Nicholas E. Nanninga

\section{Recommended Citation}

Nanninga, Nicholas E., "High cycle fatigue of AA6082 and AA6063 aluminum extrusions ", Dissertation, Michigan Technological University, 2008.

https://doi.org/10.37099/mtu.dc.etds/18

Follow this and additional works at: https://digitalcommons.mtu.edu/etds

Part of the Engineering Science and Materials Commons 


\title{
HIGH CYCLE FATIGUE OF AA6082 AND AA6063 ALUMINUM EXTRUSIONS
}

By

Nicholas E. Nanninga

\author{
A DISSERTATION \\ Submitted in partial fulfillment of the requirements \\ for the degree of \\ DOCTOR OF PHILOSOPHY \\ (Materials Science and Engineering) \\ MICHIGAN TECHNOLOGICAL UNIVERSITY \\ 2008
}

Copyright@Nicholas E. Nanninga 2008 
This dissertation, "High cycle fatigue behavior of AA6082 and AA6063 aluminum extrusions," is hereby approved in partial fulfillment of the requirements for the degree of DOCTOR OF PHILOSOPHY in the field of Materials Science and Engineering.

\section{DEPARTMENT:}

Materials Science and Engineering

\section{Signatures:}

Dissertation Advisor

Typewritten Name _ Calvin L. White

Department Chair Typewritten Name Mark R. Plichta.

Date 


\section{Abstract}

The high cycle fatigue behavior of hollow extruded AA6082 and AA6063 aluminum extrusions has been studied. Hollow extruded aluminum profiles can be processed into intricate shapes, and may be suitable replacements for fatigue critical automotive applications requiring reduced weight. There are several features inherent in hollow aluminum extrusions, such as seam welds, charge welds, microstructural variations and die lines. The effects of such extrusion variables on high cycle fatigue properties were studied by taking specimens from an actual car bumper extrusion. It appears that extrusion die lines create large anisotropy differences in fatigue properties, while welds themselves have little effect on fatigue lives. Removal of die lines greatly increased fatigue properties of AA6082 specimens taken transverse to the extrusion direction. Without die lines, anisotropy in fatigue properties between AA6082 specimens taken longitudinal and transverse to the extrusion direction, was significantly reduced, and properties associated with the orientation of the microstructure appears to be isotropic. A fibrous microstructure for AA6082 specimens showed great improvements in fatigue behavior. The effects of elevated temperatures and exposure of specimens to $\mathrm{NaCl}$ solutions was also studied. Exposure to the salt solution greatly reduced the fatigue lives of specimens, while elevated temperatures showed more moderate reductions in fatigue lives. 


\section{Acknowledgements}

The funding of this research project by Hydro Aluminium was greatly appreciated. I would like to thank my advisor, Dr. Calvin White, for his continual encouragement, support and knowledge. I want to thank my family for their support of me through graduate school. The assistance of MTU faculty and staff members was greatly valued, specifically, John Lukowski, Mike LaCourt and Owen Mills. I would also like to recognize Trond Furu, Richard Dickson, Ola Anderson and Helen Wykamp of Hydro Aluminum for materials and support. 


\section{TABLE OF CONTENTS}

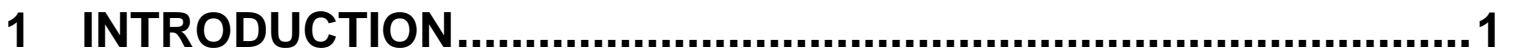

2 BACKGROUND ....................................................................... 4

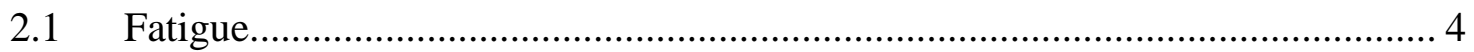

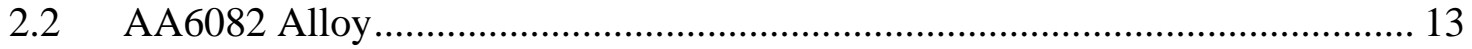

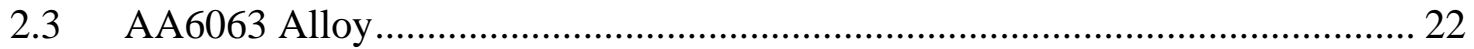

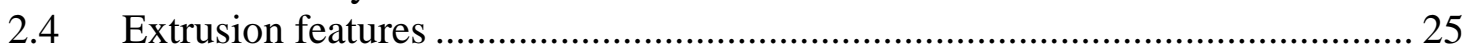

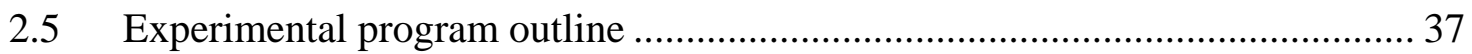

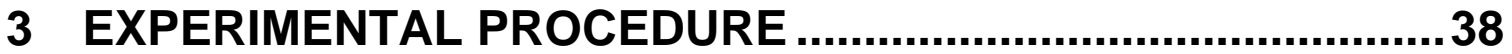

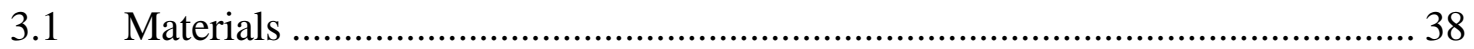

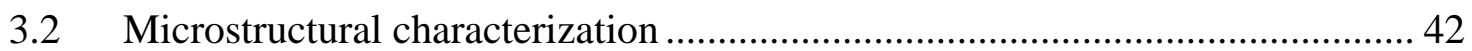

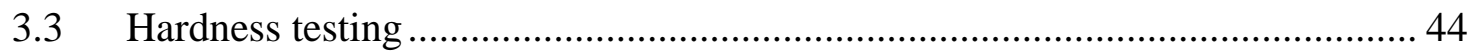

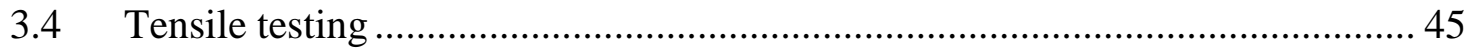

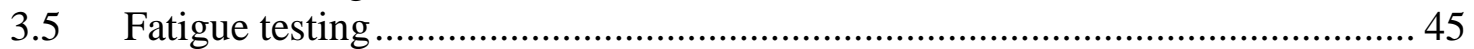

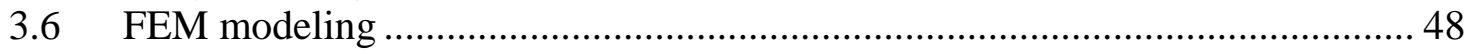

4 AA6082 RESULTS AND DISCUSSION $\ldots \ldots \ldots \ldots \ldots \ldots \ldots \ldots \ldots \ldots \ldots \ldots$

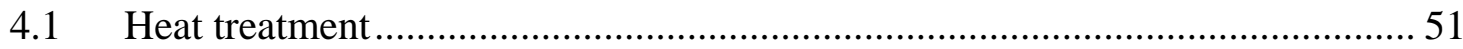

4.2 Heat treated microstructure........................................................................... 53

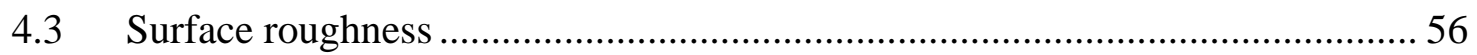

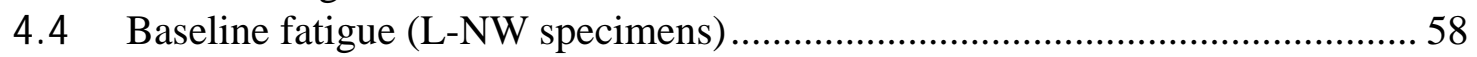

4.5 Effect of orientation/die lines on fatigue ......................................................... 60

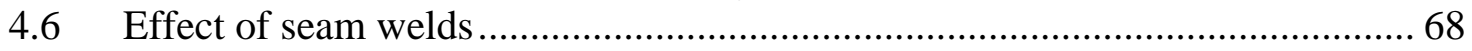

4.7 Effect of charge welds (position along extrusion length) .................................. 75

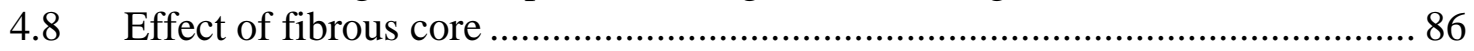

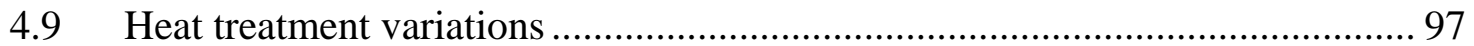

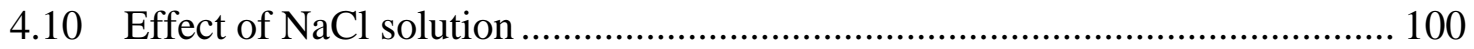

4.11 Effect of elevated temperature .......................................................................... 108

5 AA6063 RESULTS AND DISCUSSION ................................115

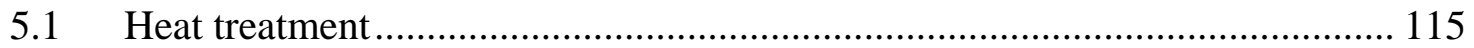

$5.2 \quad$ Heat treated microstructure.............................................................................. 116

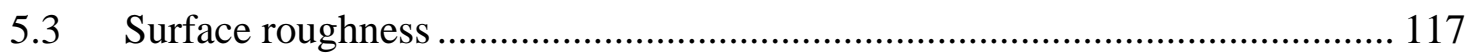

5.4 Baseline fatigue (L-NW specimens) ...................................................... 118

5.5 Effect of orientation/die lines on fatigue .................................................... 120

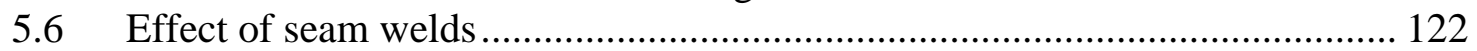

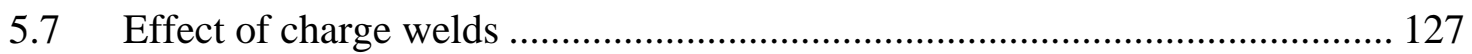

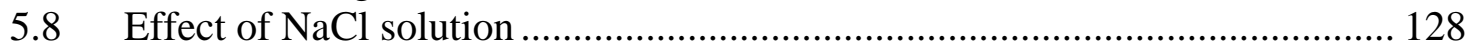

6 EFFECT OF ROUGHNESS ON RUN-OUT STRESS ...............133

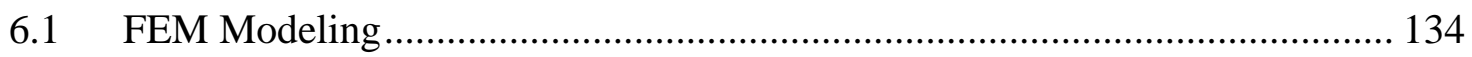

7 CONCLUSIONS ....................................................................... 141

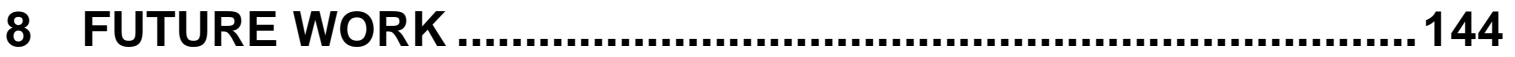

9 REFERENCES...................................................................... 146 


\section{LIST OF FIGURES}

Figure 2-1. Schematic illustration of stages in fatigue failure ......................... 5

Figure 2-2. Association between in-service and laboratory stress cycles that lead to fatigue failure and nomenclature used in characterizing fatigue behavior of materials (after [6]) ……......................... 8

Figure 2-3. Illustration of a stress-life curve (after [6]) ................................ 10

Figure 2-4. Illustration of competing roles of particle cutting and dislocation bowing in age hardening (after [6])........................................ 17

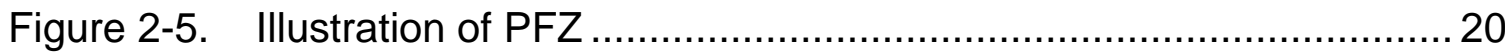

Figure 2-6. Schematic of seam weld origin in extrusion process .................... 28

Figure 2-7. a. Illustration of the origin of charge weld interfaces b. relationship between charge and seam welds........................................... 29

Figure 2-8. The four stages or zones that can occur during continuous billet

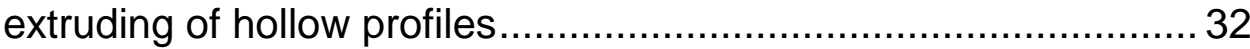

Figure 2-9. Schematic of die line origins................................................... 33

Figure 2-10. Schematic S-N curve for smooth and notched fatigue specimens 36

Figure 3-1. Schematic illustration of profile and specimen locations obtained from A, B and C faces of extrusion profile ................................... 39

Figure 3-2. Specimen geometry (in $\mathrm{mm}$ ). Specimen thickness varies from 2.5 to $3.5 \mathrm{~mm}$ depending on extrusion wall .................................... 41

Figure 3-3. Alignment specimen in grips (photograph by author) .................. 46

Figure 3-4. Tube furnace for elevated temperature study (photography by author)

Figure 3-5. FEA simulation of stress concentrations at notch and as-extruded

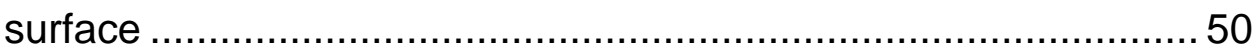

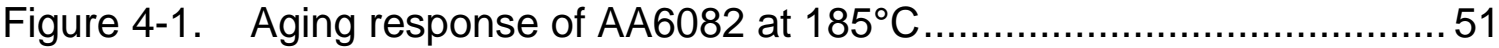

Figure 4-2. Tensile properties of various AA6082 peak aged specimen types 52

Figure 4-3. Optical images of AA6082 microstructures a. mainly fibrous AA6082 shown longitudinal to extrusion direction b. AA6082 seam weld c. AA6082 charge

Figure 4-4. EBSD analysis of AA6082 alloy a. $<111>$ pole figure through cross section b. Orientation image map. 55

Figure 4-5. AA6082 TEM images in peak aged condition a. hardening $\beta$ " precipitates in recrystallized grain, b. grain boundary in fibrous core showing PFZ, c. grain boundary showing dispersoid phase ( $\beta$ " precipitates viewed in aluminum [110] zone axis) 56 
Figure 4-6. Optical and SEM image showing die line surface roughness relative to the extrusion direction for AA6082 alloy..... 57

Figure 4-7. Fatigue lives of peak aged AA6082 specimens tested on different machines

Figure 4-8. S-N curve for peak aged AA6082 L-NW and T-NW specimen types 61

Figure 4-9. Fractographs of peak aged AA6082 L-NW specimen $\left(\sigma_{a}=125, N_{f}=\right.$ $2.2 \times 10^{5}$ ) a. macro of AA6082 specimen b. crack growth transition from recrystallized to fibrous grains $\mathrm{c}$. grain boundary at crack initiation site 63

Figure 4-10. Fractographs of peak aged AA6082 T-NW specimen $\left(\sigma_{\mathrm{a}}=80 \mathrm{MPa}\right.$, $\left.\mathrm{N}_{\mathrm{f}}=2.6 \times 10^{6}\right)$ a. macro-fracture surface, b. magnified initaiton site, c. magnified initiation site tilted $45^{\circ}$ to show die lines 64

Figure 4-11. S-N curve comparing fatigue lives of peak aged AA6082 T-NW polished specimens with T-NW and L-NW specimens maintaining as-extruded surface

Figure 4-12. Fatigue lives of peak aged AA6082 L-W specimens .................... 69

Figure 4-13. S-N curve for peak aged AA6082 T-W and 45-W specimens ....... 70

Figure 4-14. Fatigue lives of peak aged AA6082 polished T-W specimens....... 72

Figure 4-15. Fractography of a.-c. as-extruded $\left(\sigma_{a}=97 \mathrm{MPa}, \mathrm{N}_{\mathrm{f}}=7.5 \times 10^{4}\right)$ and d.-f. polished $\left(\sigma_{a}=105 \mathrm{MPa}, \mathrm{N}_{\mathrm{f}}=2.4 \times 10^{6}\right)$ peak aged AA6082 T-W specimens

Figure 4-16. Optical micrographs of fatigue initiation and fracture sites a. asextruded T-W $\left(\sigma_{\mathrm{a}}=97 \mathrm{MPa}, \mathrm{N}_{\mathrm{f}}=7.5 \times 10^{4}\right)$ b. polished T-W $\left(\sigma_{\mathrm{a}}=\right.$ $\left.105 \mathrm{MPa}, \mathrm{N}_{\mathrm{f}}=2.4 \times 10^{6}\right)$

Figure 4-17. Etched images showing charge weld separation a. etched specimen $\sim 2 \mathrm{~m}$ from stop mark showing charge weld separation of about $2.6 \mathrm{~mm}$ b. etched specimen $\sim 6.5 \mathrm{~m}$ from stop mark showing charge weld interfaces butting against seam weld. 76

Figure 4-18. Relationship between charge weld separation and distance from stop mark for $A$ and $C$ wall sections

Figure 4-19. Fatigue results for AA6082 peak aged L-NW specimens showing the effect of extrusion zones on fatigue life at $\sigma_{a}=110 \mathrm{MPa}$ (error bars signify standard deviation).

Figure 4-20. Fatigue data for AA6082 peak aged T-W specimens showing the effect of extrusion zones (error bars signify standard deviation)(TW(3) data from Figure 4-13)

Figure 4-21. SEM fracture analysis of several T-W(2) AA6082 specimens with charge weld separations near $5 \mathrm{~mm}$ 
Figure 4-22. Optical image of cross section of $\mathrm{T}-\mathrm{W}(2)$ specimen $\left(\sigma_{\mathrm{a}}=100 \mathrm{MPa}\right.$, $\mathrm{N}_{\mathrm{f}}=5.7 \times 10^{4}$ ) (Figure 4-21e) showing typical fatigue failure with crack growth along charge weld interface.....

Figure 4-23. S-N curve showing effect of removing the surface recrystallized layer of the AA6082 alloy 88

Figure 4-24. Microhardness results through $D$ wall cross section a. indentations in cross section b. hardness through cross section. 90

Figure 4-25. Fatigue fracture surface of peak aged AA6082 fully fibrous (1.6 $\mathrm{mm}$ ) specimen $\left(\sigma_{\mathrm{a}}=160 \mathrm{MPa}, \mathrm{N}_{\mathrm{f}}=2.4 \times 10^{5}\right)$ a. macro-fractograph b. early crack growth $\mathrm{c}$. $\mathrm{FCl}$ site d. magnified $\mathrm{FCl}$ site .................. 93

Figure 4-26. Fatigue lives of AA6082 L-NW specimens with different aging treatments

Figure 4-27. Relationship between yield strength and endurance limit for L-NW AA6082 specimens aged at different times and temperatures.... 100

Figure 4-28. Effect of salt and distilled water solutions on fatigue lives of peak aged L-NW AA6082 specimens 101

Figure 4-29. Scanning microscopy analysis showing fractographs of peak aged AA6082 L-NW tested in $\mathrm{NaCl}$ soluton. Column one shows macrofractographs, highlighting initiation site (white dot). Column two provides higher magnification imaging at initiation site. 103

Figure 4-30. Pitting progression on the as-extruded surface of AA6082 specimens fatigue tested in air and $\mathrm{NaCl}$ solution d. held for 11.5 hrs at zero load in MTS machine. 106

Figure 4-31. Polarized light image of cross-section of peak aged AA6082 L-NW specimen tested at $\left(\sigma_{A}=40 \mathrm{MPa}, N_{f}=2.4 \times 10^{6}\right)$, showing localized pitting that exposed the grain boundaries to corrosion deep within the recrystallized surface layer 108

Figure 4-32. Fatigue behavior of peak aged AA6082 specimens tested at $150^{\circ} \mathrm{C}$ 109

Figure 4-33. Fractographs of peak aged AA6082 L-NW specimens tested at $150^{\circ} \mathrm{C}$ a.-d. high stress amplitude, e.-h. low stress amplitude..... 112

Figure 5-1. Aging response of AA6063 at $185^{\circ} \mathrm{C}$ 115

Figure 5-2. AA6063 microstructure a. optical microstructure of peak aged AA6063 specimen b. TEM image of peak aged AA6063 specimen (viewed in [110] aluminum zone axis) .................................. 117

Figure 5-3. S-N curve for baseline peak aged L-NW AA6063 specimens ..... 119

Figure 5-4. S-N curve for peak aged AA6063 L-NW,45-NW and T-NW specimen types 
Figure 5-5. S-N curve for peak aged AA6063 45-W and T-W specimens ..... 123

Figure 5-6. SEM fractographs showing fatigue failures in peak aged AA6063 alloy a.-c. Fracture surface of L-NW specimen $\left(\sigma_{a}=90 \mathrm{MPa} \mathrm{N}=\right.$ $1.6 \times 10^{6}$ cycles), d.-e. Fracture surface of T-W specimen $\left(\sigma_{a}=105\right.$ $\mathrm{MPa} \mathrm{N} \mathrm{f}_{\mathrm{f}}=1 \times 10^{5}$ cycles), f. Fracture face of specimen in $\mathrm{d}$. and e. showing initiation at die line

Figure 5-7: SEM fractographs showing primary and secondary cracking at die lines of an AA6063 45-W specimen $\left(\sigma_{a}=110 \mathrm{MPa}\right.$ and $\mathrm{N}_{\mathrm{f}}=1 \times 1126$

Figure 5-8. Fatigue behavior of peak aged AA6063 T-W(2) and T-W(3) specimens (T-W(3) curve from Figure 5-5) ............................. 128

Figure 5-9. Stress-life curve of peak aged L-NW AA6063 specimens tested in

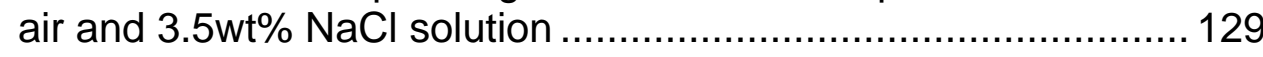

Figure 5-10. Scanning micrographs of fatigued L-NW AA6063 specimens tested in air ( $\mathrm{a} \& \mathrm{~b}, \sigma_{\mathrm{a}}=100 \mathrm{MPa}, \mathrm{N}_{\mathrm{f}}=5 \times 10^{5}$ cycles) and in $\mathrm{NaCl}$ solution (c \& d, $\sigma_{\mathrm{a}}=60 \mathrm{MPa}, \mathrm{N}_{\mathrm{f}}=5 \times 10^{5}$ cycles). Images $\mathrm{b} \& \mathrm{~d}$ show the locations of fatigue crack initiation

Figure 6-1. Static stress concentration as a function of notch/die line depth . 137 


\section{LIST OF TABLES}

Table 2-1. Chemical composition of AA6082 .................................... 14

Table 2-2. Specified tensile properties of AA6082 .............................. 22

Table 2-3. Chemical composition of AA6063..................................... 23

Table 2-4. Specified tensile properties of AA6063 .............................. 24

Table 3-1. Chemical composition of billets ........................................ 38

Table 3-2. Specimen orientations and locations taken from profile ............... 41

Table 4-1. Roughness of AA6082 extrusion profile walls ......................... 58

Table 4-2. Averaged tensile properties of AA6082 specimens taken from

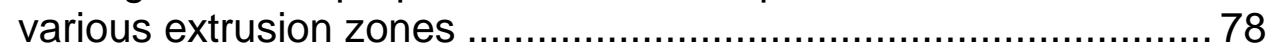

Table 4-3. Effect of microstructure on tensile and fatigue properties.............89

Table 5-1. Tensile properties of peak aged AA6063 L-NW and T-W specimens 116

Table 5-2. Roughness of AA6063 extrusion profile walls ........................ 118

Table 6-1. Prediction of run-out stress values from profilometer roughness. 138 


\section{INTRODUCTION}

The driving force for use of aluminum and other lightweight materials in automotive applications has been greatly increasing over the past years. The versatility of hollow aluminum extrusions makes them suitable for incorporation in many automotive components, such as, engine cradles and steering knuckles. The design of such critical components requires knowledge of high cycle fatigue behavior, where relatively small fluctuations in stress may lead to fatigue crack initiation and failure under otherwise innocuous loading conditions. The Al-Mg-Si (AA6XXX) series aluminum extrusion alloys have been used in automotive applications like impact bumpers and frames, and are under consideration for replacement of fatigue critical components. This dissertation discusses the high cycle fatigue properties of two AA6XXX series aluminum alloys AA6082 and AA6063, extruded in the form of a hollow profile. The AA6082 alloy is a higher strength alloy with a fibrous core microstructure, whereas, the AA6063 has moderate tensile strength values and a fully recrystallized microstructure. Specimens used in this study were taken directly from hollow rectangular impact bumper profiles.

The baseline material fatigue properties of these alloys has been reported by other investigators [1, 2], but to date, very little research on the high cycle fatigue properties associated with features characteristic of the extrusion process has been published in open literature. There are four main features inherent to hollow extruded aluminum profiles that could play a role in fatigue behavior; 
extrusion microstructure (grain size, aspect ratio, precipitate structure and texture), seam welds, charge welds and die lines. While the effect of extrusion microstructures on fatigue has been studied to some extent [2-4], the other three extrusion features have received much less attention. Seam welds are inherent in all hollow extruded profiles, and originate due to material flow around die mandrel supports. The interface between successive billets that are extruded is termed a charge weld, and charge welds exist whenever continuous billet to billet extruding occurs. Both seam and charge welds are solid state welds that form at high pressures and temperatures during extrusion. Scoring of the extrusion surface results in surface asperities called die lines. These die lines are highly anisotropic, aligned in the extrusion direction, and can vary in degree at different locations on the extruded surface.

The original thrust of this research was to quantify the role that extrusion welds have on fatigue lives of the two alloys. After initial fatigue testing, it became evident that the effects of die line roughness may be more important than seam and charge welds in controlling fatigue lives of specimens with asextruded surfaces. Following the discovery that die line surface roughness may be controlling fatigue lives of specimens taken at non-longitudinal orientations relative to the extrusion direction, testing of polished specimens became necessary to separate and independently study the effects of die lines and seam welds on high cycle fatigue lives. 
Aside from microstructural and surface features, the fatigue lives of hollow extruded automobile components could be affected by various environments. Corrosive, chloride environments can lead to corrosion-fatigue interactions and therefore a limited number of specimens were fatigue tested in a $3.5 \% \mathrm{NaCl}$ solution. The effect of seam welds on the corrosion-fatigue behavior was also examined. Engine cradles are ideal component applications for hollow extruded aluminum alloys, and since engine compartment temperatures could see elevated temperatures, fatigue testing of some specimens at $150^{\circ} \mathrm{C}$ was also carried out.

Fatigue is typically conceptualized as a three stage process consisting of crack initiation, crack growth and overload failure. The effects of extrusion features and environment could play a role in any or all of these three stages. Because failures in high cycle fatigue are typically dominated by the time required to nucleate a fatigue crack, the mechanisms governing fatigue crack initiation $(\mathrm{FCl})$ in this study are examined in-depth and fatigue crack growth rates were not studied. The microstructural aspects of fatigue crack initiation were characterized through detailed SEM examination of fracture surfaces of fatigued specimens. Grain boundary separation was almost always present at the $\mathrm{FCl}$ site, therefore, the chemistry and microstructure of grain boundaries was studied using TEM analysis. 


\section{BACKGROUND}

\section{$2.1 \quad$ Fatigue}

The term "fatigue" refers to the delayed fracture of a material subject to cyclic loading where the maximum stresses are typically below the materials ultimate strength. Fatigue is often considered a three step process, with initiation or nucleation of a crack being the first step, followed by fatigue crack propagation and final overload failure, as illustrated schematically in Figure 2-1. Fatigue crack growth is typically governed by the crack tip stress intensity and is characterized by cycle by cycle growth usually perpendicular to the applied tensile load [5]. Fatigue crack propagation (FCP) can be separated into three stages. Stage I crack growth is usually limited to within a single grain and is generally characterized by crack propagation through shear decohesion on a single slip system. The crack will transition to Stage II type growth at higher stress intensities where two slip systems will be active and multiple grains will be located within the crack tip plastic zone. Stage II crack growth is characterized by crack growth normal to the loading direction and the formation of fatigue striations on the fracture surface. The final step in the fatigue process is overload fracture (Stage III crack propagation), which leads to the complete failure of the material. Overload fracture is limited by either the ultimate tensile strength or by the fracture toughness of the material. It occurs once the cross sectional area supporting the load decreases to a point where the maximum 
applied stress during the applied tensile load cycle is sufficient to cause failure in a single load cycle.

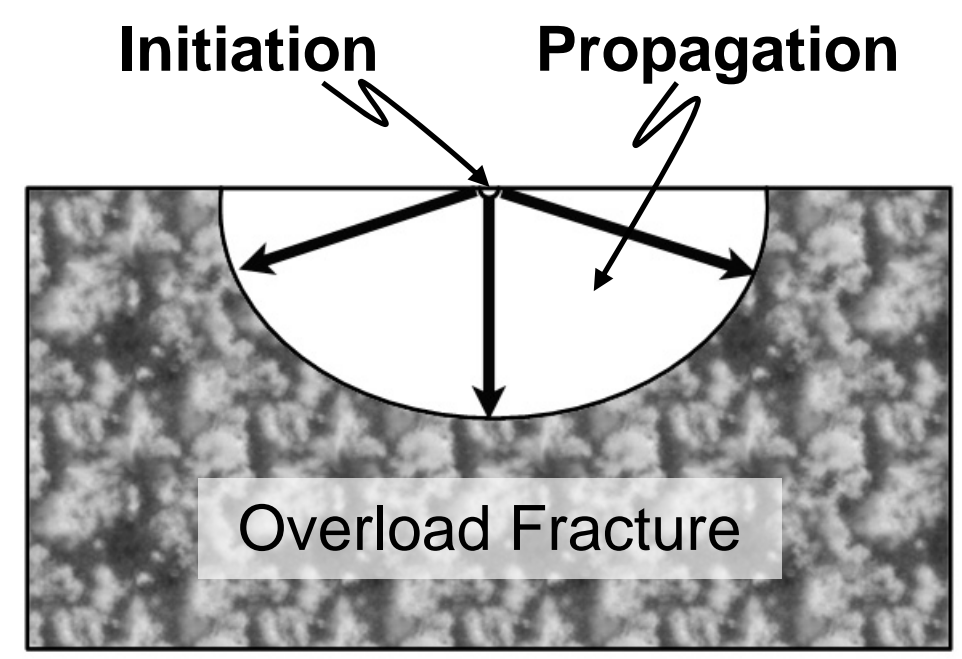

Figure 2-1. Schematic illustration of stages in fatigue failure

When the maximum cyclic stresses are above the yield strength of the material, gross plasticity within the material leads to rapid crack initiation and the number of cycles to failure is typically determined by the rate at which the crack propagates through the material [6]. This process is typically termed low cycle fatigue, whereas, the process of high cycle fatigue is somewhat different. During high cycle fatigue, the cyclic load is such that applied stresses are initially well below the macroscopic yield strength of the material. In high cycle fatigue inhomogeneous localized plasticity leads to fatigue crack initiation ( $\mathrm{FCl})$. In spite of the low applied loads in high cycle fatigue, sites of localized microplasticity within engineering materials may occur at defect sites such as; inclusions, secondary phases, surface asperities or grain boundaries [6]. Fatigue crack 
initiation usually occurs on the surface of a specimen or component, since slip in surface grains or around surface features is less constrained than in the interior [5], but fatigue crack nucleation can occur internally if local stress concentrations at internal defects are sufficiently high. Fatigue crack initiation can also occur in high purity single phase, single crystal and polycrystalline materials with very smooth surfaces. Under these idealized conditions, fatigue crack nucleation is often the result of stress concentrations that originate at persistent slip bands on the surface of the material [5]. In this study, there were only a few specimens that showed evidence of initiation of fatigue cracks at slip bands, specifically those tested at $150^{\circ} \mathrm{C}$. Grain boundary separation was the most common fatigue crack initiation mechanism of AA6082 and AA6063 specimens that were examined.

A detailed study on the mechanism of intergranular crack initiation in low cycle fatigue of annealed polycrystalline copper was conducted by Kim and Laird [7, 8]. Although this study details grain boundary crack initiation during high stress loading, some of the criteria described have also been shown to lead to grain boundary $\mathrm{FCl}$ in low stress (high cycle) fatigue [9, 10]. Kim and Laird showed that fatigue crack initiation could occur at surface steps resulting from grain boundary sliding [8]. The grain boundary sliding led to surface steps of 1.5 $\mu \mathrm{m}$ after less than 100 cycles in high strain fatigue tests. Such steps were attributed to anisotropic elastic strains at boundaries between differently oriented grains. The step heights were consistently higher in the tension cycle than that 
of the compression cycle. It was further shown that three prerequisites exist for grain boundary separation to occur in polycrystalline materials [8]. The surface grain boundary must lie at an angle of $30-90^{\circ}$ relative to the loading direction, the active slip direction in one of the two grains should intersect the boundary and finally there must be a high level of crystallographic mis-match between the two grains. A more recent study on the fatigue crack initiation of the alloy WASPALOY showed similar requirements for grain boundary crack nucleation [11].

In addition to studying the fatigue crack nucleation process, Stage I crack propagation was also examined by Kim and Laird [7, 8]. The Stage I cracking took place along the grain boundary surface and extended up to $180 \mu \mathrm{m}$ into the specimen surface along the internal boundary as the crack advanced by the plastic blunting process. Crack propagation shifts from Stage I to Stage II when the crack reaches a triple point junction or when the stress intensity is high enough to activate multiple slip systems. Although, the grain boundary crack initiation process described by Kim and Laird does not consider PFZs or impurity segregation along grain boundaries, the mechanistic process will most likely be similar, but the rate of fatigue crack nucleation and early propagation during high cycle fatigue will likely be affected by any weakening of grain boundaries.

Design against fatigue failure often involves testing of components in a laboratory environment where service stresses are simulated. Figure 2-2 schematically illustrates how an in-service loading sequence can be translated 
into a laboratory materials testing protocol. During fatigue testing, cyclic loading is applied to the test specimen under either load or strain control. During low cycle fatigue testing, strain control testing is utilized, since macroplasticity will change the stress state of the material. High cycle fatigue tests are more often performed under load(stress) control, since the stress levels are low enough to limit strain to elastic values.

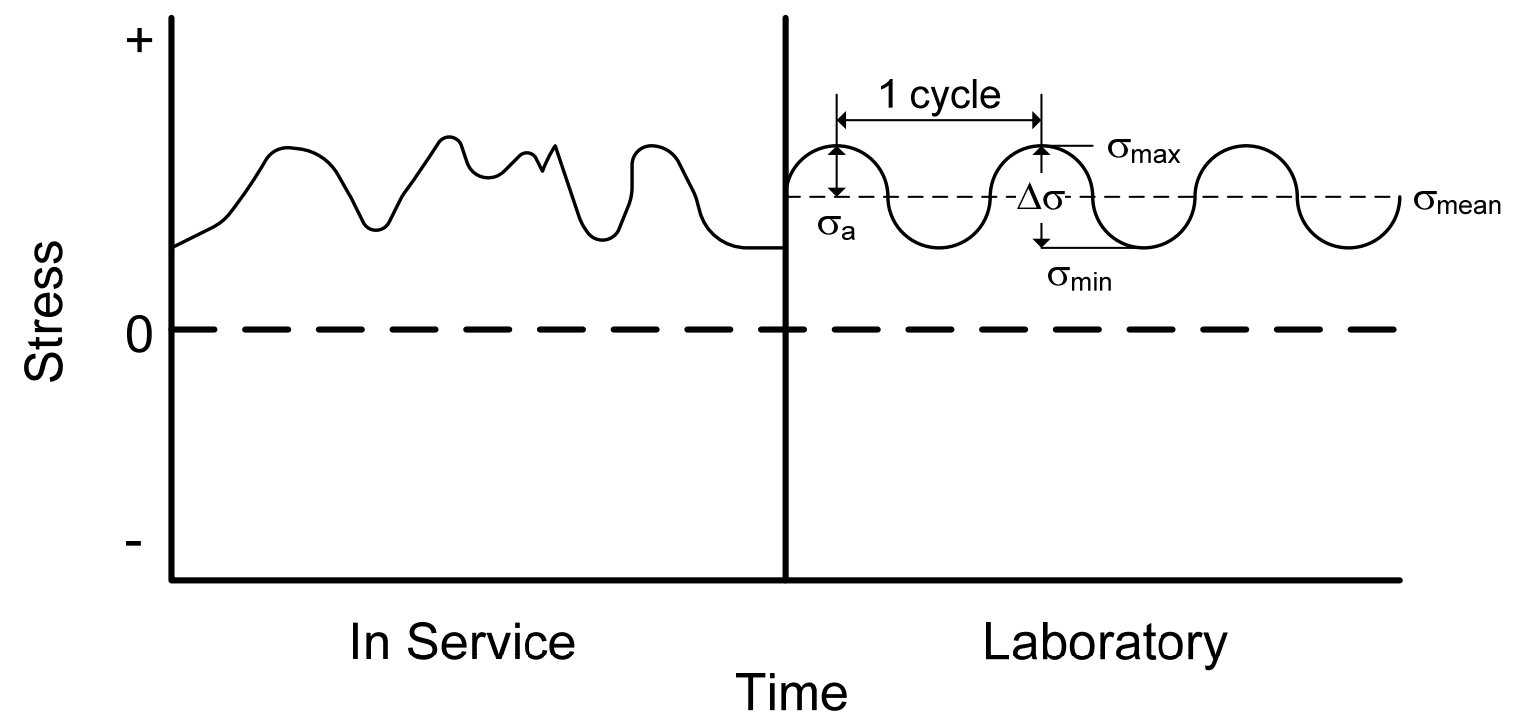

Figure 2-2. Association between in-service and laboratory stress cycles that lead to fatigue failure and nomenclature used in characterizing fatigue behavior of materials (after [6])

Wave functions, as shown in Figure 2-2, are typically used to simulate the cyclic loading during fatigue testing. Loading wave profiles that are typically utilized in fatigue testing include trapezoidal, triangular, sinusoidal or square. The terms used to describe constant amplitude stress controlled waveform 
fatigue testing are given as Equations 2-1 through 2-7 and are also shown schematically in Figure 2-2.

$$
\begin{aligned}
& \mathrm{N}_{\mathrm{f}}=\text { number of cycles to failure } \\
& \sigma_{\max }=\text { maximum stress applied during cyclic loading Equation 2-2 } \\
& \sigma_{\min }=\text { minimum stress applied during cyclic loading Equation 2-3 } \\
& \sigma_{\mathrm{a}}=\text { stress amplitude for the fatigue test } \\
& =\frac{\Delta \sigma}{2}=\frac{\sigma_{\max }-\sigma_{\min }}{2} \\
& \sigma_{\text {mean }}=\text { average stress applied during cyclic loading } \\
& =\frac{\sigma_{\max }+\sigma_{\min }}{2} \\
& \Delta \sigma=\text { stress range } \\
& =\sigma_{\max }-\sigma_{\text {min }} \\
& r=\frac{\sigma_{\min }}{\sigma_{\max }}=\text { fatigue stress ratio }
\end{aligned}
$$

These loading variables will affect fatigue lives and should be reported along with fatigue results. The fatigue lives of specimens depend upon many different stress loading parameters, including but not limited to; frequency ( $f$, mean stress (Equation 2-5), stress ratio (Equation 2-7), stress amplitude (Equation 2-4), and testing environment. Changes in loading parameters, $\sigma_{a}, \sigma_{\text {mean }}$ and $r$, affect the lives of specimens through changes in the applied loads; for example, increases in the stress amplitude at a given $r$ value will increase $\sigma_{\text {mean, }} \Delta \sigma$ and $\sigma_{\max }$ and should result in lower fatigue lives. Fatigue testing is often done at a fixed stress ratio, controlled stress amplitude and variable mean stress, but empirical equations exist for relating mean stress effects on fatigue lives [6]. Frequency of loading can also affect the fatigue behavior of a metal, but typically only at frequencies greater than $200 \mathrm{~Hz}$ for metals [6]. 
During fatigue testing, the stress amplitude is typically varied and the number of cycles leading to complete failure of the specimen is recorded. This data can then be utilized to form a stress-life (S-N) curve, as in Figure 2-3. Stress-life curves are utilized extensively in design against fatigue failure and S$\mathrm{N}$ curves have been generated for many different materials and alloy systems. As the stress amplitude is decreased, the number of cycles leading to failure will increase. For steel and other ferrous alloys, a fatigue limit or endurance limit is usually observed at stress levels around $40 \%$ of the tensile strength [6]. For applied stress amplitudes below the endurance limit, the specimen will withstand a hypothetically infinite life. Fatigue behavior for aluminum and some other FCC materials is often quite different from steel alloys in that they typically do not reach true endurance limits at low stress levels [6]. For these materials the stress levels corresponding to failure after some specific high number of cycles (typically $1 \times 10^{7}$ cycles) is substituted as the fatigue limit and used as a fatigue design parameter [12].

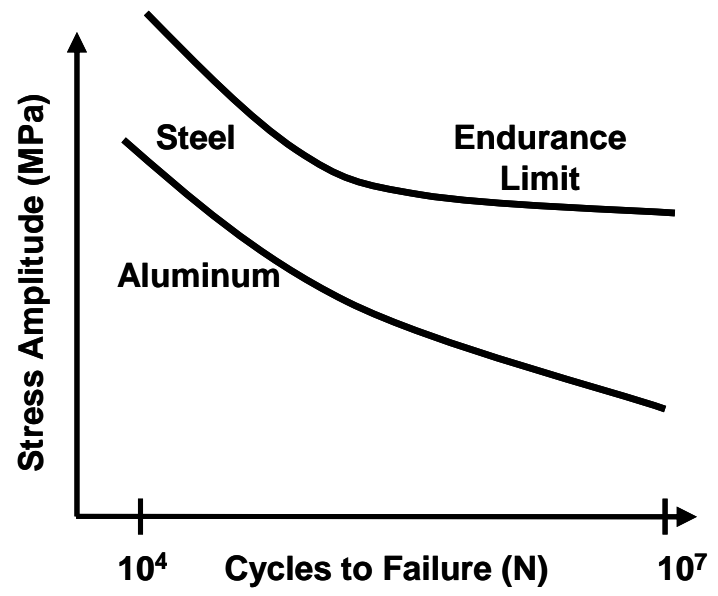

Figure 2-3. Illustration of a stress-life curve (after [6]) 
The fatigue lives of specimens may be affected by factors other than the intrinsic features (microstructure, texture, welds, surface finish) and testing protocols. External variables such as temperature and exposure to corrosive environments can also influence fatigue behavior. Since automotive components are often exposed to salt solutions (containing damaging chloride ions), from either marine environments or road salt, the static and dynamic effects of corrosion and corrosion-fatigue on potential materials and material processing routes must be considered. Also, automotive components could experience elevated temperatures due to the transfer of heat from the engine, exhaust gases or braking friction. Moderately elevated temperatures, specifically in engine compartments, could affect the fatigue properties of aluminum.

Since engine compartment temperatures in current automotive applications could reach temperatures significantly above ambient, for the purpose of this study, such elevated temperature effects on fatigue will be assessed by testing at $150^{\circ} \mathrm{C}$. Elevated temperature could change the fatigue behavior of hardened aluminum alloys through several mechanisms; including: over-aging, residual stress relaxation, grain boundary segregation, oxidation of free surfaces, cyclic hardening (softening) response and creep. Due to the slow kinetics at $150^{\circ} \mathrm{C}$, over-aging of the precipitate due to coarsening and increased elemental segregation in AA6XXX aluminum alloys is unlikely to occur during the fatigue testing and therefore should not affect the fatigue. Also, the relatively low 
temperature, large surface grains and high frequencies utilized in this study should also limit the role of creep in fatigue. This leaves relaxation of residual stresses and oxidation of free surfaces as the mechanisms most likely to affect fatigue in this experimental program. Srivatsan et. al. conducted studies on the effect of moderately elevated temperatures on low cycle fatigue lives of AA6061 and AA7055 $[13,14]$. A reduction in the low cycle fatigue lives at elevated temperatures was attributed to increased localized oxidation and repeated breakdown of the oxide layer in stage I and II crack propagation. Since work here is focused on high cycle fatigue, oxidation at initiation sites is probably of more concern. A study on the high cycle fatigue of an Al-Li alloy showed a decreasing trend in fatigue life as the testing temperature was moderately increased up $250^{\circ} \mathrm{C}$ and some tests showed atypical fatigue crack propagation $45^{\circ}$ relative to the loading direction [15].

The corrosion behavior of aluminum alloys could also affect the fatigue properties through several mechanisms, i.e. crack initiation at pits [16-19], rapid crack growth in aggressive environments [18] and stress corrosion cracking or hydrogen embrittlement [20-24]. While there have been several studies on the corrosion-fatigue behavior of aircraft aluminum alloys, AA2024 and AA7075 [1619], relatively little information exists on the corrosion-fatigue behavior of AA6XXX alloys, specifically AA6063 and AA6082 [24]. On the other hand, the general corrosion behavior of AA6XXX aluminum alloys has been studied extensively [25-30]. The corrosion behavior of AA6XXX alloys generally behaves 
in one of three manners, localized pitting corrosion, grain boundary corrosion or some combination of the two. Localized pitting corrosion often occurs due to the microscopic galvanic potential differences between the aluminum matrix and undissolved constituent phases that contain one or more $\mathrm{Mn}$, $\mathrm{Fe}, \mathrm{Cr}$, or $\mathrm{Cu}$ elemental species. This potential difference results in anodic dissolution (pitting) of the aluminum matrix around the secondary phase particles which act as localized cathodic sites [31]. Intergranular corrosion (IGC) is often associated with the presence of copper, whether as Q' phase particles or in thin films on the grain boundaries [29], but copper is not a prerequisite for IGC [28], and electrochemistry at PFZs or grain boundary dispersoids can result in IGC of AA6XXX aluminum alloys. The pitting potentials $\left(E_{\text {pit }}\right)$ of $A A 6082$ in $3.5 \% \mathrm{NaCl}$ and tap water has been reported as -0.72 and $-0.47 \mathrm{~V}_{\mathrm{SCE}}$, respectively [22], while open circuit corrosion potentials $\left(E_{\text {corr }}\right)$ for AA6XXX alloys are generally around $0.72 V_{S C E}[32,33]$. Electrochemical potentials can also be affected by surface roughness, with smooth specimens showing higher pitting potentials [25]. The roughness could play a role in this work since corrosion-fatigue studies were performed on specimens with as-extruded surfaces.

\section{$2.2 \quad$ AA6082 Alloy}

The AA6XXX aluminum alloys are magnesium and silicon containing alloys that are widely used in transportation and building applications. These are wrought alloys that are typically processed through forging, extruding or rolling. Specific applications of AA6XXX aluminum alloys are in automotive sheet and 
tread plates, architectural components, pipelines, ladders, etc. [34]. The research described here focused on hollow extruded aluminum profiles suitable for automotive applications. Testing was performed on specimens taken from a car bumper profile, which are typically manufactured from the alloys AA6082 and AA6063.

The chemical composition of AA6082, specified by Hydro Aluminium standards, is provided in Table 2-1 [35]. The microstructures of AA6XXX extruded alloys can be influenced by both extrusion parameters and alloying. The extruded AA6082 and AA6063 materials used in this study differ in both grain structure and crystallographic texture. The precipitate hardening sequence for the two alloys is similar, but $\mathrm{Mn}$ and higher $\mathrm{Si}$ in the AA6082 alloy result in a refined grain structure leading to higher overall strength. The Mn and excess Si form $\alpha$-Al-(Fe,Mn, $\mathrm{Cr})-\mathrm{Si}$ dispersoids, on the order of $0.5 \mu \mathrm{m}$, that pin the grain boundaries and inhibit recrystallization and grain growth [36-39]. The presence of dispersoids in the AA6082 results in a fibrous core microstructure due to the pinning of the grain boundaries. The large strain accumulation near the surface of the extruded product usually results in a recrystallized surface structure. The dispersoid additions do not have a large effect on tensile properties, but could affect ductility, toughness and fatigue crack initiation and propagation [40-43].

Table 2-1. Chemical composition of AA6082

\begin{tabular}{|c|c|c|c|c|c|c|c|c|c|c|}
\hline \multirow{2}{*}{ wt\% } & \multirow{2}{*}{$\mathrm{Si}$} & \multirow{2}{*}{$\mathrm{Fe}$} & $\mathrm{Cu}$ & \multirow{2}{*}{$\mathrm{Mn}$} & \multirow{2}{*}{$\mathrm{Mg}$} & $\mathrm{Zn}$ & $\mathrm{Ti}$ & \multicolumn{2}{|c|}{ Other elements } & \\
\cline { 1 - 5 } & & & & & & & & Each & Total & Al \\
\hline Min. & 0.70 & - & - & 0.40 & 0.40 & - & - & - & - & \multirow{2}{*}{ Balance } \\
\hline Max. & 1.30 & 0.50 & 0.10 & 1.00 & 1.00 & 0.02 & 0.02 & 0.02 & 0.10 & \\
\hline
\end{tabular}


The grain structure can play an important role in the fatigue behavior of extruded aluminum alloys, but the main strengthening mechanism of AA6082 and other AA6XXX alloys is through precipitation hardening. Following the extrusion process, the profiles are often quenched at the press, resulting in a structure where the $\mathrm{Mg}$ and Si remain in solid solution. The precipitation aging sequence and precipitate structure, following solutionizing, for AA6XXX alloys has been fully characterized and will be discussed only briefly here [44-48]. The precipitation sequence is generally believed to progress as follows:

Solid Solution $\rightarrow$ atomic clusters $\rightarrow$ GP zones $\rightarrow \beta^{\prime \prime}\left(\mathrm{Mg}_{5} \mathrm{Si}_{6}\right) \rightarrow \beta^{\prime}$ $\left(\mathrm{Mg}_{1.8} \mathrm{Si}\right) \rightarrow \beta\left(\mathrm{Mg}_{2} \mathrm{Si}\right)$

Equation 2-8 Intermediate phases similar to the $\beta^{\prime}$ phase were also noted [47]. The $\beta$ phase is the stable FCC $\mathrm{Mg}_{2} \mathrm{Si}$ that will form after prolonged aging, but peak hardening of Al-Mg-Si alloys is attributed to the metastable $\beta$ " phase. The $\beta$ " precipitates are needle shaped with a preferred alignment of the needles along the $<100>\mathrm{Al}$ direction and a monoclinic crystal structure [43, 47].

Like most age hardening alloys, the strength of AA6XXX alloys depends on the size, coherency and volume fraction (spacing) of the $\beta$ "-precipitate [6]. The peak hardness of precipitation hardened aluminum alloys occurs at the transition point between cutting/shearing of precipitates and bowing of dislocations around precipitates [6]. Figure 2-4 provides a schematic illustration 
of the competing deformation processes of cutting and bowing as a function of particle size. At small particle sizes, dislocations can by-pass the small rod shaped particles by shearing them, but as the rods grow the particles begin to resist the shearing, increasing the yield strength. As the particles grow, the spacing between them also increases, and eventually leads to bowing of dislocations around the precipitates rather than shearing them. The competition between bowing of dislocations and shearing of particles by dislocations results in a critical precipitate size corresponding to optimized yield strength. The strength can of course be further raised by alloying to create either a finer dispersion of particles or a harder precipitate that can resist cutting. The overall strength will also be influenced by both the intrinsic strength of the aluminum matrix and solid solution strengthening remaining after aging. A popular model for simulating strengthening in aluminum alloys, specifically AA6082, is the Shercilff-Ashby model which describes the hardening method within the terms just mentioned [49]. Another method for modeling age strengthening in aluminum alloys is through a nucleation, growth and coarsening model, where peak strength is achieved when precipitate kinetics transitions from nucleation to growth [50]. 


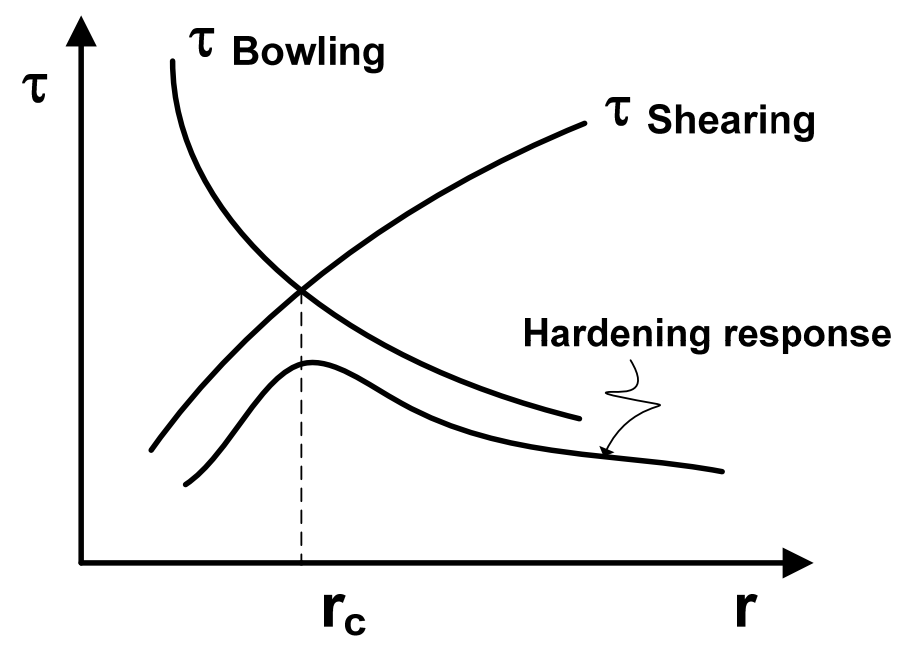

Figure 2-4. Illustration of competing roles of particle cutting and dislocation bowing in age hardening (after [6])

Studies have been conducted on the fatigue and deformation behavior of AA6XXX aluminum alloys with different heat treatments (over, under and peak aged), and specifically the interactions between dislocations, slip band structures and precipitates $[42,43,51,52]$. In one study, tensile and fatigue crack growth properties for under- and over-aged specimens were compared to peak aged specimen of Al-Mg-Si alloys [42, 43]. Three different alloys were studied, each maintaining $\mathrm{Si}$ to $\mathrm{Mg}$ ratios of 2 to 1 , with increasing levels of manganese. Two different heat treatments were employed, one under-aged resulting in fine $\beta^{\prime \prime}$ precipitates and the other over-aged to produce coarse $\beta^{\prime}$ precipitates. By varying the amount of $\mathrm{Mn}$, the relationship between both the precipitate structure, dispersoid content and dislocation structures leading to failure could be determined. The precipitate free zone (PFZ) of the under-aged specimens was $40 \mathrm{~nm}$ wide, whereas the PFZ of the over-aged specimens was $80 \mathrm{~nm}$. It was 
found that bowing at the over-aged $\beta^{\prime}$ precipitates lead to more homogenous slip, while the under-aged $\beta$ " precipitates shear and result in heterogeneous slip. Increased dispersoid content also produced more homogenous slip character. The thinner PFZ in the under-aged specimens resulted in higher failure strengths, failure strains and decreased amounts of intergranular fracture due to the higher constraint of plasticity. When studying the fatigue crack growth rates and fatigue crack threshold stress intensity $\left(\Delta \mathrm{K}_{\mathrm{th}}\right)$, very little difference was found to exist between under and over aged specimens. This was attributed to the competing roles of slip heterogeneity and grain boundary precipitation in underand over-aged specimens. Also, $\Delta \mathrm{K}_{\text {th }}$ values, where fatigue crack growth rates are typically undetectable, for peak aged specimens was slightly lower than for both under- and over-aged specimens, which was a result of the more coarse slip distribution and resultant lower cyclic ductility. The threshold stress intensity did increase as the dispersoid concentration was increased, but the growth rates were comparable for specimens with and without dispersoids.

The grain textures of the extruded profiles could also have a pronounced effect on the fatigue properties. It is well known that fatigue occurs due to localized plasticity, often at grains that are preferentially oriented for easy slip [7, $8,11,53]$. If grains within a sample have a preferred orientation relative to the loading direction of the specimen that is prone to slip, then fatigue crack initiation may occur more readily than if the orientations are random. Since grains may exhibit preferred crystallographic orientations relative to the extrusion direction, 
i.e. longitudinal or transverse to the extrusion direction, fatigue lives may depend on the orientation of specimens with respect to the extrusion direction. Preferred orientations in extruded sheet profiles of alloy AA6082, with a fibrous core microstructure, have previously been characterized and were reported to be representative of a $\beta$-fiber type texture, with a strong $\{011\}<211>$ Brass component [54]. The Brass, $\beta$-fiber, texture implies that $\{011\}$ planes are aligned roughly parallel to the extrusion surface, with the $<211>$ direction in the $\{011\}$ plane parallel to the extrusion direction. The $\beta$-fiber texture in the AA6082 cross section becomes degenerate and loses its symmetry near the surface, but it should be noted that the extrusion studied did not have a typical recrystallized surface layer [54]. In a separate study, orientations of AA6082 extruded plates with a recrystallized surface layer were reported to have a similar $\beta$-fiber texture in the fiberous core, but a lack of any preferred orientation in the recrystallized surface grains [37]. Since most of the AA6082 specimens tested in this study maintained the recrystallized surface layer and fatigue initiation always occurred on the specimen surface, this lack of surface grain texture may be important.

The occurrence of intergranular failure in AA6XXX alloys $[3,4,37,43,51$, $52,55]$, which was also present in nearly all fatigue crack initiation sites in this study, calls for some discussion of the nature of grain boundaries. The presence of grain boundary failure in aluminum alloys is generally attributed to precipitate free zones (PFZ) $[3,4,43,51,52]$ but segregation of impurities to grain boundaries [56], the existence of high angle grain boundaries [57] or large slip 
gradients across grains $[7,8,11,53]$ could also lead to failure at boundaries in polycrystalline materials. A schematic illustration of a PFZ at a grain boundary triple junction is shown in Figure 2-5.

Figure 2-5. Illustration of PFZ

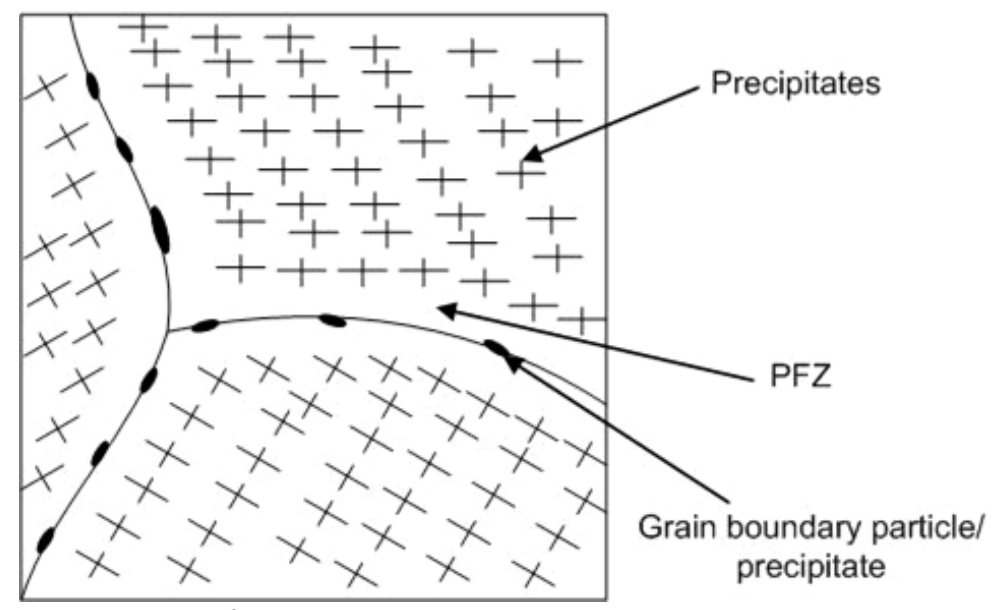

Precipitate free zones in precipitation strengthening alloys can occur either from heterogeneous vacancy distributions or from nucleation and growth of grain boundary precipitates [58]. High vacancy concentrations, that are essential for precipitation kinetics, are generated during high temperature solutionizing treatments and become trapped in the interiors as a result of quenching. During quenching, or during aging treatments, excess vacancies immediately adjacent to "vacancy sinks" such as interfaces can diffuse to those sinks, thus depleting a thin layer of excess vacancies. The lack of vacancies in proximity to the grain boundaries and internal interfaces results in slower localized solute diffusion and the precipitation reaction in these regions will be slower than the bulk of the 
grain. This leads to under-aged precipitates or no precipitation near the grain boundary while precipitates in the bulk of grains have grown to sizes corresponding to peak aging strength.

Particle nucleation at grain boundaries, following quenching, can also deplete the region adjacent to grain boundaries of solute and lead to PFZ formation [58]. Grain boundary precipitation in aluminum alloys has been reported, but not typically in the context of PFZ formation [59-61]. Since vacancy concentrations and particle growth kinetics are temperature and rate dependant, low solutionizing temperatures and fast quench rates can minimize the width of PFZs. The variation in hardness from the boundary edge to the bulk of a grain in a Al-Cu-Si-Ge alloy has been measured using nano-indentation [62]. The hardness was reduced by $75 \%$ near the grain boundary, within a PFZ. It is likely that these lowered strength values will induce localized strain accumulation at grain boundaries during fatigue testing.

Segregation of impurity elements could also lower the strength of grain boundaries by lowering the cohesive strength. If segregants in aluminum, such as $\mathrm{Fe}, \mathrm{Mn}, \mathrm{Cr}, \mathrm{S}, \mathrm{P}, \mathrm{An}$, or $\mathrm{Cu}$ segregate to the boundary they could weaken the interface, leading to lowered fracture strengths, and failure at grain boundaries [63]. Grain boundary decohesion due to impurities is prevalent in steels and superalloys but is less commonly documented in aluminum alloys.

The tensile properties of peak aged extruded aluminum alloy AA6082 are given in Table 2-2 [35]. The fatigue behavior of extruded AA6082 has been 
studied by other researchers $[1-4,64]$. During one study, fully reversed cyclic loading of AA6082 specimens with a yield strength of $347 \mathrm{MPa}$, lasted nearly $2 \times 10^{6}$ cycles at a stress amplitude of $100 \mathrm{MPa}$ [1]. A separate study focusing on the effect of surface finish on fatigue properties (stress ratio $=0.1$ ) of AA6082, with a yield strength of $310 \mathrm{MPa}$, resulted in fatigue run-out $\left(1 \times 10^{7}\right.$ cycles) values of $\sim 115 \mathrm{MPa}$ [2]. Under various strength, loading and surface finish conditions, other researchers have report fatigue limits of 90-120 MPa stress amplitude for AA6082 $[3,64,65]$. It is expected that baseline specimens taken longitudinal to the extrusion direction and under peak aged conditions, will have fatigue properties in this range.

Table 2-2. Specified tensile properties of AA6082

\begin{tabular}{ccc}
\hline $\begin{array}{c}\text { Yield Strength } \\
\text { (MPa) }\end{array}$ & UTS (MPa) & Elongation (\%) \\
\hline 260 & 310 & 8 \\
\hline
\end{tabular}

\section{$2.3 \quad$ AA6063 Alloy}

The AA6063 alloy is similar to that of AA6082 in many respects. The specified chemical composition defining AA6063 is provided in Table 2-3 [35]. The AA6063 alloy has less Si than AA6082 and essentially no Mn. The lower concentration of these elements causes much less of the dispersoid phase to be formed, resulting in a fully recrystallized microstructure following hot extrusion. Previous research has shown that the recrystallized grain structure of extruded 
AA6063 has a cube $(\{100\}<001>)$ texture in the core and an absence of preferred orientation on the extrusion surface [37].

The presence of iron in the AA6063 alloy does lead to the formation of $\alpha$ Al-Fe-Si secondary constituent phase particles, but the concentrations of dispersoid and constituent phases are much lower than in AA6082. The main strengthening mechanism for AA6063, like AA6082, is through precipitation hardening. The precipitation sequence of AA6063 is shown as Equation 2-8, where the optimization of size and density of the $\beta$ " phase leads to peak hardness values. Since compositional differences exist between the two alloys, it is possible that the aging kinetics of the two alloys may be slightly different.

Table 2-3. Chemical composition of AA6063

\begin{tabular}{|c|c|c|c|c|c|c|c|c|c|c|}
\hline \multirow{2}{*}{$w t \%$} & \multirow{2}{*}{ Si } & \multirow{2}{*}{$\mathrm{Fe}$} & \multirow[b]{2}{*}{$\mathrm{Cu}$} & \multirow[b]{2}{*}{ Mn } & \multirow[b]{2}{*}{$\mathrm{Mg}$} & \multirow{2}{*}{$\mathrm{Zn}$} & \multirow{2}{*}{$\mathrm{Ti}$} & \multicolumn{2}{|c|}{ Other elements } & \\
\hline & & & & & & & & Each & Total & $\mathbf{A l}$ \\
\hline Min. & 0.20 & - & - & - & 0.45 & - & - & - & - & Jance \\
\hline Max. & 0.60 & 0.35 & 0.10 & 0.10 & 0.90 & 0.02 & 0.02 & 0.02 & 0.10 & Balance \\
\hline
\end{tabular}

Typical Tensile properties of peak aged AA6063 specimens are provided in Table 2-4 [35]. The yield and ultimate strength of the recrystallized AA6063 alloy is reduced by nearly $25 \%$ when compared to the fibrous AA6082 alloy. Certainly solid solution strengthening and dispersoid/second phase particles can contribute to some of this difference in strength, but the majority of the difference is explained by the large recrystallized grain structure and grain boundary strengthening effects. The base-line fatigue properties of AA6063 have been 
studied by other researchers $[1,2,51,52]$. An investigation on the effect of machining surface finish on peak aged extruded AA6063 specimens produced a fatigue run-out stress $\left(1 \times 10^{7}\right.$ cycles) of approximately $90 \mathrm{MPa}$ when using a stress ratio of 0.1 , on an alloy with yield strength equal to $207 \mathrm{MPa}$ [2]. Other researchers have reported endurance limits near $80 \mathrm{MPa}$ for peak aged AA6063 specimens $[1,51,52]$. The effect of aging treatment on fatigue and tensile properties of AA6063 has also been studied [51, 52]. Three heat treatments were employed to yield an under-aged, peak-aged and over-aged precipitate structures corresponding to GP-zones, $\beta^{\prime \prime}$ and $\beta^{\prime}$, respectively. The width of PFZ's in the AA6063 alloy were also determined as a function of aging time and were reported to be $270 \mathrm{~nm}$ for over-aged specimens and $120 \mathrm{~nm}$ when peakaged. The ratio of ultimate tensile strength to the maximum stress at the endurance limit was calculated and values of $0.81,0.64$ and 0.78 for under-aged, peak-aged and over-aged specimens respectively. The fracture surfaces of fatigue specimens were largely faceted and transgranular with only peak-aged specimens showing substantial intergranular behavior. As with the AA6082 alloy, peak aged, baseline fatigue results on extruded AA6063 are expected to correspond with those reported in the literature.

Table 2-4. Specified tensile properties of AA6063

\section{Yield Strength} (MPa) UTS (MPa) 195 245 Elongation (\%) 10 


\section{$2.4 \quad$ Extrusion features}

The extrusion process is a unique processing technique where intricate shapes can be produced in large volumes. The basic principle of extrusion is to push a heated billet through a die, thereby, mechanically deforming the metal into a desired geometry. Extrusion processing is a dynamic forming process where mechanical working, friction and heat transfer can continuously evolve during the shaping process. Extrusion parameters such as billet pre-heat temperature, extrusion speed and die reduction ratios are critical for producing quality aluminum extrusions.

Control of extrusion parameters, coupled with alloying, can be used to optimize the grain structure of extruded aluminum products. Several studies have examined the relationship between recrystallization, specifically surface recrystallized layers, and extrusion parameters $[36,38,39,66]$. In general, the amount of recrystallization increases proportional to the amount of work hardening during extrusion. This occurs when a lower billet temperature, higher

reduction ratio or faster ram speed are used during extrusion. Minimizing the amount of work hardening by optimizing the extrusion parameters leads to higher levels of fibrous microstructure for the AA6082 alloy. Also, the quench rate at the extrusion press can affect the amount of recrystallization that occurs, specifically, slack quenching can lead to thicker recrystallized layers in AA6082 [36, 55]. When extruding the AA6063 alloy, the low level of dispersoids, results in a fully recrystallized microstructure, independent of the extrusion parameters. When 
fully recrystallized structures are inevitable, increasing the rate of work hardening reduces the overall recrystallized grain size, which in turn should results in higher strength and better high cycle fatigue properties.

The improved strength of the AA6082 alloy compared to AA6063 is mainly a result of the fine fibrous core microstructure in the AA6082 alloy. The fine grain structure provides grain boundary strengthening, where dislocations are pinned at grain boundaries, and Hall-Petch type relationships apply [6]. Also, high dislocation densities and fine sub-grain structures in the fibrous core of the AA6082 extrusion could further increase strength. Since high cycle fatigue properties, and endurance limits, scale with yield strength, it is expected that materials with smaller grain sizes will have better fatigue properties. Pedersen et. al. have reported two papers examining the effects of both the overall grain size and the thickness of the surface recrystallized layer on the high cycle fatigue behavior of AA6082 $[3,4]$. When the recrystallized surface layer was removed from the surface, a tenfold increase in the high cycle fatigue life resulted [3]. Pedersen also studied the effect of grain size and morphology on high cycle fatigue behavior [4]. The fine grained highly aligned fibrous structure resulted in the best fatigue properties, whereas, a highly cold worked and recrystallized (50 $\mu \mathrm{m}$ grain size) microstructure yielded slightly lower but comparable fatigue properties. As the grain size was further increased, high cycle fatigue life was degraded. Pedersen also observed a transition in fatigue initiation mechanism, dependant on the morphology of the grains. The highly columnar coarse grains 
resulted in crack nucleation at persistent slip bands, while more equiaxed structures resulted in crack nucleation due to grain boundary separation [4]. Since Pedersen tested specimens from extruded rods, he was only able to test specimens with the fibrous grain structure oriented parallel to the loading direction, and did not study anisotropy effects related to the highly elongated and directional grains. The extrusion profile used in this study allowed us to examine the possibility that the fatigue behavior of the fibrous may vary with orientation. It is likely that the microstructures of the two alloys studied here will have a profound effect on the fatigue properties. Studies on the fatigue behavior associated with fibrous, recrystallized and mixed microstructure will be carried out.

Two microstructural features inherent in hollow aluminum extrusions are the seam (longitudinal) and charge (transverse) welds. Longitudinal seam welds are formed when metal flows around mandrel supports in dies. To obtain a seam weld with mechanical properties comparable to the parent material, the die must be designed to impart the required pressure for a strong solid state weld [67-71]. Figure 2-6 provides a schematic illustration of hot extrusion of hollow aluminum profiles. As the billet is pressed through the die porthole (section A-A), the metal flows around the mandrel supports, and for this example is broken into four separate metal streams. The mandrel supports hold the mandrel in place during extrusion, and must be rigid enough to maintain dimensional stability. When the metal fronts reach the welding chamber (section B-B) the four fronts are pressed 
together and form the seam weld interface. The final profile in this schematic will contain five seam welds within the cross section, one on each of the four corners and one in the center of the middle cross member. Because of the different locations of the die supports for the extrusions used in this study, the number and location of seam welds are different from those shown in Figure 2-6.

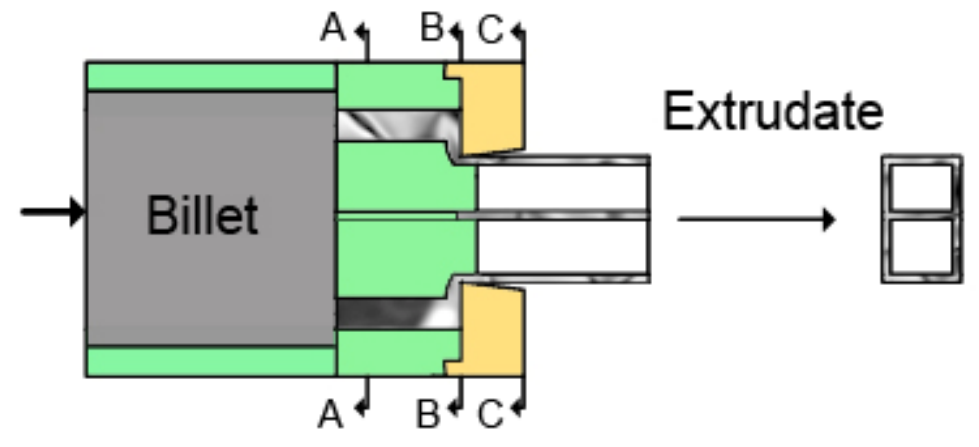

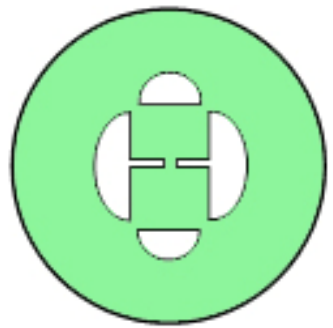

A-A

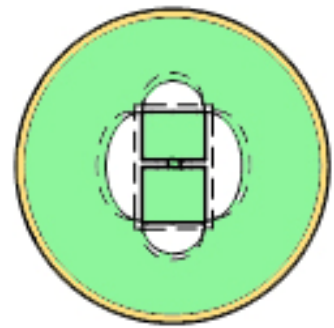

B-B

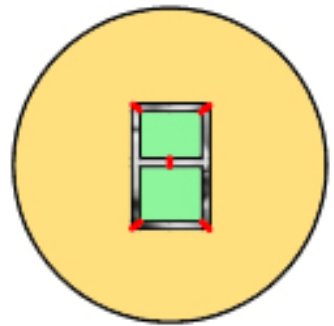

$\mathrm{C}-\mathrm{C}$

Figure 2-6. Schematic of seam weld origin in extrusion process

Charge welds result from the interface between successive billets in multibillet extrusion processes. The extrudate from the first billet used in a freshly cleaned die does not, therefore, contain a charge weld [68, 72]. Figure 2-7a provides an illustration showing the origin of the charge weld interface and its relationship to the seam weld in 2-7b. Billet butt cutting (Billet \#1 in Fig. 2-7a) is the most critical aspect of the extrusion process related to charge weld integrity. 
The end of the previous billet (\#1), containing the contaminated and highly sheared residual material should be removed properly without the use of lubricants that could become entrapped in the charge weld [68]. The charge weld interface is formed between the sheared end of Billet \#1 and the new billet (\#2). While the charge weld is initially transverse to the extrusion direction, it becomes highly elongated and essentially parallel to the seam weld over most of the extrusion length, as shown in Figure 2-7b. Also, throughout most of the extrusion length, charge welds in hollow extrusions are so close to the seam welds as to be indistinguishable from them. Only near the initial location of the charge weld, usually close to the die "stop mark" (die mark on extrusion product when extrusion of next billet begins), will the charge weld be clearly distinguishable from the seam weld.
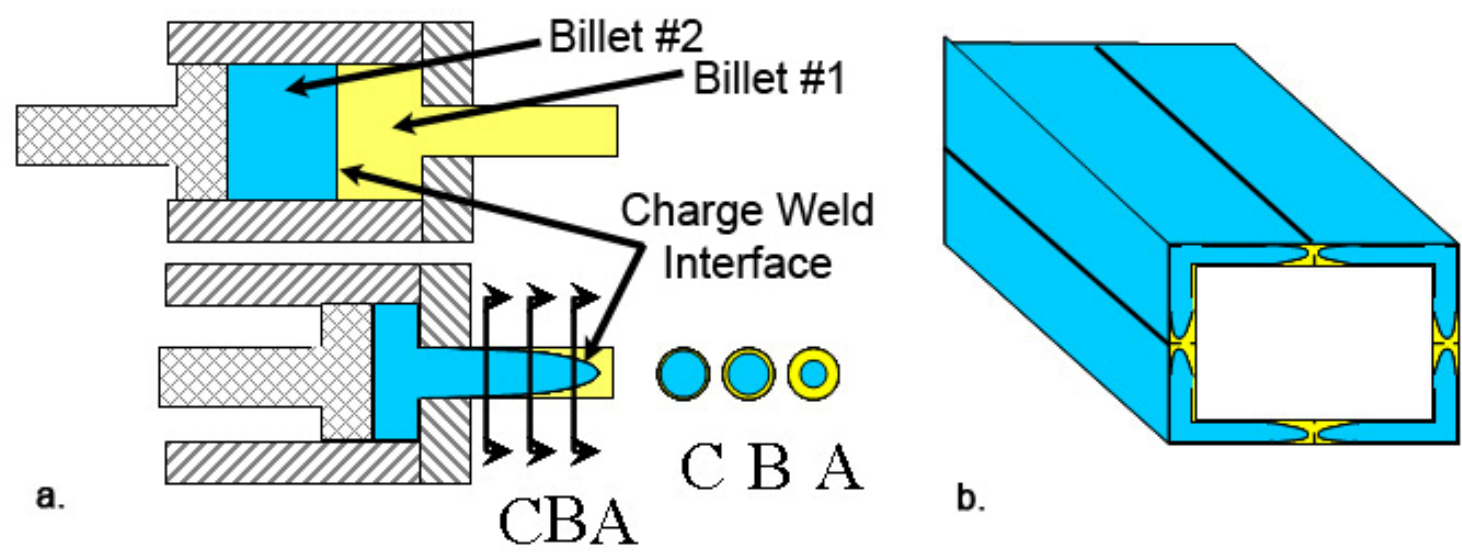

b.

Figure 2-7. a. Illustration of the origin of charge weld interfaces b. relationship between charge and seam welds 
The tensile properties transverse to the seam welds have been documented by other authors $[68,72,73]$. Tensile tests reported by Rijkom and Bolt, comparing specimens with and without transverse welds, for both AA6060 and AA6082, showed drops in elongation of $20.7 \%$ and $37.5 \%$, but drops of less than $10 \%$ in the ultimate and yield strength of these alloys when charge welds were present [72]. Akeret also reported a loss in elongation but no significant drop in yield or ultimate strength, when comparing tensile properties of base material with that of specimens containing welds close to the die stop. At a distance of approximately $2.5 \mathrm{~m}$ from the die stop the decrease in properties is much less noticeable [68]. It is common practice to discard a portion of the extrusion near the stop mark so that any defective material resulting from the charge weld is not included in extruded components. To date, nothing was found in the open literature relating seam weld or charge weld interfaces to high cycle fatigue and fatigue crack nucleation, although, a recent paper by Donati [70] examined the effect of seam weld quality on fatigue crack growth, showing that under optimized welding conditions, the growth rate was similar to specimens without welds. The initial focus of this work was to determine what, if any, affect the solid state welds inherent to the continuous extrusion of hollow aluminum extrusions have on high cycle fatigue behavior.

Another feature of the extrusion process occurs from dead zones in the extrusion die chamber that can cause highly sheared material to be pushed to the back end of the extruded billet, resulting in what are called coring effects [71, 
74]. The highly deformed billet material will be the last material to become extruded and contains much of the material from the billet surface and will have higher concentrations of oxides. Coring can be observed after about $85 \%$ of the billet is extruded [74]. Therefore, coring effects could occur in the last $15 \%$ of material from the first billet, including material after the stop mark up to the point where material from the next billet exits the die. Once material from the second billet exits the die, the charge weld results, and charge weld separation in hollow extrusions could consume $\sim 10 \%$ of the length of the extruded product from the second billet. Figure 2-8 provides an illustration of a profile length showing the four different stages that occur after extruding a hollow profile from subsequent billets. Loss of material (i.e. scrapping) due to coring effects is not common, but some variations in properties could exist along the length of extruded profiles due this phenomenon, therefore a thorough study of the variation in tensile and fatigue properties at each of the four stages was undertaken. 


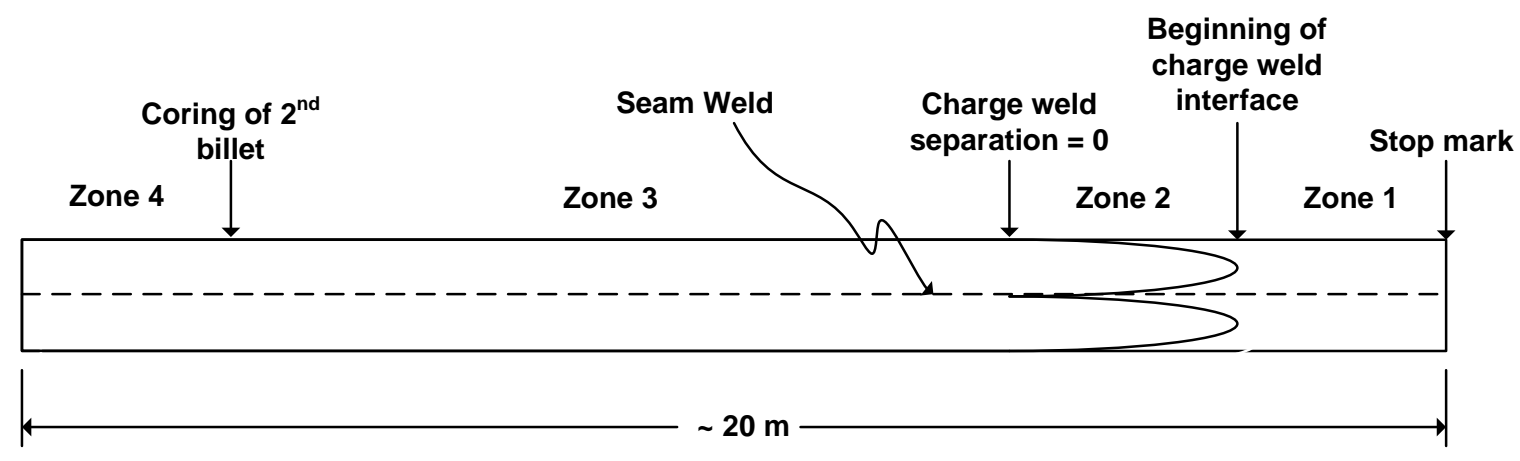

Zones: 1) Possible coring effect from first billet

2) Charge weld separation between $1^{\text {st }}$ and $2^{\text {nd }}$ billets

3) Charge weld separation $=0$

4) Possible coring effect from second billet

Figure 2-8. The four stages or zones that can occur during continuous billet extruding of hollow profiles

All extrusions contain surface related features called die lines. The causes of these die lines, and the extrusion practices utilized to minimize these die line, such as control of billet chemistry, die length, die surface finish and extrusion temperature have been studied extensively [75-77]. Clode and Sheppard have classified the extrusion die lines into two categories [75]. The major cause of the die lines is the build-up of metal in the die choke area. The die choke is the location where metal flows between the die land and the inner mandrel. This metal work-hardens, oxidizes, and scores the surface of the extruded material. They also determined that "micro die lines" form from the fracture and cavitation of iron bearing intermetallic particles at or near the surface. Figure 2-9 schematically illustrates an extrusion press with the die choke magnified to show the oxide scoring on the surface of the extruded profile. The die line roughness can vary between profile walls, on the inside or outside 
face of those walls, and down the length of the extruded profile. The roughness also typically increases as the dispersoid alloy element concentrations are increased, therefore, it would be expected that the AA6082 alloy, with higher Mn concentrations should have higher die line surface roughness values.

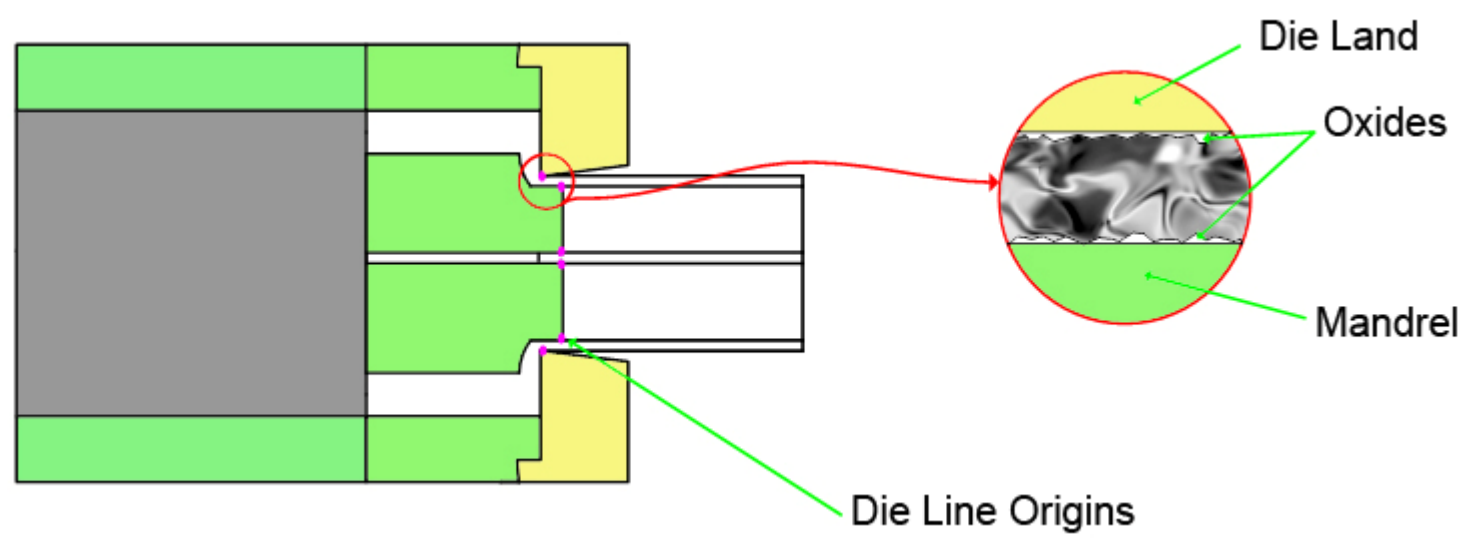

Figure 2-9. Schematic of die line origins

Although, the origin of die lines and their properties with respect to extrusion appearance and anodizing has been studied, and in spite of the known link between surface roughness and fatigue properties [2, 12, 78, 79], there appears to have been little research relating die line surface finishes to the fatigue properties of extrusions. In a study performed by As et. al., the fatigue lives of polished and rough ground AA6082 extruded specimens were compared [78]. The rough specimens, having surface roughness values, $R_{a}$ between 3.3 and $9.3 \mu \mathrm{m}$, showed a 10 fold drop in fatigue life when compared to specimens with a polished surface finish. 
Empirical and mechanistic models exist to account for the reduced fatigue strength of notched members [12, 80-82]. Many textbooks often refer to the empirical models presented by Pedersen and Nueber $[5,12]$. An in-depth discussion on the subject of notch effects on fatigue life will not be presented, but the relevance of both the static stress concentration and fatigue notch factor, which are utilized in analysis on the relationship between die lines surface roughness and high cycle fatigue life presented later in this dissertation, will be briefly discussed here. The static stress concentration factor $\left(K_{t}\right)$ is the ratio of the maximum stress at a notch root to the nominal stress in a smooth specimen.

$$
K_{t}=\frac{\sigma_{\text {notch }}}{\sigma_{\text {nom. }}}
$$

Equation 2-9

The fatigue notch factor $\left(\mathrm{K}_{\mathrm{f}}\right)$ is the ratio of fatigue stress for a smooth member to that of a notched member at a specified number of cycles to failure [12].

$$
K_{f}=\frac{\sigma_{a(\text { smooth })}}{\sigma_{a(\text { notch })}}
$$

Figure 2-10 illustrates the dramatic effect that a small notch can have on the fatigue life of a specimen. For this specific example, the fatigue endurance limit is dramatically reduced, but in general the notch depth, notch radius, material properties and fatigue initiation mechanisms are all factors that can induce premature fatigue failure in either macro- or micro-notched specimens. The effect of loading, i.e. stress amplitude on the fatigue notch factor is also illustrated in Figure 2-10. At high stress levels (low cycle fatigue), macroscopic, uniform plasticity will occur and the fatigue notch factor will be close to unity. At 
intermediate stress levels, only local yielding will occur and the fatigue notch factor will be between unity and $\mathrm{K}_{\mathrm{t}}$. If the stress levels are low enough, leading to endurance limit values, either no localized plasticity will induce a fatigue crack even in notched specimens or if cracks form they will not grow under low stress intensities, and $\mathrm{K}_{\mathrm{f}}$ will be approximately equal to $\mathrm{K}_{\mathrm{t}}$. Under certain conditions of material and notch profile, $\mathrm{K}_{\mathrm{t}}$ will be equal to $\mathrm{K}_{\mathrm{f}}$ at very low cyclic stresses, but typically $\mathrm{K}_{\mathrm{t}}$ values are slightly higher than $\mathrm{K}_{\mathrm{f}}$ values [12]. This is most likely due to the statistical variability of microstructural factors leading to fatigue failure and the stress gradient that exists at stress concentrations [12]. The relationship between the fatigue notch factor and the static stress concentration factor associated with die lines roughness on the surface of AA6082 and AA6063 specimens will be discussed in connection with high cycle fatigue results presented later. 


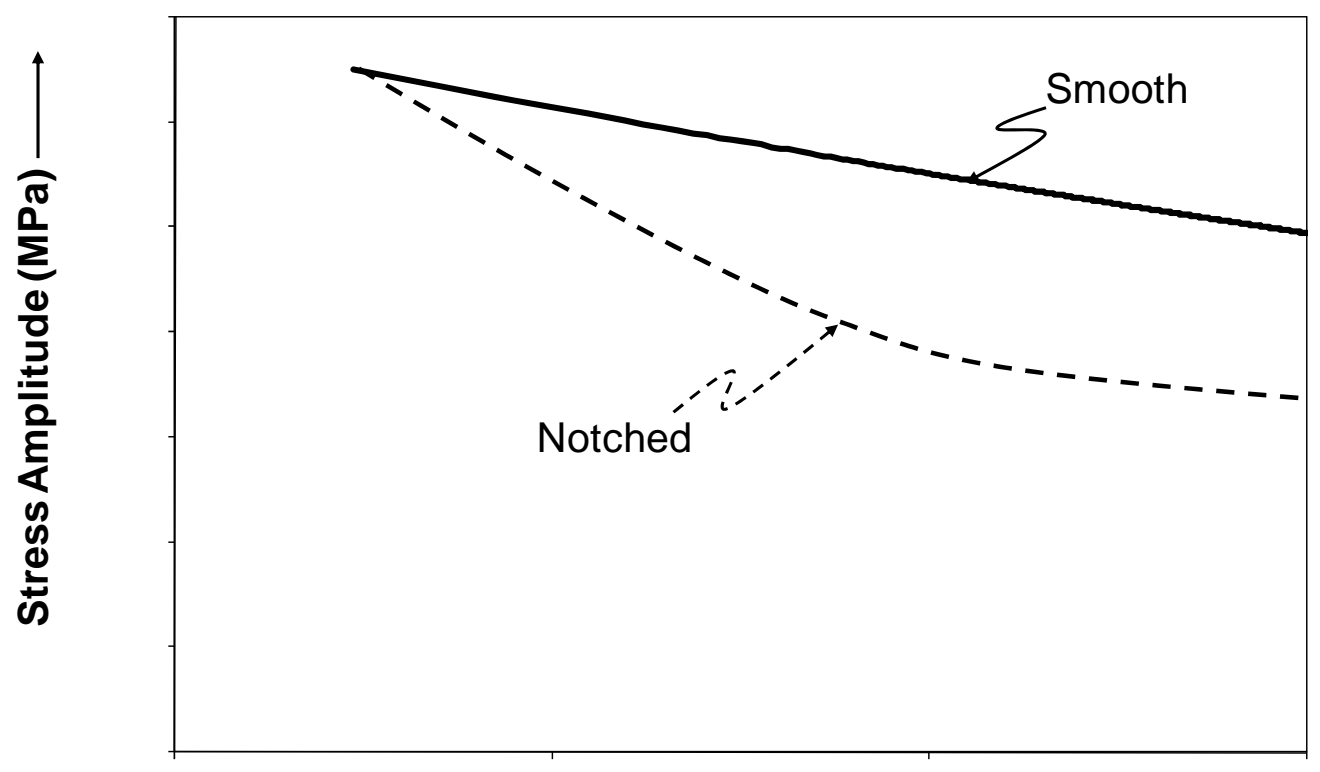

$\log N_{f} \longrightarrow$

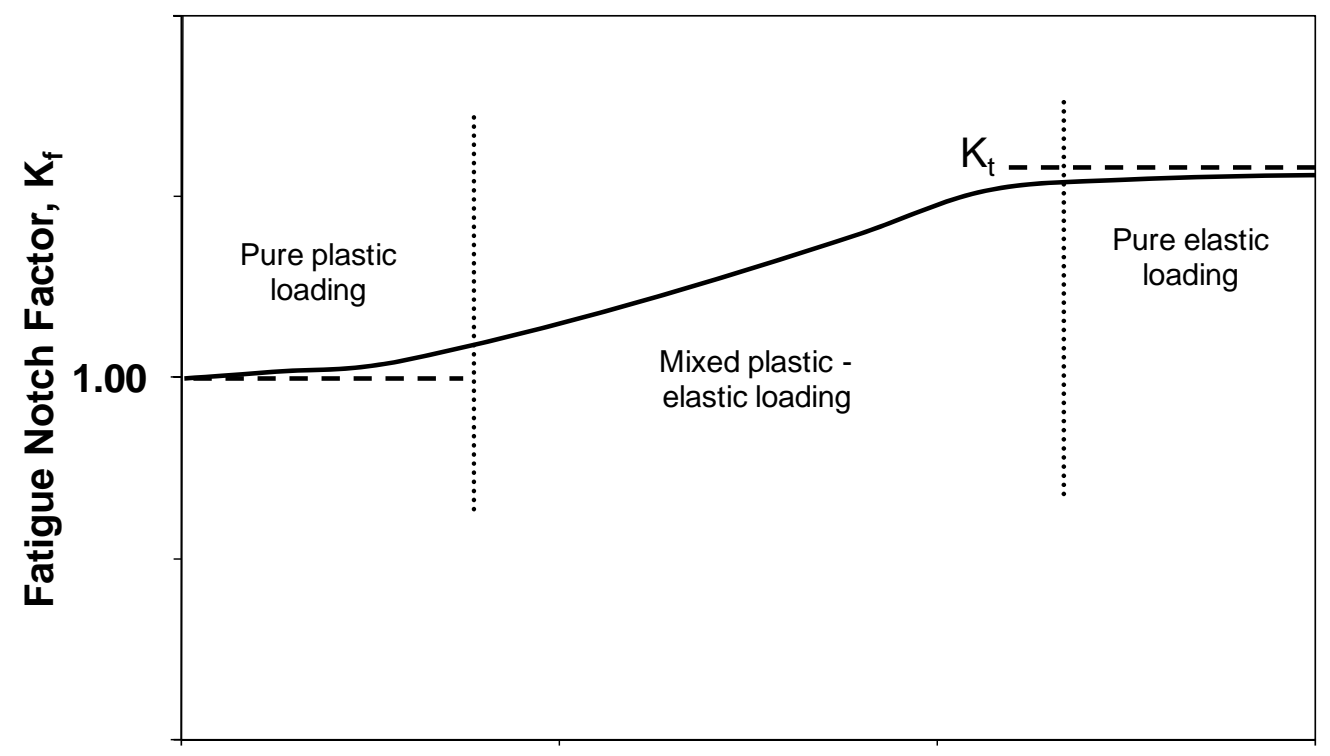

$\log N_{f} \longrightarrow$

Figure 2-10. Schematic S-N curve for smooth and notched fatigue specimens and the fatigue notched factor as a function of number of cycles to failure (after [12]) 


\subsection{Experimental program outline}

Several of the variables that can affect the strength and fatigue behavior of hollow aluminum extrusions have been discussed. The experimental program was designed to determine what specific variables should be of concern if hollow aluminum extrusions are incorporated into fatigue critical automotive components. The effects of the seam weld were specifically targeted as a potential microstructural feature that could play a dominant role in defining the high cycle fatigue behavior of hollow extrusions, specifically for AA6082 extrusions. Specimens containing charge weld interfaces were also expected to decrease the high cycle fatigue life, therefore, work was undertaken to determine the fatigue lives of specimens containing such defects. Fatigue testing early in the research program revealed highly anisotropic behavior, attributed to die line surface roughness. A comparison in fatigue lives of specimens with as-extruded surface finishes to those with finely polished surfaces confirmed this assumption. The effects of microstructure and aging treatment on fatigue life will also be discussed. The mechanism of corrosion-fatigue in both alloys was also studied and it was found that fatigue properties were severely degraded when testing specimens in a salt solution. Finally, the effects of elevated temperature on the fatigue behavior of AA6082 will be discussed. 


\section{EXPERIMENTAL PROCEDURE}

\subsection{Materials}

Fifteen sections of press spray quenched extruded AA6082 and AA6063, each approximately $150 \mathrm{~cm}$ in length, were obtained from Hydro Aluminum, Holland, MI. These 15 sections represent the total output from one fully extruded billet, with the remnants of one previous billet in the extruding press so as to have a representative charge weld. The billet chemistry of the two alloys is provided in Table 3-1.

Table 3-1. Chemical composition of billets

\begin{tabular}{cccccccccc}
\hline \multicolumn{10}{c}{ Analysis in \% of Weight } \\
\hline Alloy & Si & Fe & Cu & Mn & Mg & Cr & Zn & Ti & Al \\
\hline AA6063 & 0.45 & 0.23 & 0.04 & 0.04 & 0.49 & 0.01 & 0.02 & 0.02 & Bal. \\
AA6082 & 0.95 & 0.2 & 0.03 & 0.52 & 0.58 & 0.14 & 0.02 & 0.02 & Bal.
\end{tabular}

A schematic profile of the hollow extruded automotive bumper extrusion used as material stock and the orientations and locations of the specimens taken from the profile are shown in Figure 3-1. The walls of the profile were assigned labels so that proper identification of fatigue samples could be maintained. The spots marked on the profile in Figure 3-1 represent the locations of seam welds, determined by etching the polished surface with $25 \% \mathrm{NaOH}$ for 1 minute at $60^{\circ} \mathrm{C}$. Overall dimensions of the rectangular profile are approximately $80 \times 100 \mathrm{~mm}$, with wall thicknesses of approximately $2.5,2.8,2.7$ and $3.5 \mathrm{~mm}$ for the $\mathrm{A}, \mathrm{B}, \mathrm{C}$ and D walls, respectively. The four walls of the extrusion that were used for fatigue specimens were cut and sectioned into smaller blanks that could be 
easily heat treated. Each blank was labeled so that the exact location of each specimen within the extrusion could be established. Not only was the blank labeled for each specimen, but the distance from the extrusion stop mark was also identified on each specimen. This was done so that fatigue properties associated with the four zones shown in Figure 2-8 could be determined.

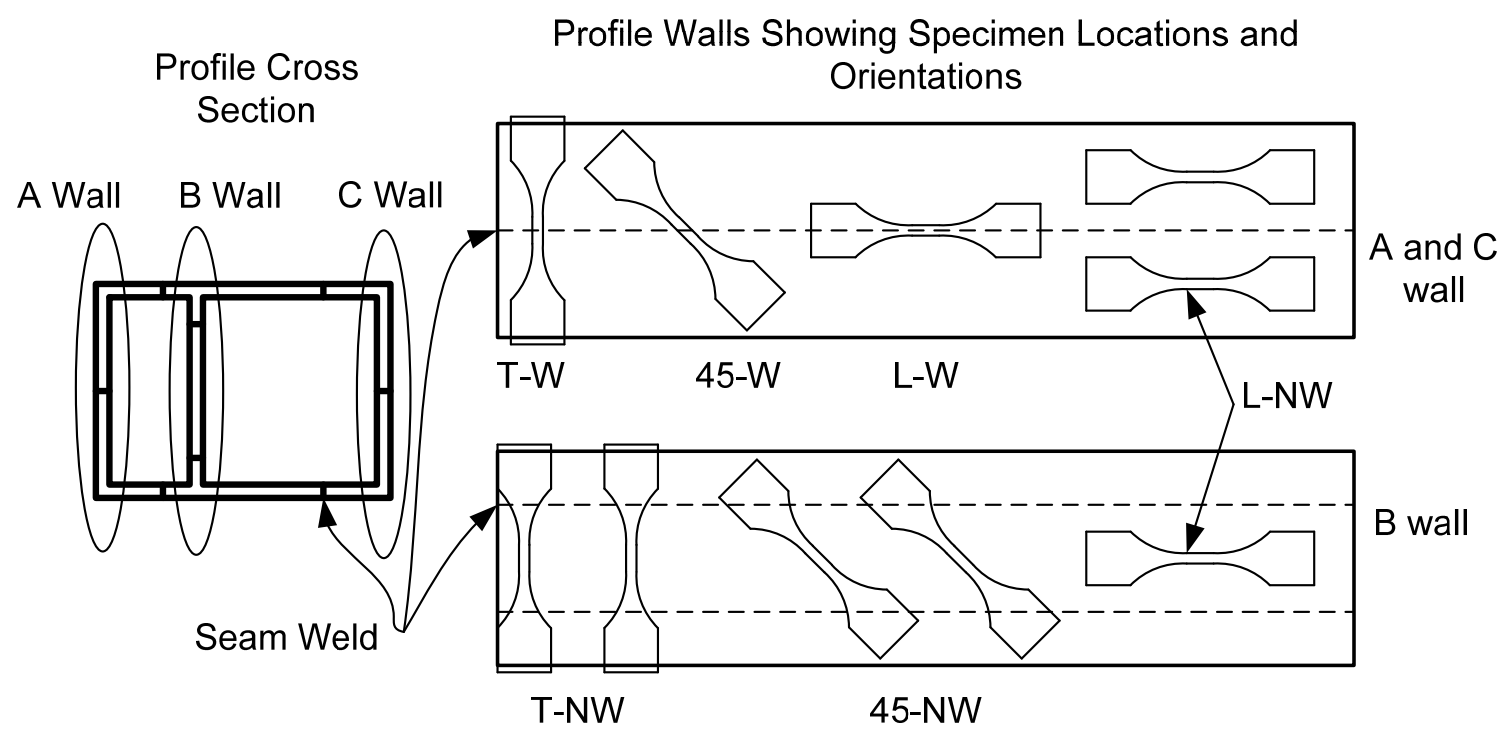

Figure 3-1. Schematic illustration of profile and specimen locations obtained from $A, B$ and $C$ faces of extrusion profile

The billet was homogenized prior to extrusion, maintained above the solutionizing temperature during extrusion and quenched at the exit port of the extrusion press. Post extrusion heat treatment only included artificial aging, typically to peak strength. In order to determine the proper peak aging time at $185^{\circ} \mathrm{C}$, the aging responses of the two alloys at this temperature were determined. Aging treatments of blanks were performed in a box furnace 
exposed to the atmosphere prior to milling of fatigue specimens. The blanks were held in the furnace for times of $0-13$ hrs before air cooling to room temperature. Tensile specimens similar to L-NW fatigue specimens (Figure 3-1) were milled from the blanks and aged for various times. To study the effect of aging treatment on strength and fatigue properties of the AA6082 extrusion, specimens aged at times and temperatures other than the standard $185^{\circ} \mathrm{C}$ for 5 hr were fatigue tested. Two aging temperatures, above $\left(175^{\circ} \mathrm{C}\right)$ and below $\left(195^{\circ} \mathrm{C}\right)$ were examined for specimens aged $5 \mathrm{hr}$. Also, specimens aged for 1.5, 3,10 , and $21 \mathrm{hr}$ at $185^{\circ} \mathrm{C}$ were tested.

The heat treated blanks were cut to smaller pieces that could be placed in the CNC mill. Specimens having three different orientations (longitudinal, transverse and at a $45^{\circ}$ angle relative to the extrusion direction) were cut for fatigue testing. Some specimens of each orientation contained extrusion welds within the center of the gauge section, as shown in Figure 3-1. Since all specimens cut transverse to the extrusion direction from the top (A wall) and bottom ( $C$ wall) contained centrally located welds, similar specimens were taken from the center ( $\mathrm{B}$ wall) to determine transverse fatigue results without welds present. Table 3-2 provides a listing of specimen types cut from the extrusion profile and also the labels for all subsequent specimen nomenclature used in this dissertation. 
Table 3-2. Specimen orientations and locations taken from profile

\begin{tabular}{|l|l|}
\hline Specimen Type & Wall \\
\hline Longitudinal No Weld (L-NW) & A, B, C, D \\
\hline Longitudinal With Weld (L-W) & A, C \\
\hline Transverse No Weld (T-NW) & B \\
\hline Transverse With Weld (T-W) & A, C \\
\hline $45^{\circ}$ With Weld (45-W) & A, C \\
\hline
\end{tabular}

The specimen geometry follows modified ASTM standard E466 [83] and is shown in Figure 3-2. A tapered radius had to be utilized due to the limited extrusion width of $80 \mathrm{~mm}$. This specimen geometry allowed the acquisition of specimens transverse to the gauge section with only a slight reduction in gripping length. Following CNC milling, the corners between the machined faces and the extrusion faces were burnished with an oil stone. This removed any machining burrs, slightly rounded the corners and induced a small surface compressive stress which generally forced crack nucleation to occur on the extrusion face.

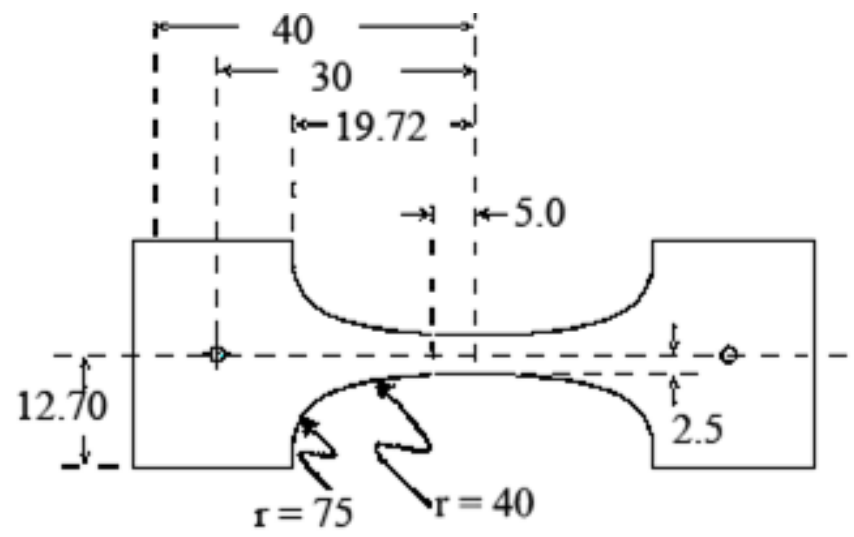

Figure 3-2. Specimen geometry (in $\mathrm{mm}$ ). Specimen thickness varies from 2.5 to $3.5 \mathrm{~mm}$ depending on extrusion wall 
Fatigue and tensile testing was typically performed on specimens maintaining the two un-milled as-extruded surfaces. In order to independently study the effects of seam welds, die lines and microstructure, select AA6082 specimens were polished by mounting on a fixture designed to operate with a Leco automatic polishing head. The polishing sequence consisted of 600 and 1000 grit SiC grinding followed by 3 and $1 \mu \mathrm{m}$ diamond polish. Both of the asextruded surfaces on some specimens were ground and polished approximately $100 \mu \mathrm{m}$ on each side to remove the die lines but maintain the recrystallized surface layer. On other specimens the surfaces were ground and polished to depths greater than $0.4 \mathrm{~mm}$, which is approximately the thickness of the recrystallized surface layer in the B wall of the AA6082 extrusion. The milled surfaces were also polished with a Dremel tool to minimize premature fatigue crack initiation on the edges of the specimen gauge section. The corners of these specimens were also burnished prior to polishing.

\subsection{Microstructural characterization}

The grain structure of the extrusion at the locations where the fatigue specimens were obtained was characterized by anodizing the surface cross section. Representative samples mounted in epoxy were first polished to a $1 \mu \mathrm{m}$ finish then anodized on a Struers LectroPol-5, utilizing a 5\% $\mathrm{HBF}_{4}$ solution and $20 \mathrm{~V}$ potential. The polishing and grinding sequence consisted of 240 through 800 grit SiC followed by 3 and $1 \mu \mathrm{m}$ diamond polish. The microstructure was analyzed in a light microscope using polarized light. Cross sectional images of 
the fracture surfaces were also examined under optical microscopy. A limited amount of EBSD work was performed to investigate grain orientations within the cross section of the AA6082 alloy.

Fracture surfaces of representative fatigue specimens were characterized using an SEM. Low magnification images were taken to visualize the macrocopic failure of the specimens. The location of $\mathrm{FCl}$ sites was determined and high and low magnification images were taken at the crack nucleation site to determine the mechanisms responsible for initiating cracks. Images were also taken perpendicular to the extruded face to further examine $\mathrm{FCl}$ sites and fracture surfaces. This helped to determine the role of extrusion surface features, such as die lines, in the crack initiation and propagation processes.

Transmission electron microscopy was utilized to examine the fine scale precipitate structures, widths of precipitate free zones and segregation of second phase species. Specimen sections for TEM analysis were initially polished to $200 \mu \mathrm{m}$ in thickness, with a final polish using $1 \mu \mathrm{m}$ diamond paste. Three millimeter diameter specimens were punched from the thin sections and electropolished using a solution of $25 \% \mathrm{HNO}_{3}$ and high purity methanol at a current of approximately $0.15 \mathrm{~mA}$ and temperature of $-20^{\circ} \mathrm{C}$. Microscopy was performed to determine precipitate sizes under peak-aged conditions in the grain bulk, but more importantly, to determine grain boundary characteristics for each alloy. 
The surface roughness of the extruded faces was determined using a stylus profilometer. A scan length of $10 \mathrm{~mm}$ and scan time of 180 minutes was used for each scan, and two to three scans were used to characterize the roughness at locations where the different specimen types were taken. Roughness parameters for both the inside and outside surfaces of each wall are compared. The mean roughness $\left(R_{a}\right)$ is an average of the distance of each point in the profile, from the center line. Mean peak to valley height $\left(R_{z}(\mathrm{DIN})\right)$ is an average of the five largest peak and trough distances in the scan, and the maximum peak to valley height $\left(R_{t}\right)$ measures the difference between the highest point and lowest point in the scan. The $R_{a}$ value is often used to characterize surface roughness, but in fatigue crack nucleation, the $R_{z}$ or $R_{t}$ values may be more relevant since nucleation is a weakest link phenomenon, and is expected to occur at higher or deeper contours with sharp radii.

\subsection{Hardness testing}

Vickers hardness testing was performed on a limited basis. The hardness was measured through a $\mathrm{D}$ wall cross section to determine difference in microhardness between fibrous and recrystallized grain structures. Prior to hardness testing, the cross section was mounted in Bakelite and ground to a $1000 \mu \mathrm{m} \mathrm{SiC}$ finish. The applied load during hardness testing was kept low so that a number of measurements could be taken within the recrystallized surface layers. Following hardness testing the specimen was anodized to show the location of indentations relative to the grain structure. 


\subsection{Tensile testing}

Tensile testing was performed extensively on the AA6082 alloy and on the AA6063 alloy where appropriate. A screw driven Instron loading frame was utilized at a crosshead speed of $1 \mathrm{~mm} / \mathrm{min}$ with a $10 \mathrm{~mm}$ strain gauge attached to the specimen gauge. Specimen geometry for tensile testing was identical to that of the fatigue tests. Tensile tests for all specimen types listed in Table 2, from each different wall, with the exception of specimens taken $45^{\circ}$ to the extrusion direction, were performed on specimens taken from the AA6082 alloy. Only the extreme L-NW and T-W specimens were tested for the AA6063 alloy.

\subsection{Fatigue testing}

Fatigue testing was performed on two different types of testing machines; a servo-hydraulic machine at Michigan Tech and a resonance machine at Hydro Aluminium, Sunndalsøra, Norway. The frequency of all tests performed on the servo-hydraulic machine was $20 \mathrm{~Hz}$, unless otherwise noted. The frequency of tests performed on the resonance machine depended on the compliance of the specimens. Specimens from different profile walls (varying thickness) have slightly different resonance frequencies, but the frequencies were typically near $63 \mathrm{~Hz}$. All tests were load controlled and conducted in tension-tension at a stress ratio ( $r$ ) of 0.1 in order to avoid any buckling in the relatively thin specimens. Specimens that did not fail before reaching $1 \times 10^{7}$ cycles were classified as run-outs and tests were stopped. Stress amplitudes at these runout values are treated as endurance limit values for these aluminum alloys. 
Alignment and calibration of the resonance testing machine was performed through Hydro Aluminum, whereas, both calibration and alignment on the servo-hydraulic machine were performed at Michigan Tech. The calibration of the Michigan Tech load cell was verified by two methods; hanging a $100 \mathrm{lb}$ dead weight, and through the use of a separate calibrated load cell. The alignment of the load train and grips was verified using a standard strain gauged specimen as shown in Figure 3-3. A LabView program was used to collect and analyze the strains from the eight different gauges on the specimen. Through adjustment of an alignment fixture, it was possible to align the load train with the hydraulic actuator and minimize any bending stresses that could lead to inaccurate fatigue life values.

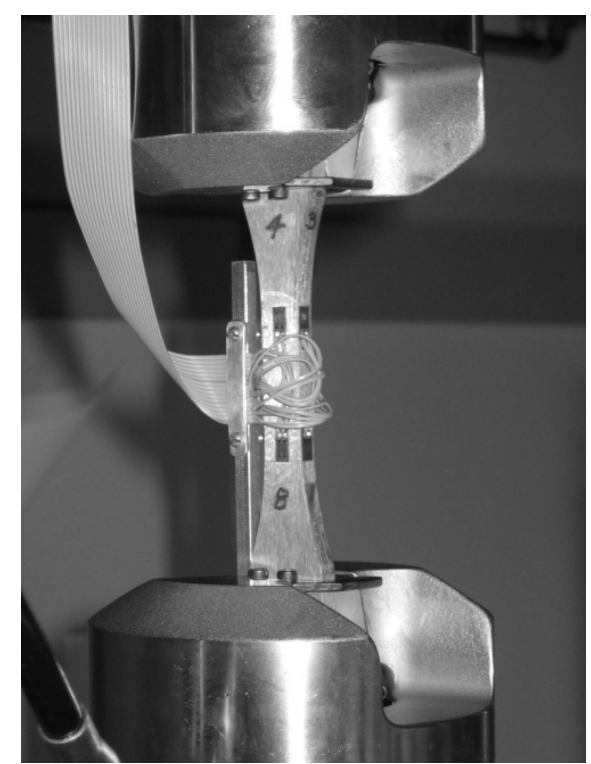

Figure 3-3. Alignment specimen in grips (photograph by author) 
Most of the fatigue results in this study can be characterized using an empirical expression first presented by Basquin [84]. This involves fitting the stress amplitude as number of cycles to failure to an equation of the form:

$$
\sigma_{a}=\sigma_{f}^{\prime} * N_{f}^{b}
$$

Equation 3-1

where $\sigma_{a}$ is the stress amplitude, $N_{f}$ is the number of cycles to failure, and $\sigma_{f}$ and $\mathrm{b}$ are fitting parameters, usually called the fatigue strength and exponent coefficients, respectively. The Basquin law was used to characterize and make direct comparison of the fatigue data collected from the various specimen types. Only data that was tested to failure was used in the Basquin fitting, since the actual fatigue life of run-outs is not known. The $R^{2}$ value of the curve fitting provides a reasonable approximation of the error in the fit of the fatigue data to the Basquin equation, with $R^{2}=1$ indicating a perfect fit.

Longitudinal specimens of each alloy were tested in a $3.5 \mathrm{wt} \%$ sodium chloride solution at stress levels leading to failure between approximately $1 \times 10^{5}-$ $1 \times 10^{6}$ cycles. A few AA6082 specimens were tested in distilled water for comparison to the air and salt solution fatigue results. These tests were performed at ambient temperature on the servo-hydraulic testing machine. The potential during the electrochemical reaction between the specimen and the salt solution was not controlled and the open circuit potential of unloaded specimens was approximately $-0.75 V_{\text {SCE. }}$. Epoxy was applied to the specimen surface from the grip to the gauge section, leaving only the constant gauge section to be exposed. The specimens were mounted with epoxy in a foam cup to retain the 
salt solution or water. Most fatigue testing of specimens was performed at 20 $\mathrm{Hz}$, but one specimen was tested at $10 \mathrm{~Hz}$ and another at $5 \mathrm{~Hz}$ for comparison.

Fatigue testing of select AA6082 specimens was also conducted in a tube furnace held at $150^{\circ} \mathrm{C}$, as shown in Figure 3-4. The furnace temperature was controlled by a thermocouple attached to the milled face of the specimen gauge section. Two other thermocouples were attached to the specimen shoulders to verify the temperature was consistent through the gauge section. A gradient of $1-2^{\circ} \mathrm{C}$ typically existed along the specimen gauge section.

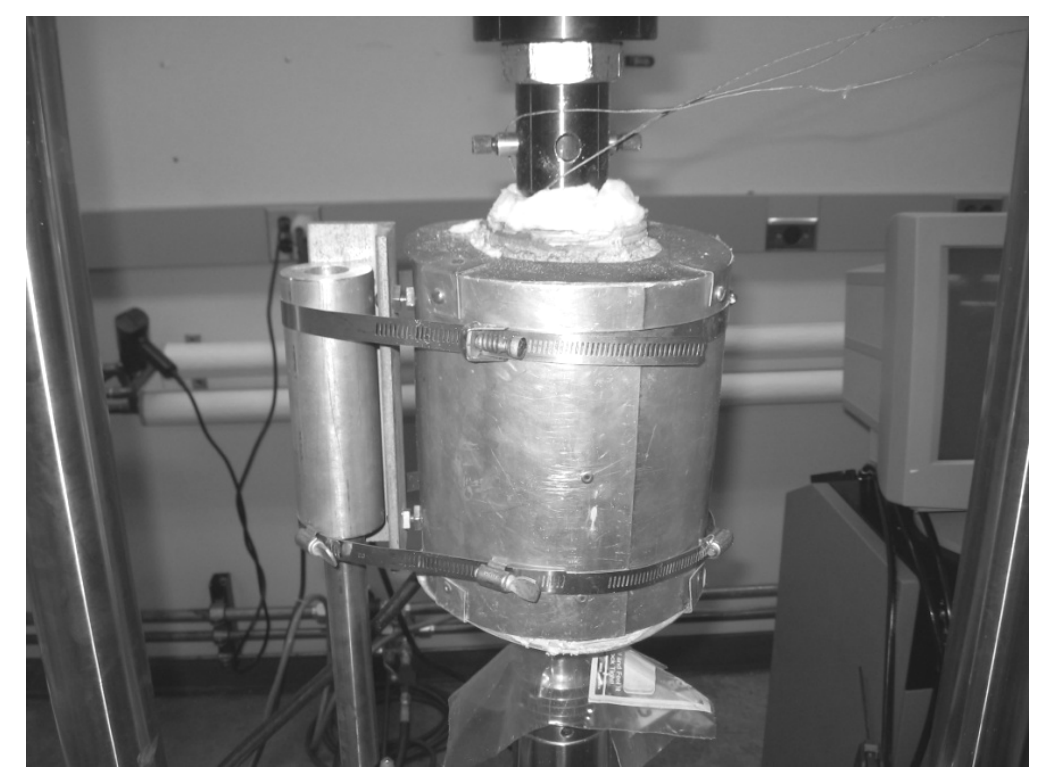

Figure 3-4. Tube furnace for elevated temperature study (photography by author)

\subsection{FEM modeling}

Stress concentrations resulting from die lines and representative notches simulating die lines were determined by FEA, utilizing the Unigraphics program NX 3.0. Roughness data from profilometer scans, taken perpendicular to the 48 
extrusion direction, were obtained at the $C$ wall seam weld location and at the B wall away from the seam weld on the AA6082 profile. This data was imported into the solid modeling program to generate a typical specimen subsection for FEA. The stress concentrations $\left(\mathrm{K}_{\mathrm{t}}\right)$ resulting from the as-extruded die lines as well as from rectangular notches (125 $\mu \mathrm{m}$ wide) of various depths were modeled in the program. Due to mesh volume limitations, only a small portion $(1 \times 1 \times 2$ $\mathrm{mm}$ ) of the specimen could be adequately meshed and modeled. The mesh was optimized prior to the stress concentration analysis and a node size of $0.14 \mathrm{~mm}$ was utilized. The Unigraphics program automatically adjusts node sizes in curved areas and nodes at the notches were $\sim 0.07 \mathrm{~mm}$. For purposes of modeling specimen loading, one end of the subsection was held fixed, while a uniaxial load equivalent to $1 \mathrm{MPa}$ was applied parallel to the specimen gage section at the opposite end. The applied load was intentionally kept small so that all portions of the solid would remain below the yield stress ( $\sim 300 \mathrm{MPa})$, allowing accurate $\mathrm{K}_{\mathrm{t}}$ values to be determined from the subsection solid model. Since this was strictly an elastic analysis (elastic modulus was assumed to be $68.9 \mathrm{GPa}$ ), all calculated stresses were proportional to the applied load, and local yielding was not directly evaluated. The local elastic stress concentration factors resulting from die line roughness and the machined notches were determined by the ratio of the maximum local stress to the nominal applied stress. Figure 3-5 shows FEA results for the $C$ wall seam weld and a $43 \mu \mathrm{m}$ deep notch. 


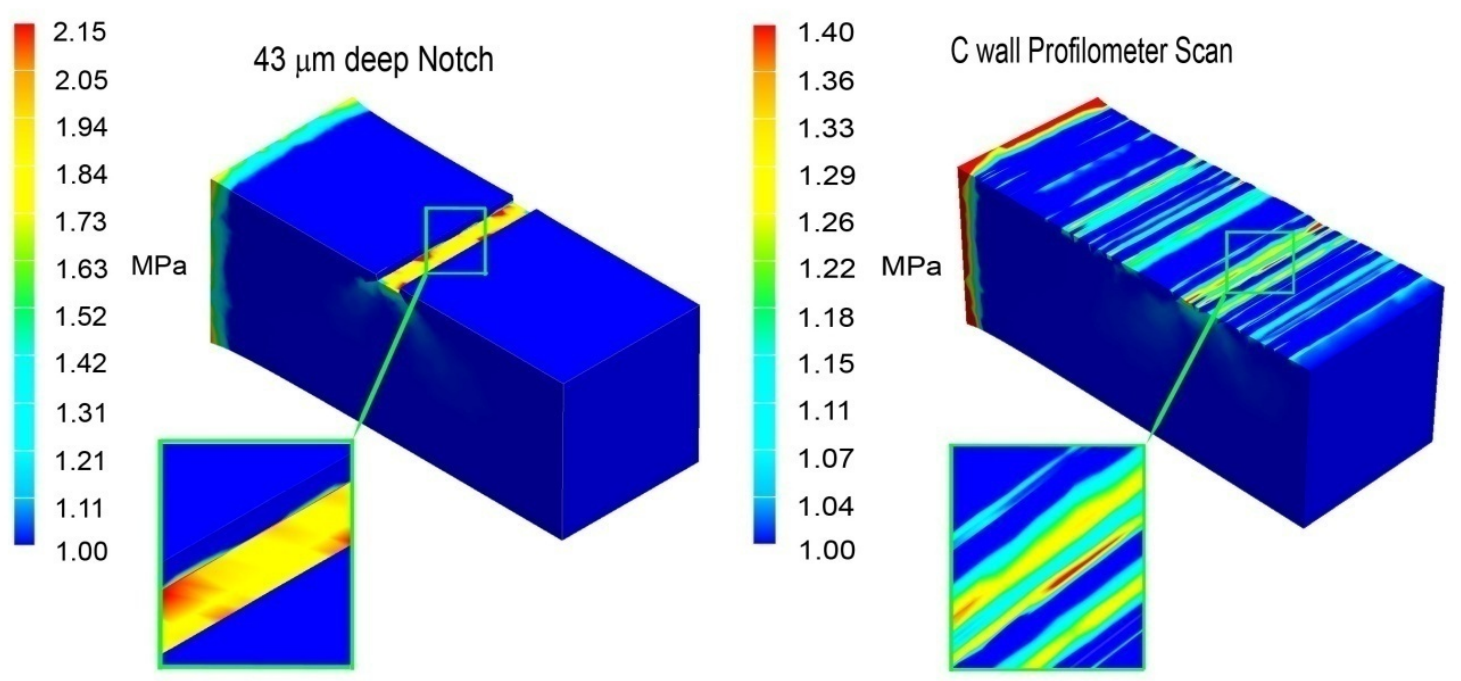

Figure 3-5. FEA simulation of stress concentrations at notch and as-extruded surface 


\section{AA6082 RESULTS AND DISCUSSION}

\subsection{Heat treatment}

The aging response of the AA6082 alloy at $185^{\circ} \mathrm{C}$ is shown in Figure $4-1$. The as-extruded yield strength is approximately $150 \mathrm{MPa}$, but at $185^{\circ} \mathrm{C}$, the strength rapidly increased and peak strength was obtained after 5 hour of aging. This time and temperature combination is typical of industry practice and, unless otherwise indicated was the condition in which the specimens were tested. Only small variations in the $0.2 \%$ offset yield strength were observed between $3-7$ hours aging, therefore, effects of minor variations in heat treatment should not significantly influence yield and ultimate tensile strength of the materials discussed here. Yield strengths of specimens aged for 5 hours at $175^{\circ} \mathrm{C}$ and $195^{\circ} \mathrm{C}$ are also included in Figure 4-1.

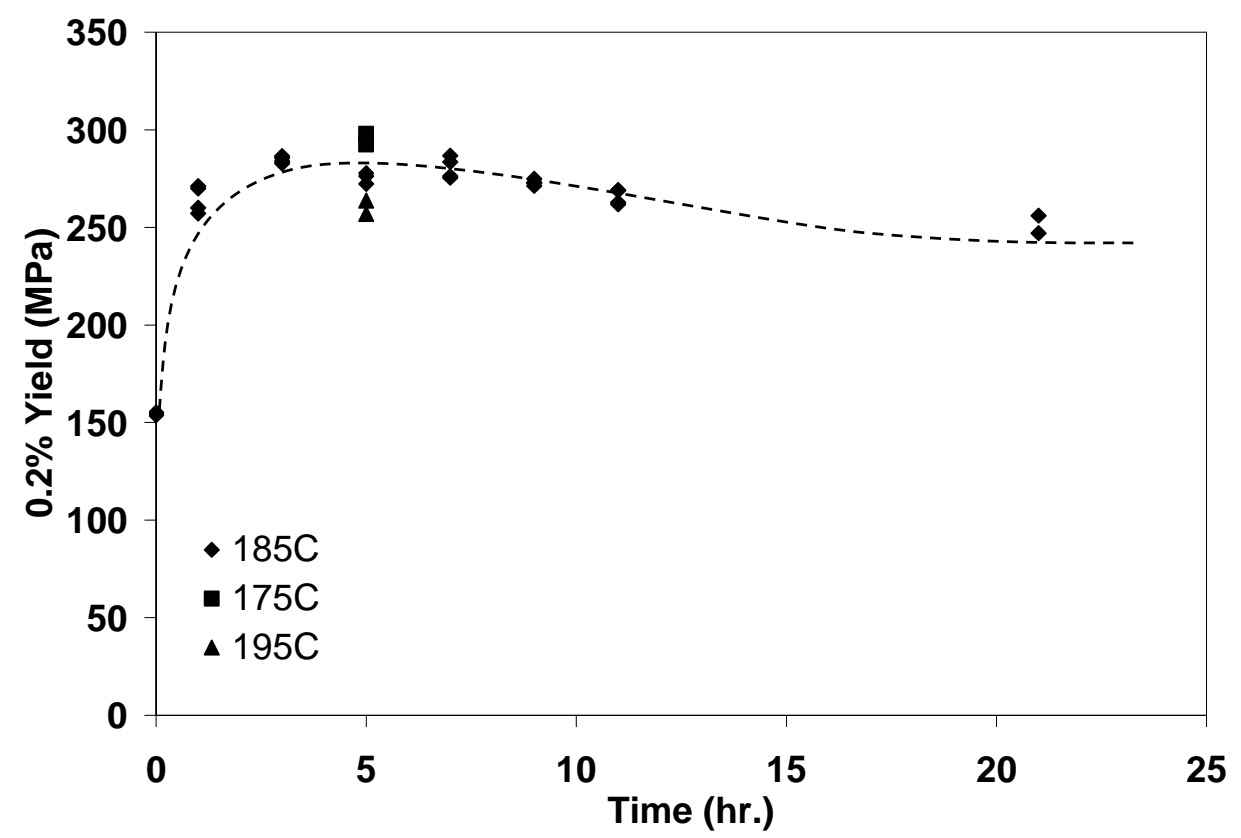

Figure 4-1. Aging response of $\mathrm{AA} 6082$ at $185^{\circ} \mathrm{C}$ 
While we do not expect significant variation in tensile properties to result from variations in heat treatment, the tensile properties of samples taken from different locations within the extrusion profile may vary. Reasons for this are that there may be differences in recrystallized layer thickness, grain texture, quench efficiency, segregation and/or the presence of seam and charge welds. In order to explore the effects of these variations, tensile properties were determined for each fatigue specimen type tested, and results are shown in Figure 4-2 (5hr@185 $\left.{ }^{\circ} \mathrm{C}\right)$. Little variation was found between tensile properties and specimen orientation, specimens from different extrusion walls or specimens containing seam welds.

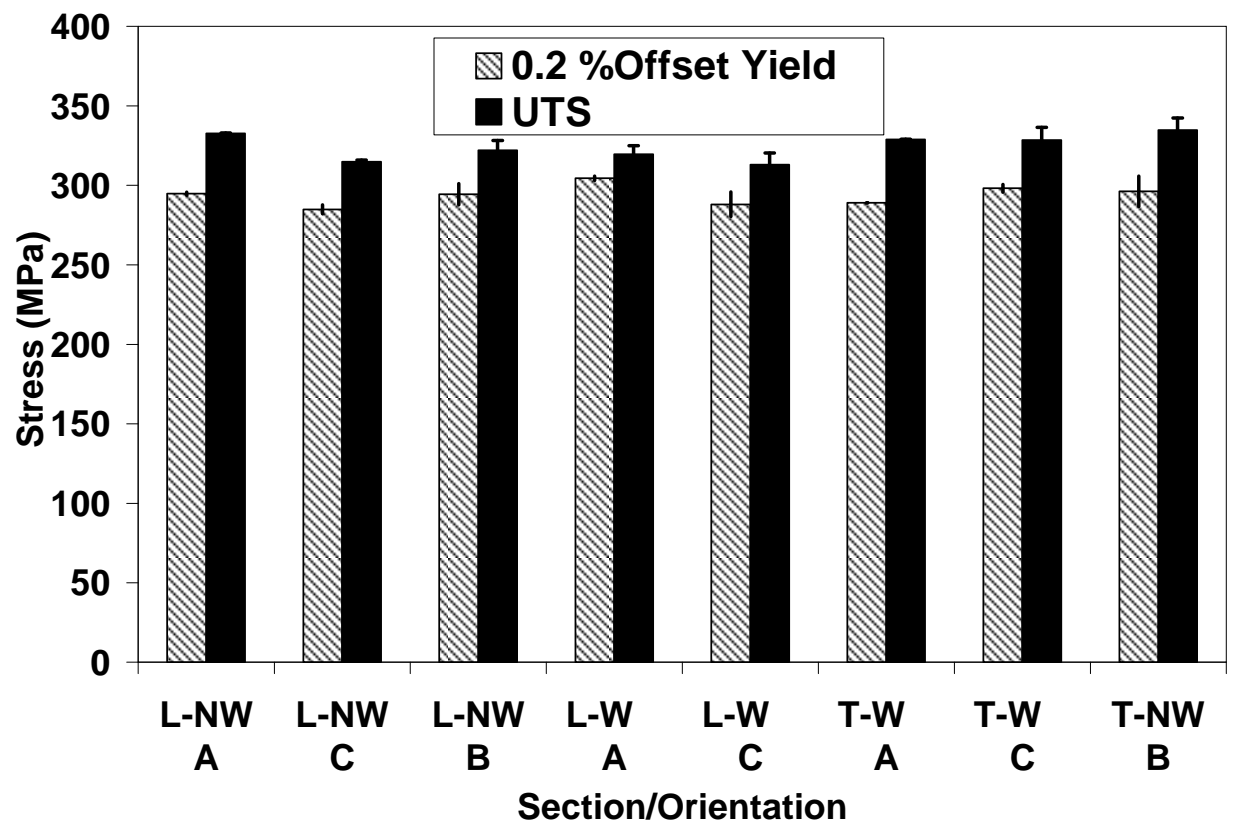

Figure 4-2. Tensile properties of various AA6082 peak aged specimen types 


\subsection{Heat treated microstructure}

Optical micrographs taken from the AA6082 extrusion cross section are shown in Figure 4-3. Figure 4-3a is an image showing the typical fibrous core microstructure with surface recrystallized layers, while Figure 4-3b\&c show the transverse microstructures at seam and charge weld interfaces, respectively. The fibrous core grain structure is elongated in the extrusion direction. The thicknesses of the fibrous grains are on the order of several microns, while the recrystallized surface grains range from 200-300 $\mu \mathrm{m}$ in diameter. The recrystallized layer was typically thicker on the inside face of the extrusion walls This phenomenon can be observed from comparing the top and bottom layer thickness in each image and the difference in thickness of the recrystallized layer is most likely due to the cooling gradient during quenching. Spray quenching was directed only at the outer surfaces of the extrusion. Inhomogeneous work hardening during extrusion could also contribute to the variation in recrystallized layer thickness.

Figure 4-3b provides an image of the cross section transverse to the extrusion direction, at the location of a seam weld interface. The solid state seam weld interface as well as the extremely large recrystallized grains at seam welds can be clearly observed in this image, both of which could play a role in the high cycle fatigue behavior. A charge weld interface can be seen in the transverse cross section of Figure 4-3c. Two features are inherent to charge weld interfaces, slightly recrystallized grains and an increased concentration of 
second phase particles. Like the seam weld, both features could affect fatigue properties and have been shown to effect tensile properties [68].
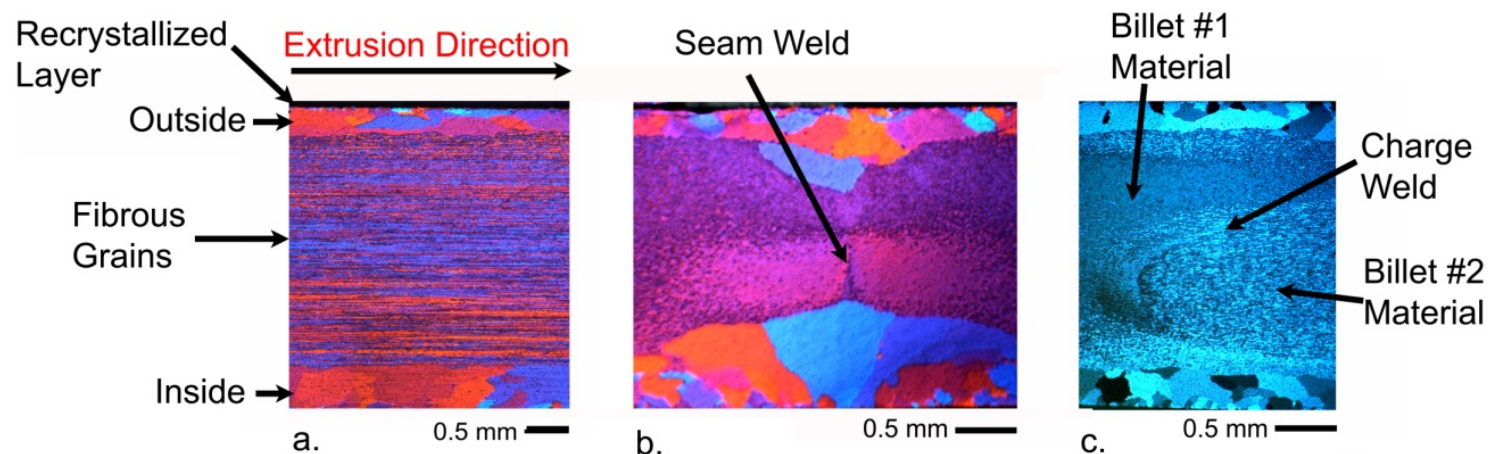

Figure 4-3. Optical images of AA6082 microstructures a. mainly fibrous AA6082 shown longitudinal to extrusion direction b. AA6082 seam weld c. AA6082 charge

The pole figure and orientation image map, determined through EBSD analysis of the A wall cross section in the AA6082 profile is shown in Figure 4-4. The $<111>$ pole figure shown in Figure $4-4 \mathrm{a}$ is similar to those of the previous studies on AA6082, where a dominant $\beta$-fiber texture exists [37, 54]. The pole figure includes orientation information from both the fibrous and surface recrystallized grains. The $\beta$-fiber texture is assumed responsible for the lack of anisotropy when comparing tensile strengths of specimens taken transverse and longitudinal to the extrusion direction. A lack of dominant texture in the recrystallized surface structure of the AA6082 alloy can be observed by examination of the orientation image map of Figure $4-4 b$. The relatively isotropic 
grain structure at the surface of the specimens will be important since most fatigue specimens maintained the fibrous core structure.
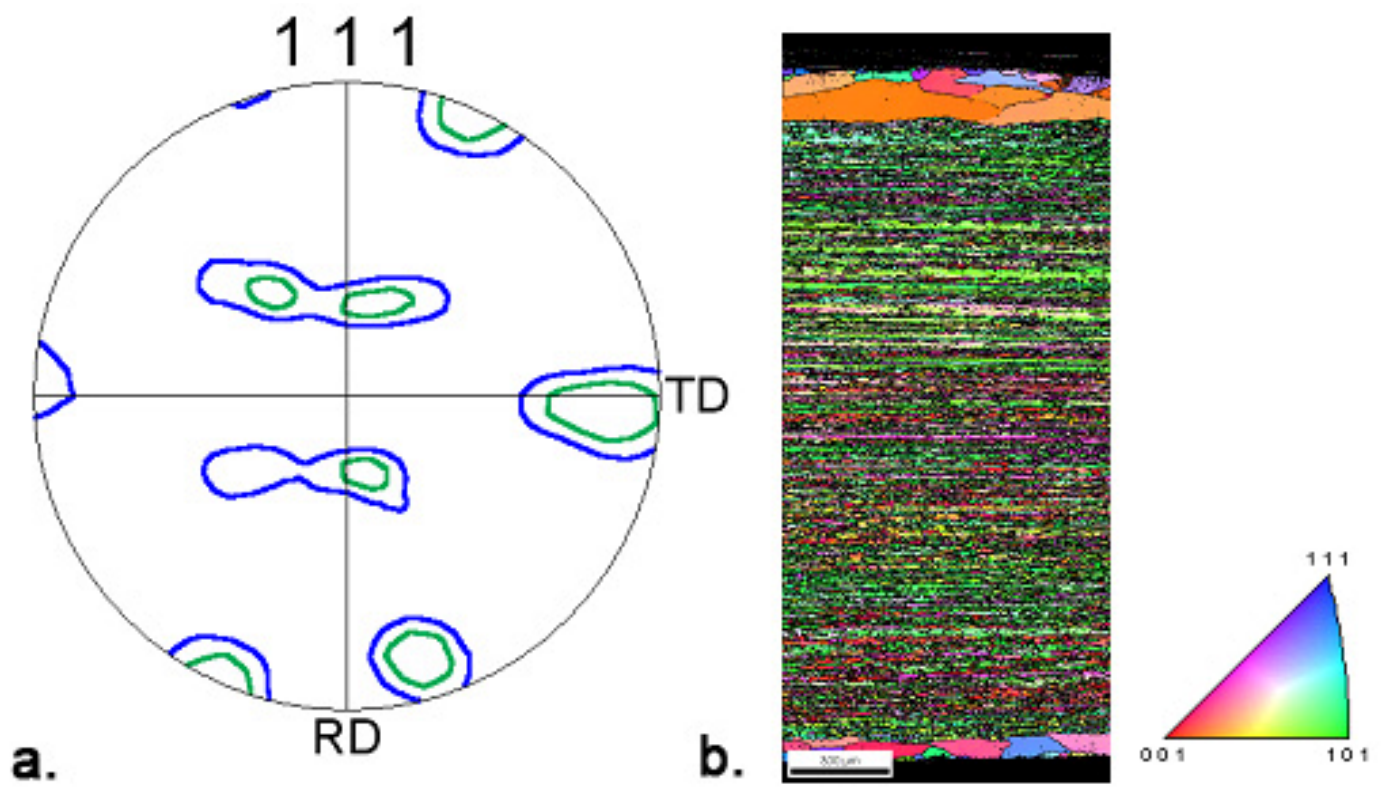

Figure 4-4. EBSD analysis of AA6082 alloy a. $<111>$ pole figure through cross section $\mathbf{b}$. Orientation image map

Transmission electron microscopy images of the AA6082 alloy are provided in Figure 4-5. The general size and distribution of the hardening $\beta$ " precipitate structure in a recrystallized surface grain is shown in Figure 4-5a. The precipitate shape and size are consistent with those reported for AA6XXX alloys $[45,47]$. The large grain size of the recrystallized surface grains made it difficult to locate grain boundaries in TEM specimens, therefore, only the boundary structure of the fibrous grains or fibrous sub-grains were investigated. Figure 4-5b shows one such boundary, with the top grain being aligned to show 
the $\beta$ " precipitates. The PFZ at the grain boundary in Figure $4-5 b$ has a width of 40-50 nm. Figure 4-4c shows a grain boundary triple junction with dispersoid particles located on the boundary. Both vacancy and solute concentrations in this alloy may lead to the formation of the narrow PFZ.
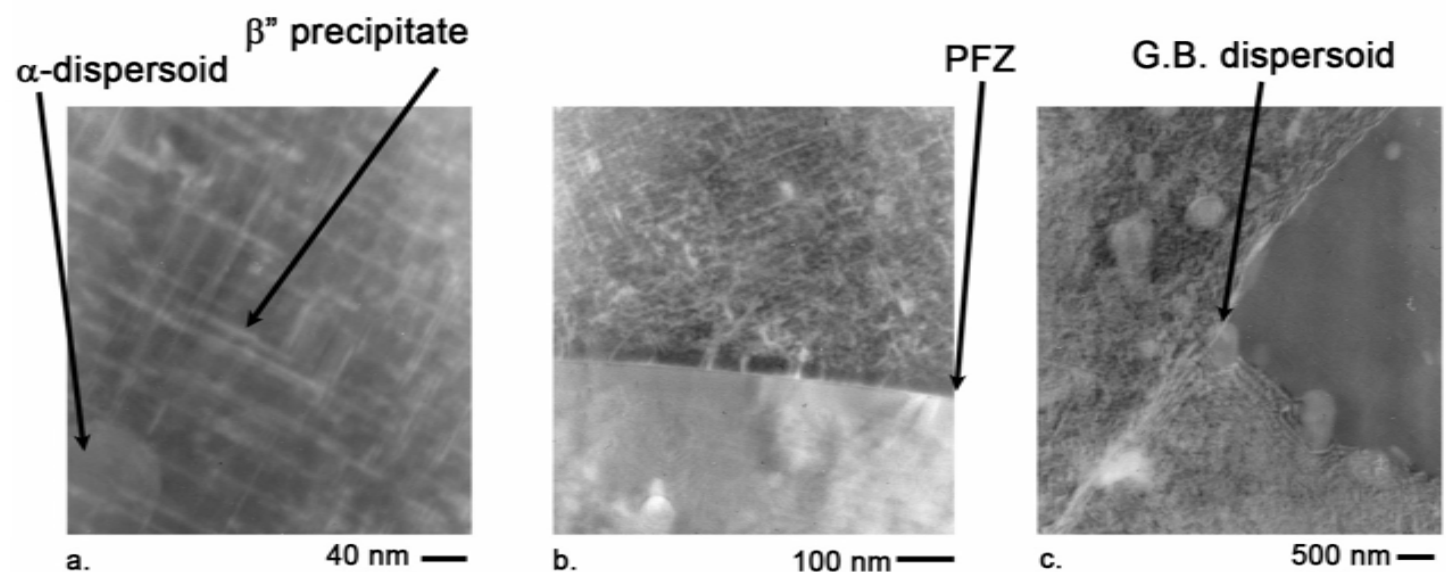

Figure 4-5. AA6082 TEM images in peak aged condition a. hardening $\beta$ " precipitates in recrystallized grain, b. grain boundary in fibrous core showing PFZ, c. grain boundary showing dispersoid phase ( $\beta$ " precipitates viewed in aluminum [110] zone axis)

\subsection{Surface roughness}

Figure 4-6 shows optical and SEM images illustrating the severity of die line roughness. The surface features are clearly highly anisotropic and therefore variations in fatigue properties relative to the extrusion direction may exist due to stress concentrations originating at die line roots. The roughness values from the profile walls of the AA6082 extrusion are shown in Table 4-1. A schematic illustration showing the location of $R_{t}$ roughness values associated with the 
profile surfaces is given with Table 4-1 for reference. The most noticeable difference between roughness values within the profile walls is evident when comparing profilometer scans across seam weld areas (center of $A$ and $C$ wall) with those scans that did not pass over welds (B wall). Since each scan was 10 $\mathrm{mm}$ in length, the high roughness values in weld areas may not be associated exclusively with the precise location of the seam weld, but with its general proximity. Also, the roughness is generally higher for the $\mathrm{C}$ wall compared to the A wall, and the inside face of each wall was rougher than the outside face. The roughness did not change significantly from the front to back of the 21 meter section of extrusion profile. The average roughness of $A$ and $C$ wall specimens and B wall, corresponding to T-W and T-NW specimens, respectively, are also shown in Table 4-1, because they will be used later to model the effect of die line surface roughness on fatigue endurance limits.
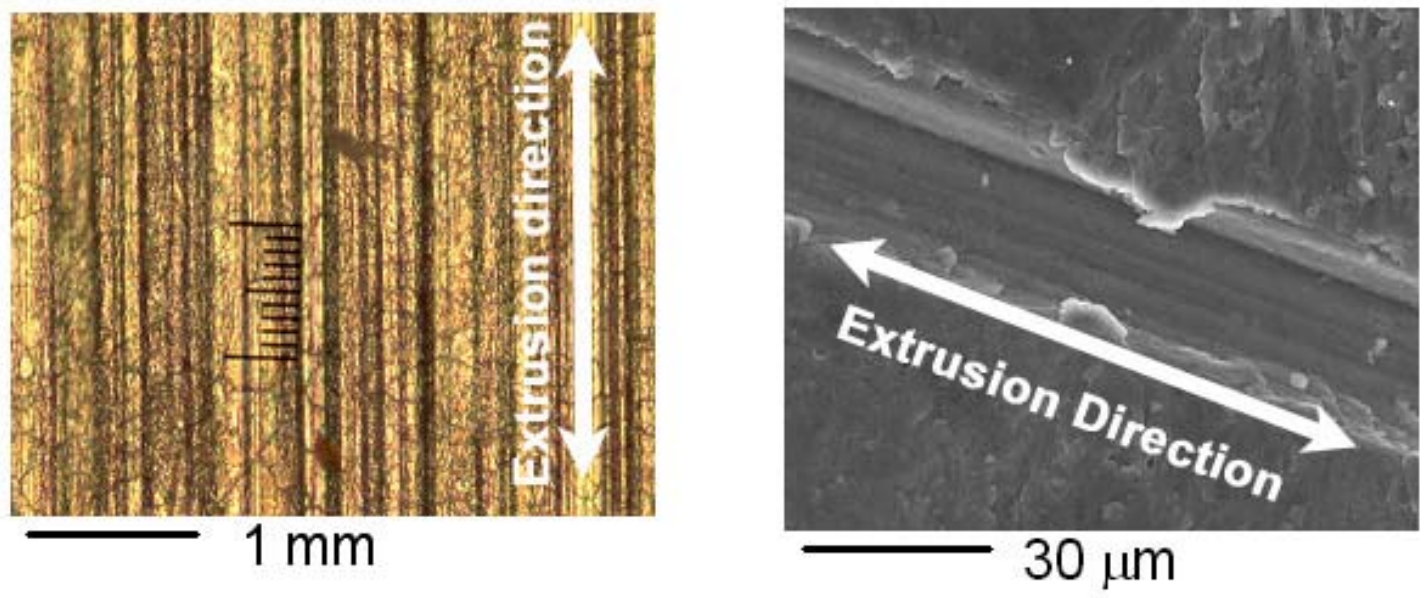

Figure 4-6. Optical and SEM image showing die line surface roughness relative to the extrusion direction for AA6082 alloy 
Table 4-1. Roughness of AA6082 extrusion profile walls

\begin{tabular}{lccc}
\hline \multirow{2}{*}{\multicolumn{1}{c}{ Scan Location }} & \multicolumn{3}{c}{ Roughness $(\mu \mathrm{m})$} \\
\cline { 2 - 4 } & $\mathbf{R}_{\mathbf{t}}$ & $\mathbf{R}_{\mathbf{z}}$ & $\mathbf{R}_{\mathbf{a}}$ \\
\hline C-inside (weld) & 25 & 16 & 3 \\
C-outside (weld) & 11 & 8 & 1 \\
A-inside (weld) & 22 & 12 & 3 \\
A-outside (weld) & 16 & 9 & 2 \\
T-W average & 19 & 11 & 2 \\
T-W deviation & 6 & 4 & 1 \\
& & & \\
C-inside & 15 & 11 & 2 \\
C-outside & 17 & 11 & 2 \\
A-inside & 22 & 11 & 4 \\
A-outside & 12 & 6 & 2 \\
D-inside & 17 & 11 & 2 \\
D-outside & 13 & 8 & 1 \\
& & & \\
B-top & 12 & 8 & 2 \\
B-bottom & 10 & 7 & 1 \\
T-NW average & 11 & 8 & 2 \\
T-NW deviation & 1 & 1 & 1
\end{tabular}

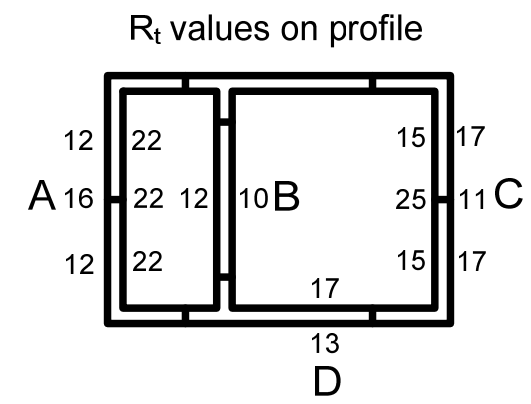

\subsection{Baseline fatigue (L-NW specimens)}

The effects of moderate changes in frequency were examined by testing specimens on the resonance testing machine at Hydro Aluminum at a frequency of $\sim 63 \mathrm{~Hz}$ and on the servo-hydraulic testing machine at MTU at a frequency of $20 \mathrm{~Hz}$. Figure 4-7 provides the data and curve fitting of L-NW specimens tested at both frequencies. There is clearly little variation in the curve fitting parameters of the fatigue data at the two different frequencies. The scatter in results for specimens tested at the lower frequency, on the servo-hydraulic machine, is higher than for specimens tested on the resonance machine. This is most likely a result of alignment and feedback control on the servo-hydraulic machine and 
not the testing frequency itself. Fatigue data that was collected on each machine will be directly compared since fatigue results appear to be similar for both testing machines. The dotted trend line in Figure 4-7 is a power law curve fit to the combined data obtained on the servo-hydraulic and resonance machines. This curve will be used as the baseline for comparing all other AA6082 fatigue data in this dissertation. The run-out stress amplitude, approximately $100 \mathrm{MPa}$ is reasonably close to values reported for peak aged AA6082 by other researchers $[1,2,64,65]$.

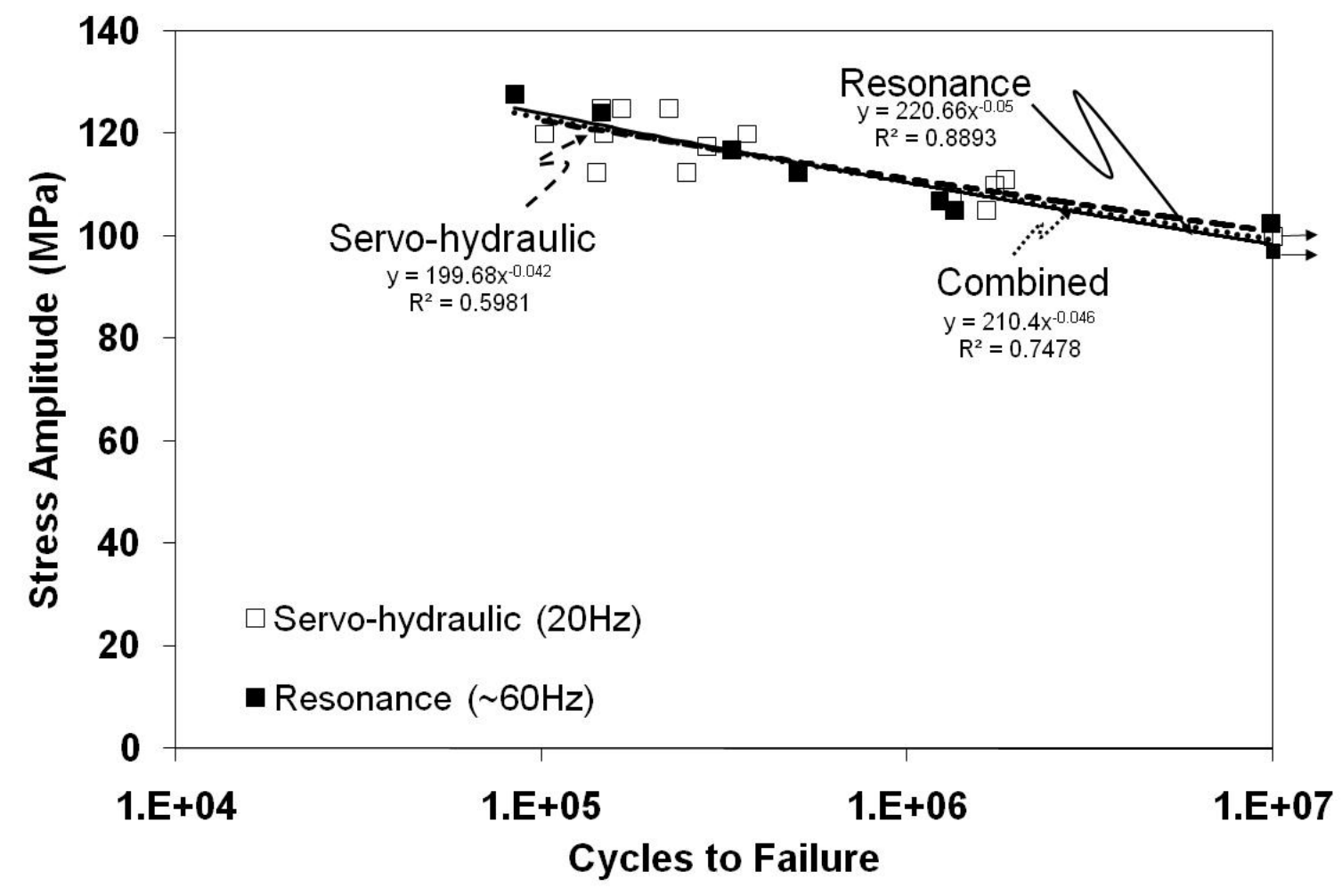

Figure 4-7. Fatigue lives of peak aged AA6082 specimens tested on different machines 


\subsection{Effect of orientation/die lines on fatigue}

The effect of specimen orientation with respect to the extrusion direction on the high cycle fatigue life of the AA6082 alloy without welds was quite pronounced. Figure 4-8 compares fatigue results for T-NW and L-NW specimens. Fatigue specimens oriented transverse to the extrusion direction exhibit fatigue lives significantly shorter than for L-NW specimens, and this difference was more pronounced as the stress amplitude was decreased. Work by Pedersen et. al. on pre-strained flat sheet AA6082 extrusions showed a similar drop in fatigue life for specimens orientated transverse to the extrusion direction [1]. There are several factors that could cause the difference in fatigue behavior between the orientations. The most obvious being the orientation of the surface roughness relative to the tensile loading. The die lines produced during extrusion are parallel to the extrusion direction, i.e. parallel to the tensile axis for L-NW and perpendicular to it for the T-NW specimens. These die lines on the transverse specimens can be expected to create stress concentrations, where fatigue crack nucleation may occur more easily than on L-NW specimens.

In principle, any anisotropy of the near surface microstructure could also play a role in the crack initiation process. If present, any texture of the surface recrystallized region might be oriented preferentially for plastic slip in transverse specimens. Microstructural anisotropy is probably not a major factor in the observed differences between L-NW and T-NW specimens since it was shown in Figure 4-4 that the surface grains do not have a dominant texture. 
The variation in microstructure across the specimen section could cause a different stress distribution, which might also effect fatigue crack initiation in high cycle fatigue. The fatigue lives of the L-NW and T-NW specimens approach each other as the stress amplitude increases, and appear to converge at a stress amplitude around $130 \mathrm{MPa}$. This stress amplitude corresponds to a maximum stress approaching the $0.2 \%$ offset yield strength of this alloy. Above this stress level, macroscopic plastic strain will dominate, and the fatigue life is expected to be limited by crack propagation [85].

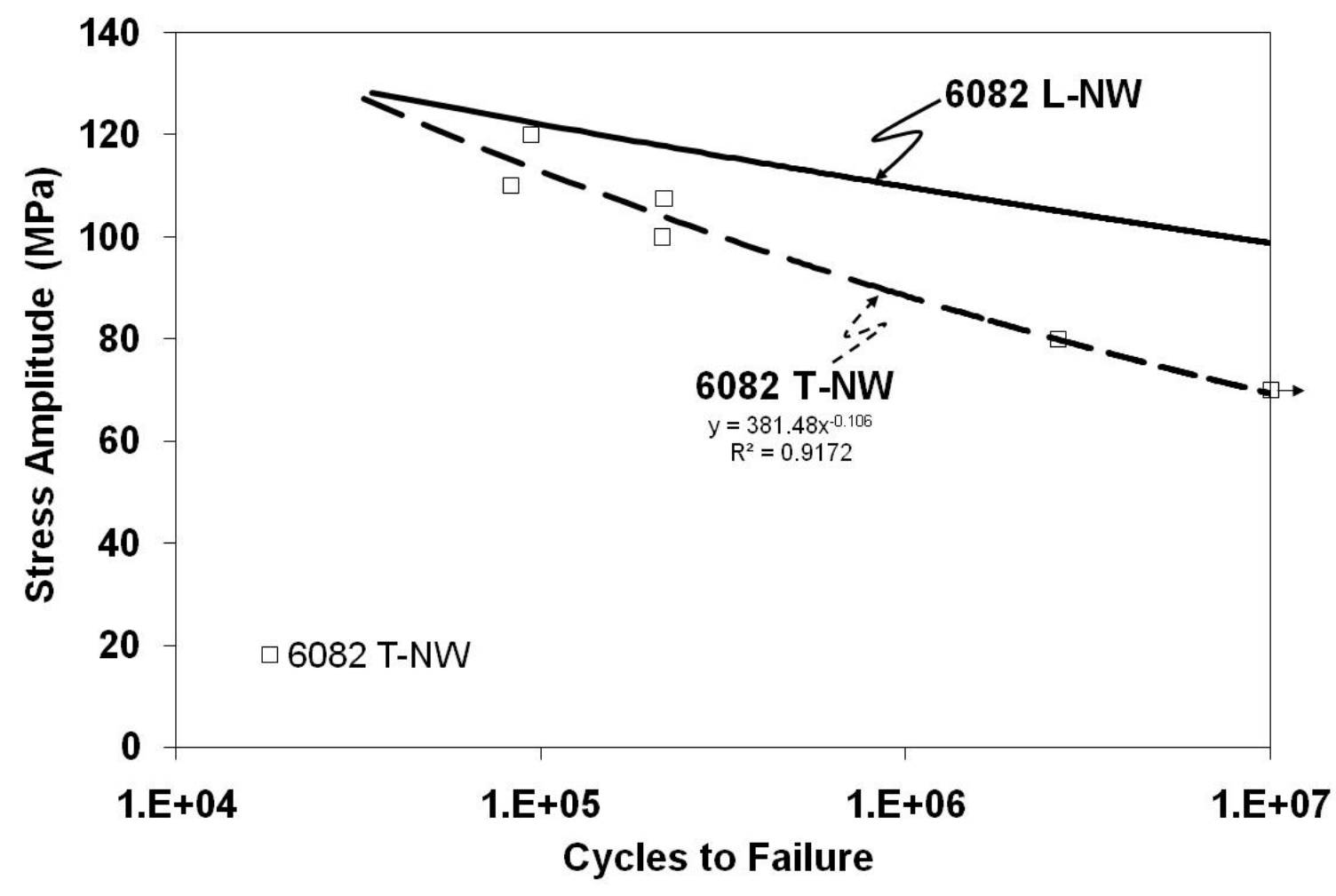

Figure 4-8. S-N curve for peak aged AA6082 L-NW and T-NW specimen types 
To examine the micro-mechanisms responsible for fatigue crack initiation, fracture surfaces of selected L-NW and T-NW specimens were examined in the SEM. The fracture surface of an AA6082 L-NW specimen is shown in Figure 49. The macro-fracture image of Figure 4-9a shows typical fatigue failure, with crack initiation at a single location followed by crack propagation up to final overload failure. This pattern existed in all fatigue failures studied here and can be most clearly identified in the AA6082 specimens, such as Figure 4-9a. Figure 4-9b shows the transition from the crystallographic crack propagation through the recrystallized surface grains to the crack growth mode through the fibrous core microstructure. The crack initiation site was intergranular and a closer examination of the initiation process at the surface of the specimen is shown in Figure 4-9c. The $\mathrm{FCl}$ site clearly shows evidence of localized intergranular failure, with the surface boundary nearly perpendicular to the loading direction in this specimen. In fact 17 out of 21 AA6082 specimens with as-extruded surfaces, examined on the SEM, clearly exhibited microscopic grain boundary separation at the fracture initiation site. The cause of grain boundary separation is most likely due to the narrow PFZ. For the specimen in Figure 4-9, the initial crack growth appears to have transitioned from propagation along the grain boundary to a transgranular mode before reaching an internal grain boundary triple junction. The depth of early crack growth along the grain boundaries varied from specimen to specimen, depending presumably on the slip in the neighboring grains and orientation of the internal grain boundaries. 


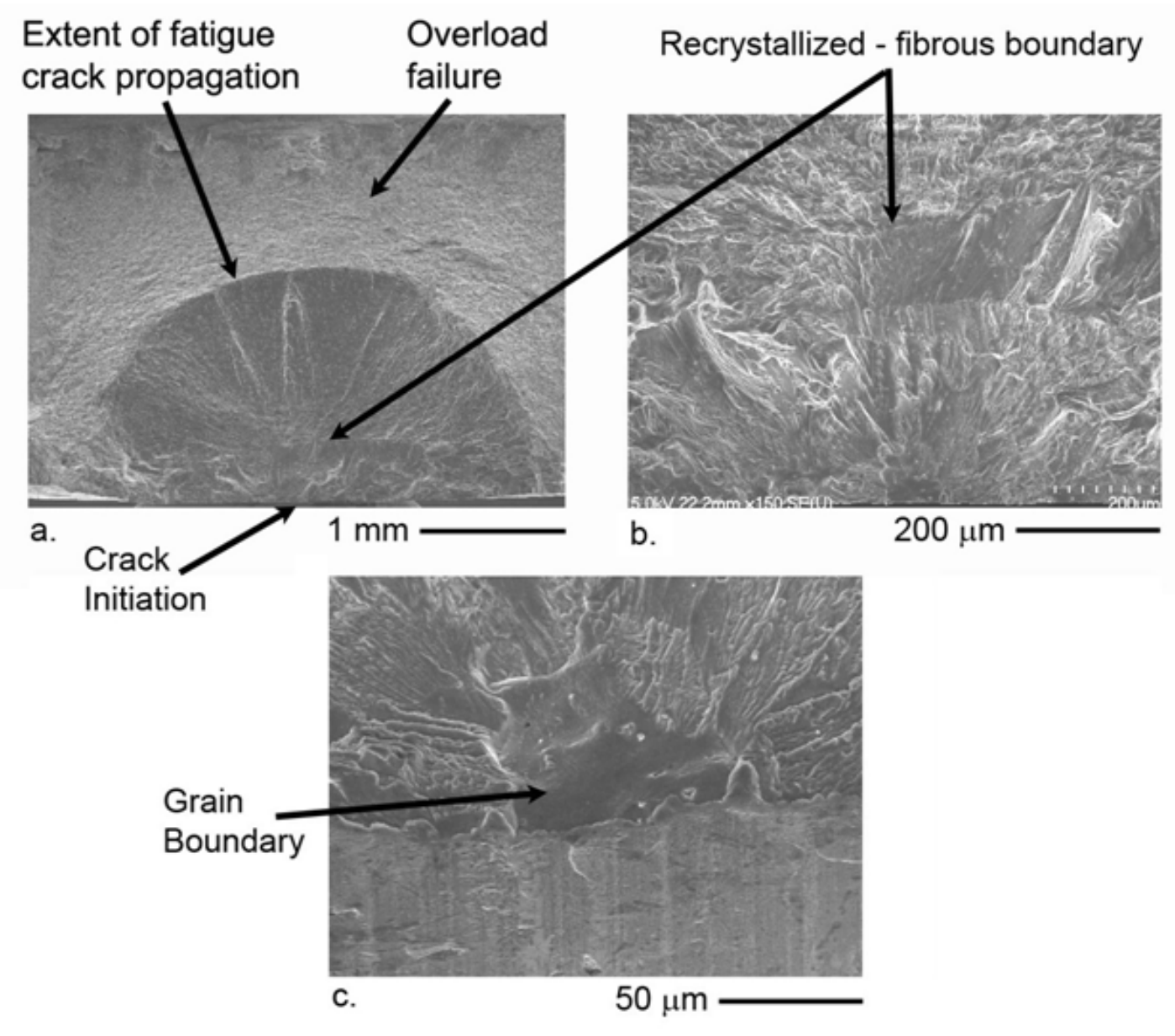

Figure 4-9. Fractographs of peak aged AA6082 L-NW specimen $\left(\sigma_{a}=125, N_{f}=\right.$ $2.2 \times 10^{5}$ ) a. macro of AA6082 specimen b. crack growth transition from recrystallized to fibrous grains $\mathrm{c}$. grain boundary at crack initiation site

Fractographs of an AA6082 T-NW specimen are provided in Figure 4-10. The images shown in Figure 4-10a\&b show similar patterns to those in Figure 49 with a typical fatigue failure macrograph in $4-10 a$ and the analogous grain boundary separated region at the initiation site (4-10b). Unlike the longitudinal specimens the transverse specimens showed intergranular fatigue crack initiation sites associated with die line features. In Figure 4-10c, the presence of the die lines at the initiation site can be clearly observed. The apparent fatigue crack 
initiation mechanism for all non-longitudinal specimens, specifically those with deeper die lines, involved grain boundary separation at die line roots. Crack initiation typically occurred where surface grain boundaries were aligned along deeper die lines.
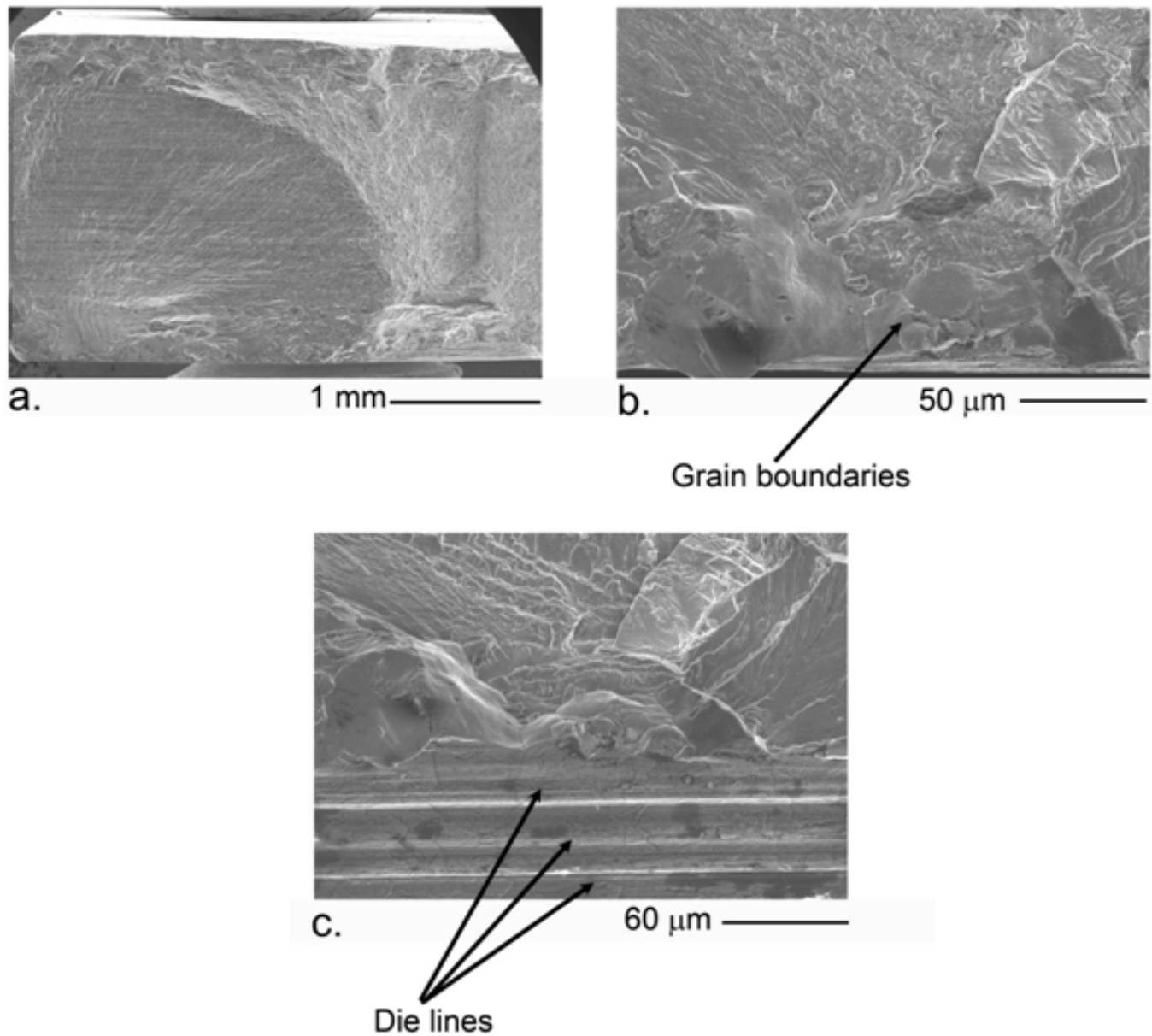

Figure 4-10. Fractographs of peak aged AA6082 T-NW specimen $\left(\sigma_{\mathrm{a}}=80 \mathrm{MPa}\right.$, $\left.\mathrm{N}_{\mathrm{f}}=2.6 \times 10^{6}\right)$ a. macro-fracture surface, b. magnified initaiton site, c. magnified initiation site tilted $45^{\circ}$ to show die lines 
Based on the apparent role of die lines in the fatigue crack initiation process, additional fatigue tests were performed on specimens that were polished to remove die lines. This allowed the role of other microstructural features to be investigated. The fatigue test results for polished AA6082 L-NW and T-NW specimens are presented as the data points in Figure 4-11. Previously mentioned results (Figures 4-8) for comparable as-extruded specimens are also provided in Figure 4-11 as power law curve fits to the data. For the as-extruded samples, fatigue crack initiation was almost always associated with the asextruded surface, and only rarely did crack initiation occur at the corners or on the milled edge of the specimen gage section. For the polished specimens in this study, however, fatigue crack initiation on the polished surface of the specimens was sometimes completely suppressed, causing fatigue cracks to initiate and propagate from corners and milled edges of the specimen. Variability in the location of fatigue crack initiation results in considerable scatter in the fatigue results, and the results from specimens where cracks did not initiate on the polished surface represents a lower limit to the fatigue life of the polished specimens.

Fatigue results for polished L-NW specimens exhibited fatigue lives very close to those observed for the as-extruded L-NW specimens. This is expected because the die lines in this specimen orientation (parallel to the loading direction) do not yield significant stress intensifications. This assumption was in agreement with FEA simulations where the load was applied parallel to the C 
wall die lines. This simulation exhibited uniform stress levels across the specimen surface, even at the die line roots.

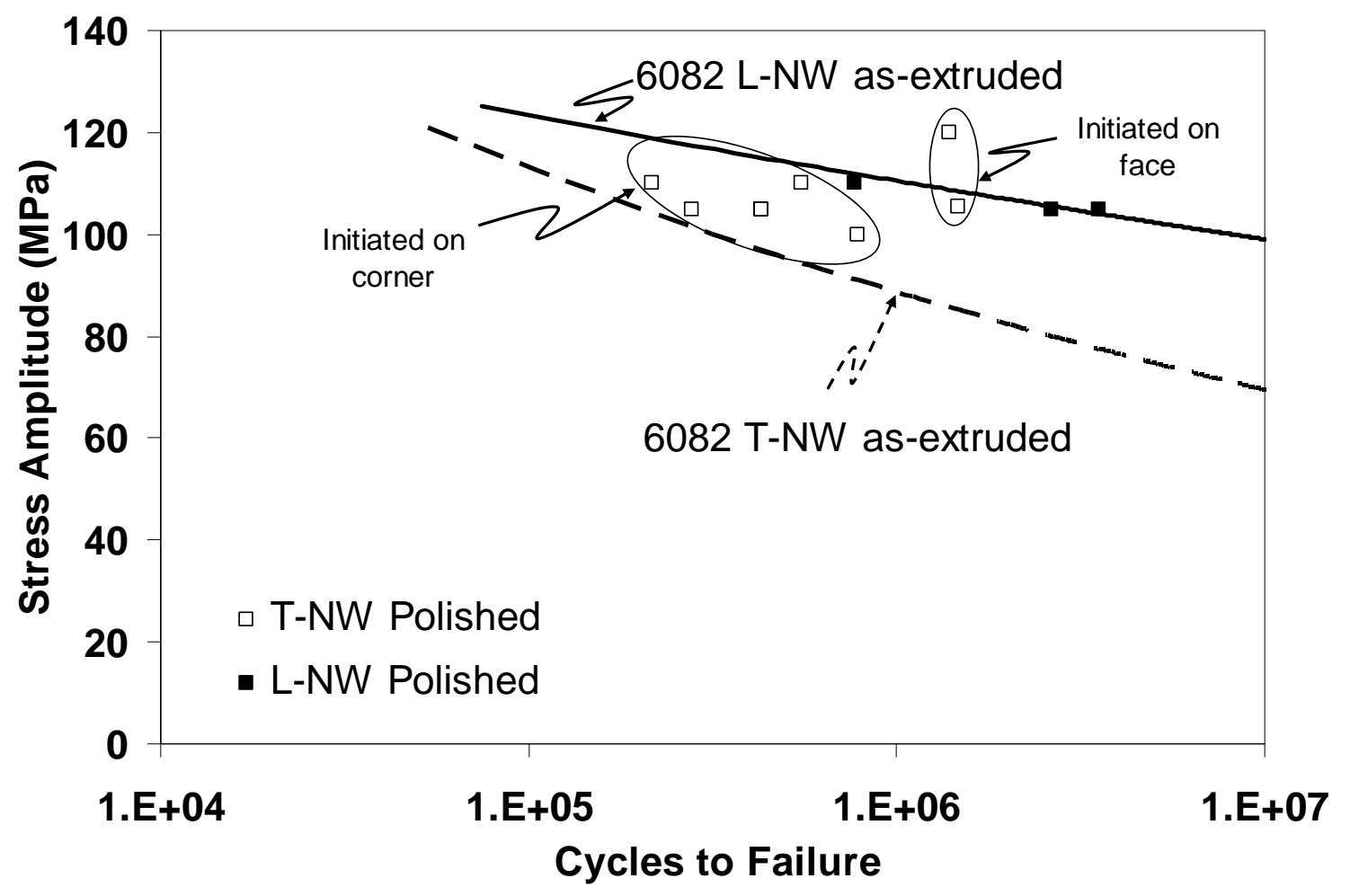

Figure 4-11. S-N curve comparing fatigue lives of peak aged AA6082 T-NW polished specimens with T-NW and L-NW specimens maintaining as-extruded surface

Polished specimens, without welds, oriented transverse to the extrusion direction exhibited fatigue lives comparable to those exhibited by both polished and unpolished longitudinal (L-NW) specimens. These results represent a significant improvement over the fatigue performance of the comparable asextruded specimens, and clearly illustrate the detrimental effect of die lines 
oriented normal to the applied tensile stress. The data in Figure 4-11 suggests that, absent the influence of die line roughness, there is little difference in the fatigue performance of transverse and longitudinal specimens. There is however significant scatter in fatigue lives of polished T-NW specimens, most likely due to fatigue initiation at corners. Indeed, while it is probably not statistically significant, one polished transverse specimen exhibited a fatigue life higher than the power law fitting of the L-NW data at the same stress level.

Because fatigue initiation results from highly localized plasticity near the specimen surface, the observation that polished T-NW specimens have essentially the same fatigue lives as both polished and as-extruded L-NW specimens suggests two additional conclusions with regard to the influence of microstructure on fatigue performance. The first of these observations is that once the role of die line roughness is removed by polishing, the orientation of the fibrous core, relative to the specimen tensile axis, seems to have little influence on the fatigue performance of the alloy. This observation is somewhat surprising since, as noted previously, the fibrous core in these extrusions is (microstructurally) highly anisotropic.

The second observation is that the orientation of the specimen tensile axis relative to any surface grain texture also seems to have little or no influence on fatigue failure in these extrusions. Extruded aluminum alloys are sometimes observed to possess preferred crystallographic textures, which could (in principle) influence fatigue crack initiation. The fibrous core of extruded AA6082 
typically maintains a $\beta$-fiber texture, while the recrystallized surface grains are generally more randomly oriented. The observation that tensile and fatigue properties of polished transverse specimens are equivalent to those for longitudinal specimens (both polished and as-extruded) are consistent with the absence of a strong influence of surface grain texture on fatigue crack initiation.

\subsection{Effect of seam welds}

The effect of solid state seam welds on the fatigue behavior of specimens taken from the hollow AA6082 profile is summarized in Figure 4-12. Specimens taken longitudinal to the extrusion direction, with a weld oriented longitudinally through the gauge direction (L-W), exhibit a significant increase in the scatter. Other than this, the curve fittings for the L-W specimen data indicate properties very similar to the L-NW specimens. The increase in scatter could be associated with segregation of impurities at seam weld locations. The presences of the thick recrystallized layer that exists at the seam weld in AA6082 specimens, through the length of the gauge, could also lead to lowered fatigue lives and more scatter in results. Overall however, the seam weld appears to have only a minor effect on the fatigue lives. 


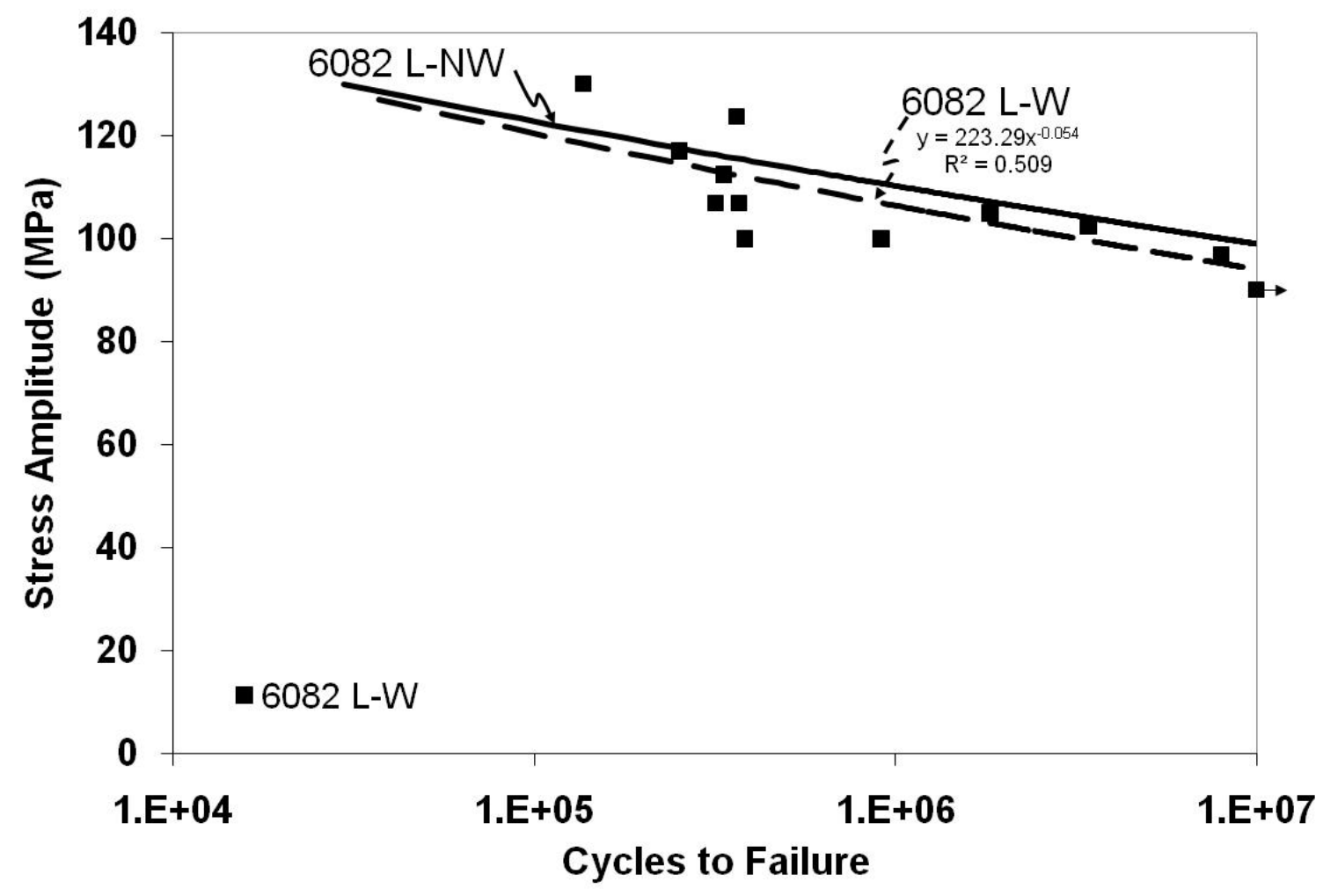

Figure 4-12. Fatigue lives of peak aged AA6082 L-W specimens

Fatigue results for AA6082 samples with welds oriented $45^{\circ}$ and $90^{\circ}$ to the tensile axis are compared with the fitted curves for L-NW and T-NW specimens in Figure 4-13. The fatigue life of specimens tested perpendicular to the extrusion direction with welds located in the center of the specimen gauge section exhibited a significant drop in fatigue life when compared to L-NW and L-W samples but the life is comparable to T-NW specimens. The fitting parameters for the T-W and 45-W specimens describe the data well at intermediate life times $\left(1 \times 10^{5}-1 \times 10^{6}\right)$, but do not represent the low stress, run-out data accurately. The data for both 45-W and T-W suggest that at significantly low stress 
amplitudes, the stress intensity at notch roots are below the yield strength, and fatigue lives behave similar to L-NW specimens.

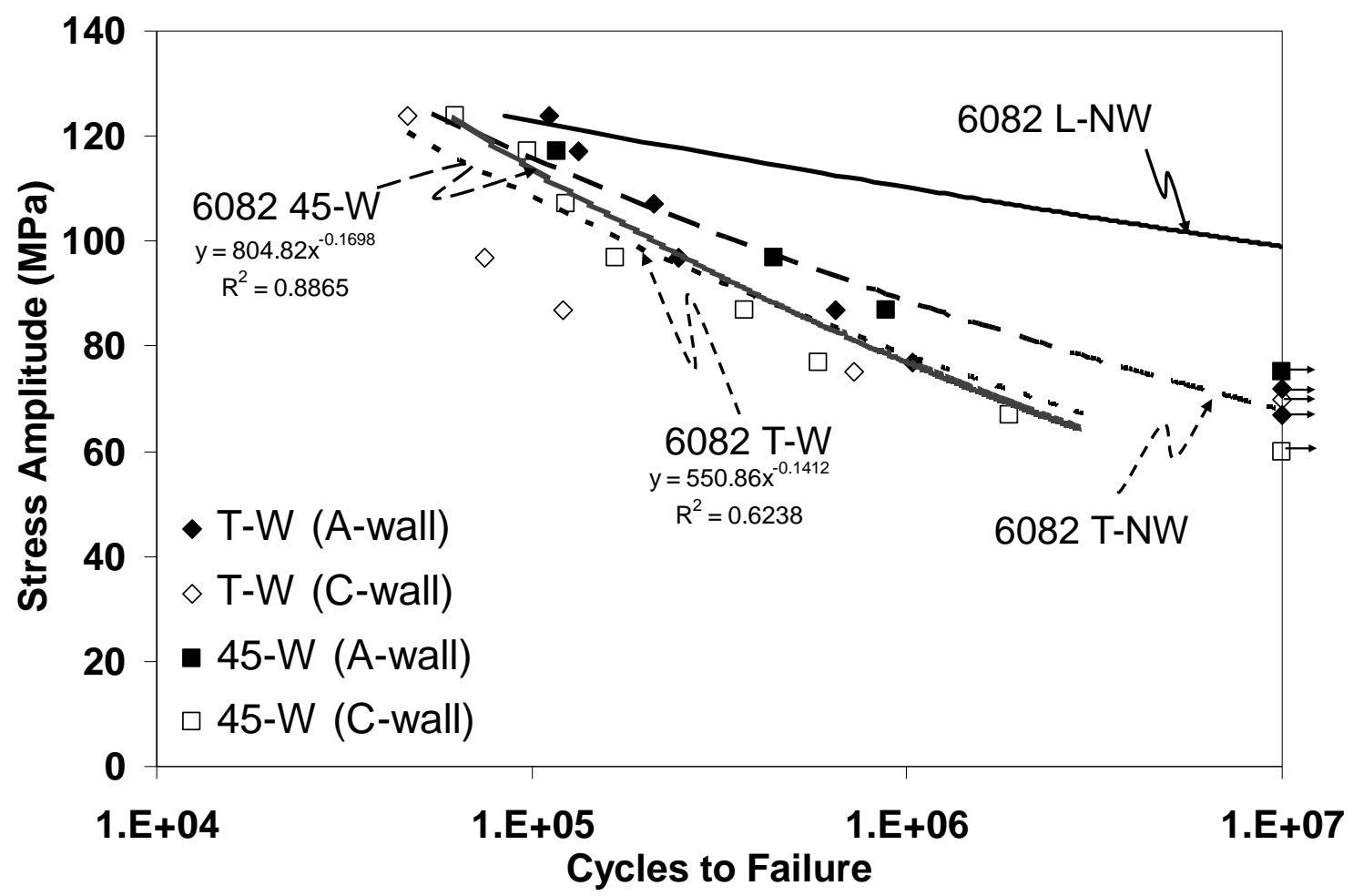

Figure 4-13. S-N curve for peak aged AA6082 T-W and 45-W specimens

Figure 4-13 also illustrates differences in fatigue properties of T-W and 45W specimens taken from the $A$ and $C$ walls of the extrusion. At higher stress amplitudes, A wall specimens ( $\mathrm{T}-\mathrm{W}$ and $45-\mathrm{W}$ ) have better fatigue properties than those of the corresponding $\mathrm{C}$ wall specimens. As the stress amplitude decreases, the difference between T-W specimens removed from $C$ and $A$ walls disappears, while differences between specimens oriented $45^{\circ}$ to the extrusion 
direction remains. Curve fitting in Figure 4-13 represents combined data from both faces. No variation in fatigue data between the different extrusion walls was observed when the specimens (both L-NW and L-W) were oriented longitudinal to the extrusion direction.

Since the decreased fatigue life of specimens containing seam welds was attributed to the increased surface roughening, a similar approach to explaining the effect of orientation on fatigue life was conducted, where several T-W AA6082 specimens were polished to remove the die line roughness. The lives of these specimens are shown in Figure 4-14, plotted similar to Figure 4-11, with the polished T-W specimen fatigue lives plotted as data points and as-extruded T-W and L-NW shown as the curve fittings. Similar to AA6082 T-NW specimens, the fatigue life of $\mathrm{T}-\mathrm{W}$ specimens after polishing recovers to values nearing the idealized L-NW specimens. This implies that the seam weld interface itself does not necessarily play a role in fatigue failure, but that the decreased fatigue life of T-W as-extruded specimens relative to T-NW specimens can be attributed to their increased surface roughness. 


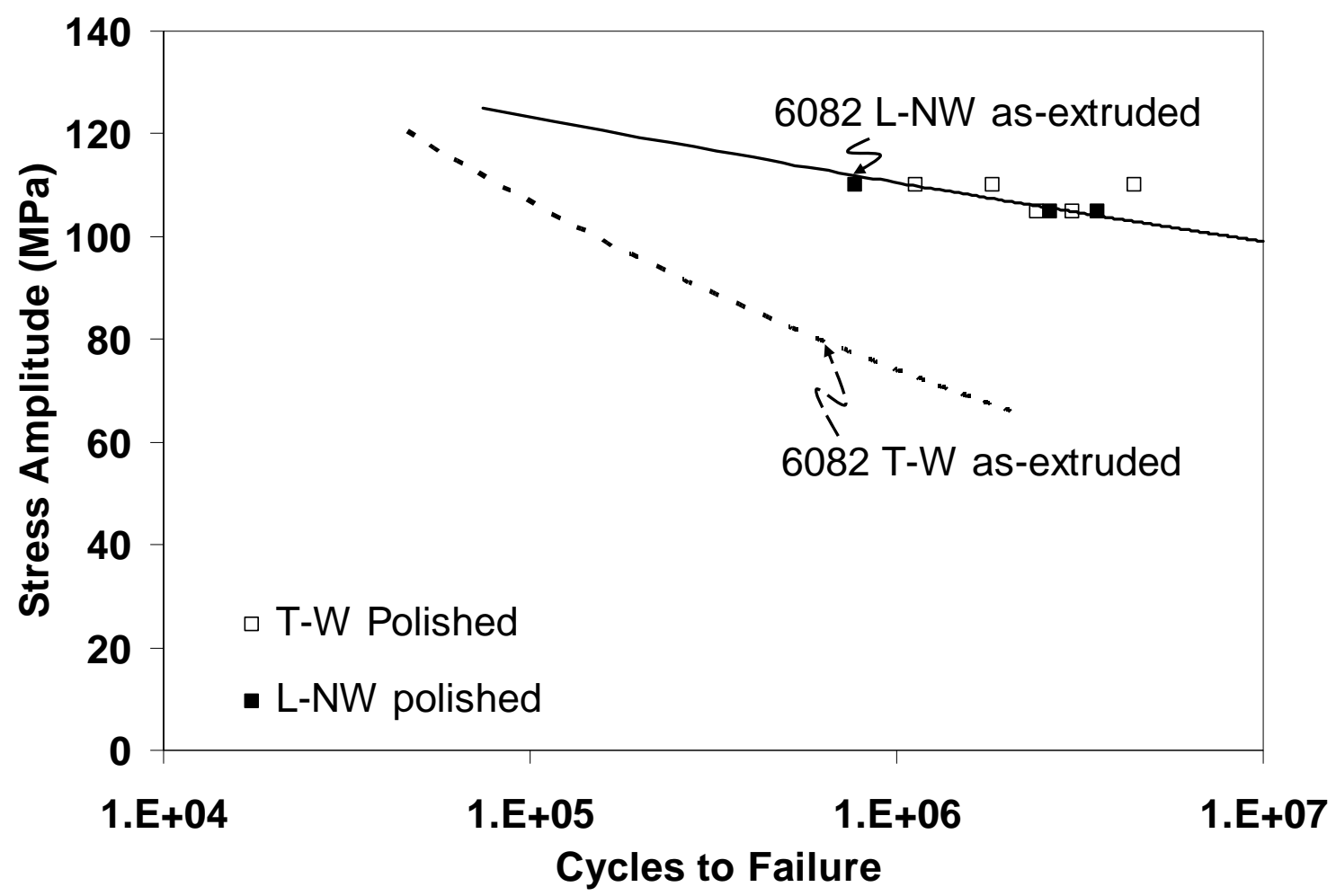

Figure 4-14. Fatigue lives of peak aged AA6082 polished T-W specimens

Although fatigue crack initiation and propagation mechanism of specimens with as-extruded surfaces are generally similar to those of polished specimens, there are some slight differences that are worth noting. Fractographs of asextruded and polished T-W specimens are shown in Figure 4-15, while optical cross sectional images of the microstructures at the fracture are provided in Figure 4-16. The presence of grain boundaries at the crack initiation site is clear in the as-extruded specimens (Figure 4-15a-c) and although present, the grain boundaries are a bit more ambiguous in the polished specimens (Figure 4-15d-f). Crack initiation in as-extruded, non-longitudinal, specimen orientations nearly 
always occurred at die lines, whereas crack initiation on polished specimens occurred at shallow scratches from polishing or handling or at the specimen corners. Propagation from a single fatigue crack initition site was observed in nearly all specimens regardless of surface finish, but in as-extruded transverse specimens it appears that the crack initially extends across the specimen face before propagating through the cross section (Figure 4-15a), whereas in polished specimens and as-extruded longitudinal specimens the crack radiates more uniformly from the initiation site (Figure 4-15d). The optical micrographs of fracture cross sections in Figure 4-16 are all very similar and clearly show the initiation of cracks within the recrystallized surface layer. Figure 4-16a\&b are TW specimens, and it does not appear that fatigue crack initiation occurred at the seam weld. Indeed, $\mathrm{FCl}$ at the seam weld or within the large recrystallized grains on the seam weld periphery was observed in only 6 of 53 polished or as-extruded T-W specimens. 


\section{As-extruded T-W}
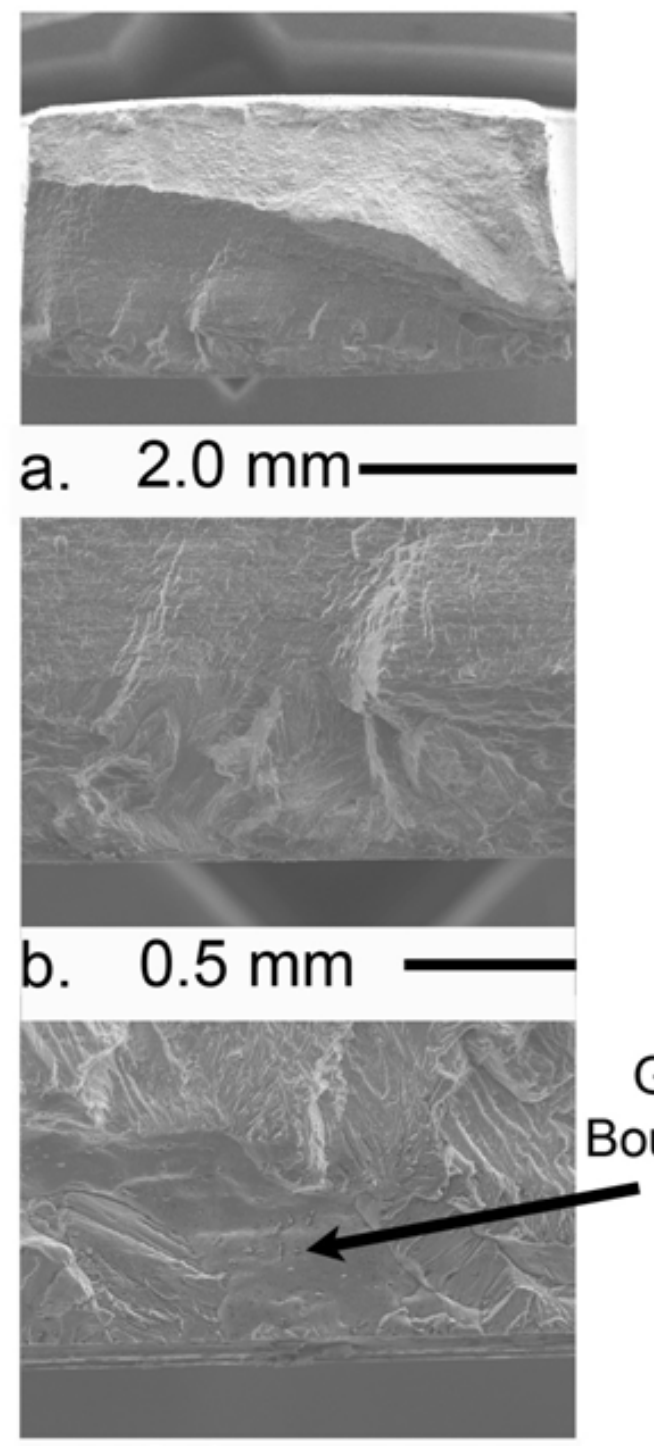

C. $0.1 \mathrm{~mm}$
Polished T-W
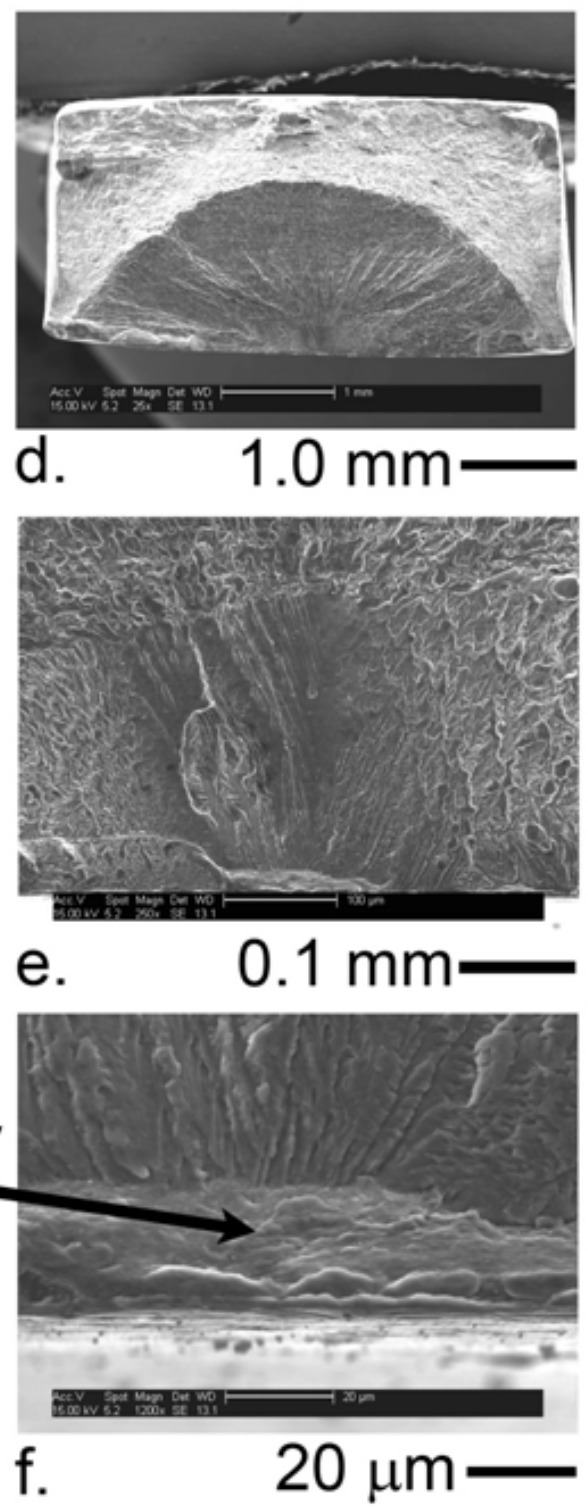

Figure 4-15. Fractography of a.-c. as-extruded $\left(\sigma_{\mathrm{a}}=97 \mathrm{MPa}, \mathrm{N}_{\mathrm{f}}=7.5 \times 10^{4}\right)$ and d.-f. polished $\left(\sigma_{a}=105 \mathrm{MPa}, \mathrm{N}_{\mathrm{f}}=2.4 \times 10^{6}\right)$ peak aged AA6082 T-W specimens 


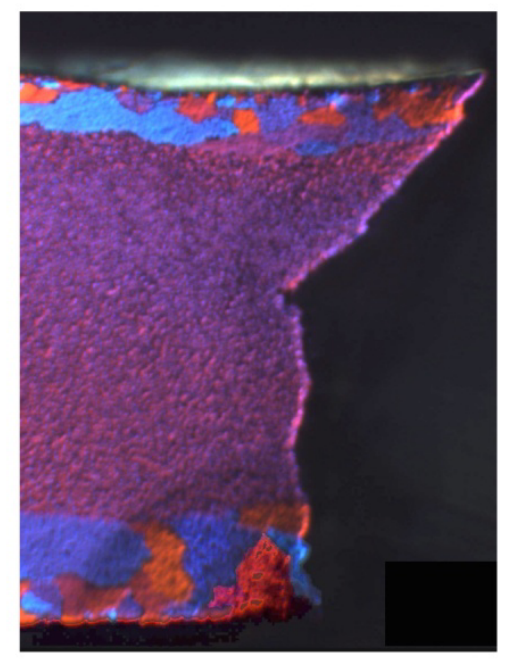

$\overline{0.655} \mathrm{~mm}$

\section{As Extruded T-W}

a.

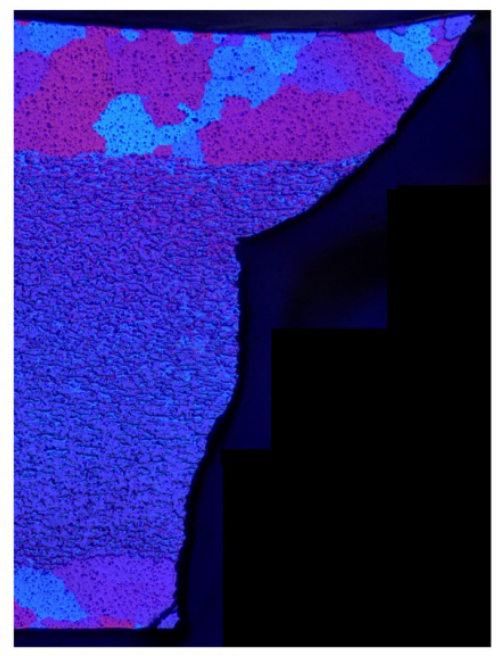

$\overline{0.615} \mathrm{~mm}$

Polished T-W

b.

Figure 4-16. Optical micrographs of fatigue initiation and fracture sites a. asextruded T-W $\left(\sigma_{\mathrm{a}}=97 \mathrm{MPa}, \mathrm{N}_{\mathrm{f}}=7.5 \times 10^{4}\right)$ b. polished $\mathrm{T}-\mathrm{W}\left(\sigma_{\mathrm{a}}=105 \mathrm{MPa}, \mathrm{N}_{\mathrm{f}}=\right.$ $\left.2.4 \times 10^{6}\right)$

\subsection{Effect of charge welds (position along extrusion length)}

Figure 4-17 shows the relationship between the charge weld and seam weld in the AA6082 extrusion, which is often quantified by the charge weld separation, described here as the distance between the charge weld fronts. For 
the extrusion profiles used in this study, the separation between the seam and charge weld interfaces goes to zero after approximately $2.5 \mathrm{~m}$, as shown in Figure 4-17b. The charge weld separation as a function of distance from the extrusion stop mark is shown in Figure 4-18. Zone 1, schematically illustrated in Figure 2-8, for the AA6082 extrusion profile corresponds to the first meter from the stop mark, but then transitions to zone 2 as the charge weld interface becomes visible in the extrusion cross section. Zone 2 extends for $1.5-2$ meters before the charge weld interfaces meet at the seam weld. Zone 3, where properties should be highly uniform, begins approximately 3 meters from the stop mark and extends through most of the extruded product.

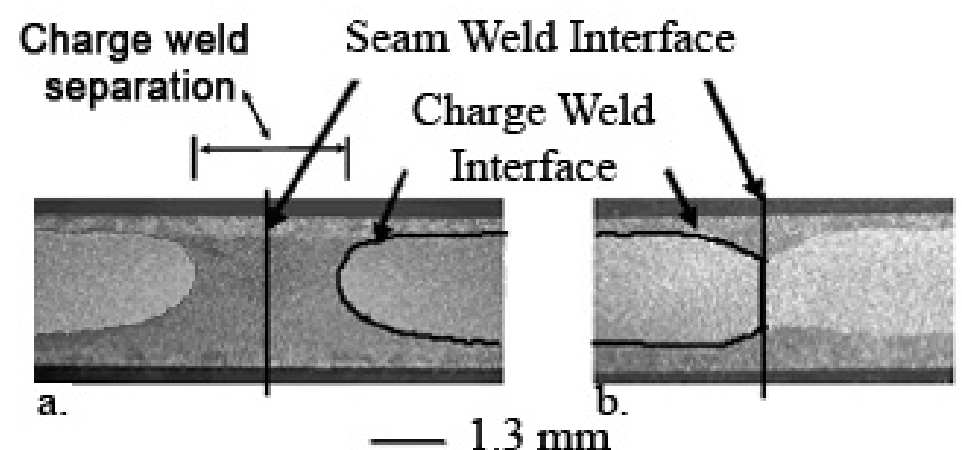

Figure 4-17. Etched images showing charge weld separation a. etched specimen $\sim 2 \mathrm{~m}$ from stop mark showing charge weld separation of about 2.6 $\mathrm{mm}$ b. etched specimen $\sim 6.5 \mathrm{~m}$ from stop mark showing charge weld interfaces butting against seam weld 


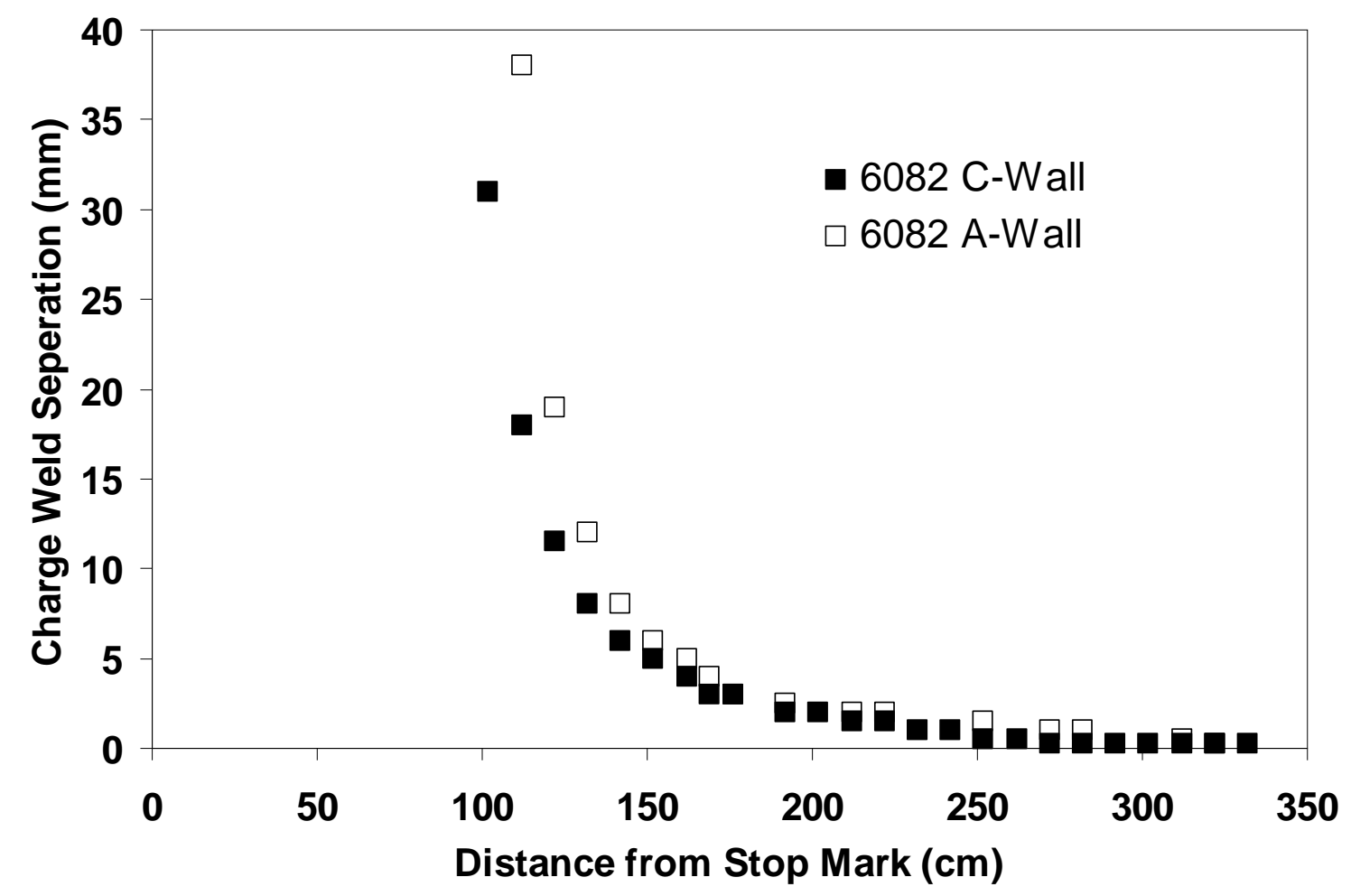

Figure 4-18. Relationship between charge weld separation and distance from stop mark for $\mathrm{A}$ and $\mathrm{C}$ wall sections

Since tensile properties have been shown to vary down the length of extruded profiles, especially near the stop mark where large charge weld interface separation occurs, experiments were undertaken to examine the tensile and fatigue properties from the four different zones defined in Figure 2-8. The tensile properties of specimens taken from locations within the various zones of the AA6082 extruded product are shown in Table 4-2. The properties are relatively uniform within each of the four zones. In zone 3, where properties should be most consistent down much of the length of the extruded product, the tensile properties were measured for T-W and L-NW specimens. There was very 
little difference in properties between these two specimen types, and yield and UTS values are averaged as 294 and $326 \mathrm{MPa}$, respectively. Zone 1 tensile properties were slightly lower with yield and ultimate values of 277 and $312 \mathrm{MPa}$ respectively, while specimens taken from zone 4 were much closer to those of zone 3. The lower strength of zone 1 specimens could be due to the coring effects or due to delayed quenching following the scalping of billet \#1 and loading of billet \#2. The lower strength could also be attributed to scatter in testing and slight variations in strength that may occur during aging hardening treatments. Average values of three specimens (Table 4-2 row 2) taken transverse to the extrusion direction, containing charge weld separations of approximately $0.25,3$ and $7 \mathrm{~mm}$, from zone 2 were also similar to the more consistent zone 3 strength levels. Also, failure did not appear to occur along the charge weld interface in any of the three tensile specimens.

Table 4-2. Averaged tensile properties of AA6082 specimens taken from various extrusion zones

\begin{tabular}{|c|c|c|c|c|}
\hline & Specimen & $\begin{array}{c}\mathbf{0 . 2 \%} \\
\text { Yield } \\
\text { (MPa) }\end{array}$ & $\begin{array}{c}\text { UTS } \\
\text { (MPa) }\end{array}$ & $\begin{array}{c}\text { Strain } \\
\text { at } \\
\text { Failure } \\
\text { (\%) }\end{array}$ \\
\hline \multirow{4}{*}{6082} & $\mathrm{~L}-\mathrm{NW}(1)$ & 277 & 312 & 27 \\
\cline { 2 - 5 } & $\mathrm{T}-\mathrm{W}(2)$ & 288 & 327 & 13 \\
\cline { 2 - 5 } & $\mathrm{L}-\mathrm{NW}(3)$ & 291 & 323 & 19 \\
\cline { 2 - 5 } & $\mathrm{T}-\mathrm{W}(3)$ & 297 & 329 & 11 \\
\cline { 2 - 5 } & $\mathrm{L}-\mathrm{NW}(4)$ & 286 & 321 & 24 \\
\hline
\end{tabular}


The fatigue lives of specimens taken longitudinal to the extrusion direction are shown in Figure 4-19 as stress-life curves. The trend line in Figure 4-19 is the power law fit of AA6082 L-NW(3) data discussed earlier for specimens taken from zone 3 (Figure 4-7). A few L-NW zone 1, 2 and 4 specimens were fatigue tested for the AA6082 alloy at, $\sigma_{a}=110 \mathrm{MPa}$, and are plotted in Figure 4-19. The data for these specimens is slightly lower than the base line curve from zone 3 , with the zone 1 data point showing the more significant reduction in fatigue life. The moderate drop in fatigue life for the zone $4 \mathrm{~L}-\mathrm{NW}$ specimens is probably within the scatter band of data for the curve fitting, but there may be some influence of microstructural inhomogeneity resulting from coring for these specimens. The more pronounced drop in fatigue life for zone 1 specimens (two specimens with similar lives) suggests that either weaker base material came from the first billet or the zone 1 material was weaker due to delayed quenching. An indication of the weaker material was also indicated by the lower tensile strength of zone 1 specimens, and as expected, as the yield strength of the material was reduced the fatigue life decreased. Fatigue lives of specimens from zone 2, containing charge weld interfaces within the gauge section of specimens, taken longitudinal to the extrusion direction, are also plotted in Figure 4-19. There appears to be little or no overall effect on fatigue lives from charge welds in L-W(2) type specimens, although, as was the case for L-W(3) specimens, the presence of the weld appears to lead to more scatter in the results. 
The stress-life curves for T-W AA6082 specimens taken from the four zones in the extruded product are shown in Figure 4-20. It has already been shown that die line surface roughness will affect the fatigue lives of T-W specimens. Due to differences in roughness between $A$ and $C$ wall specimens, fatigue specimens from each wall had to be compared individually. With this in mind, the trend lines (and T-W(3) data points for scatter comparisons) in Figure 4-20 represent power law curve fittings for both $A$ and $C$ wall $T-W(3)$ specimens (Figure 4-13). The data points shown in Figure 4-20 are from transverse specimens taken from zones 1,2 and 4 . The fatigue lives of T-W(1) specimens taken from the $C$ wall showed a drop in fatigue life similar in magnitude to the longitudinal zone 1 longitudinal specimens, whereas specimens taken from the A wall showed no drop in fatigue life compared to T-W(3) specimens. This is again associated with the lower strength material from zone 1. As with the longitudinal specimens from zone 4, the transverse specimens from either wall showed no significant drop in fatigue life. 


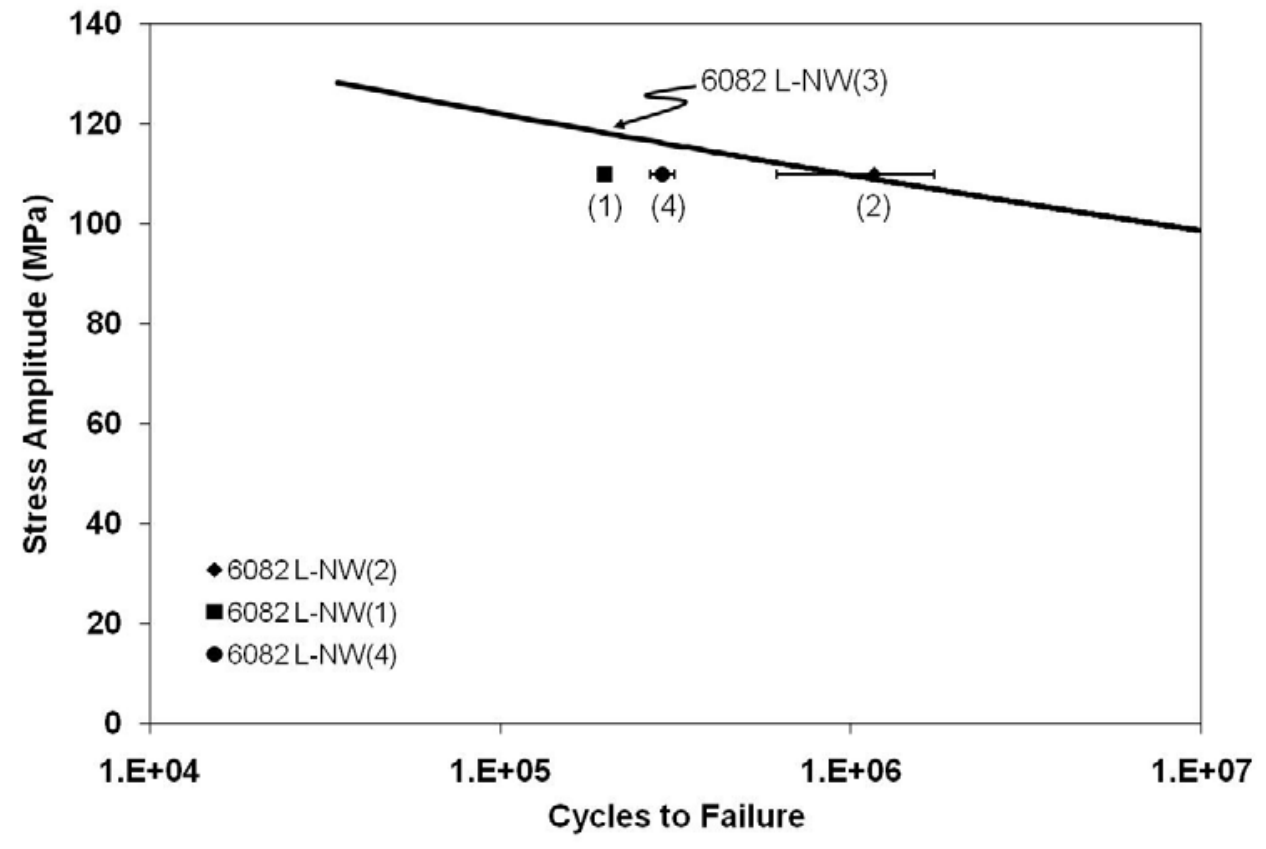

Figure 4-19. Fatigue results for AA6082 peak aged L-NW specimens showing the effect of extrusion zones on fatigue life at $\sigma_{\mathrm{a}}=110 \mathrm{MPa}$ (error bars signify standard deviation)

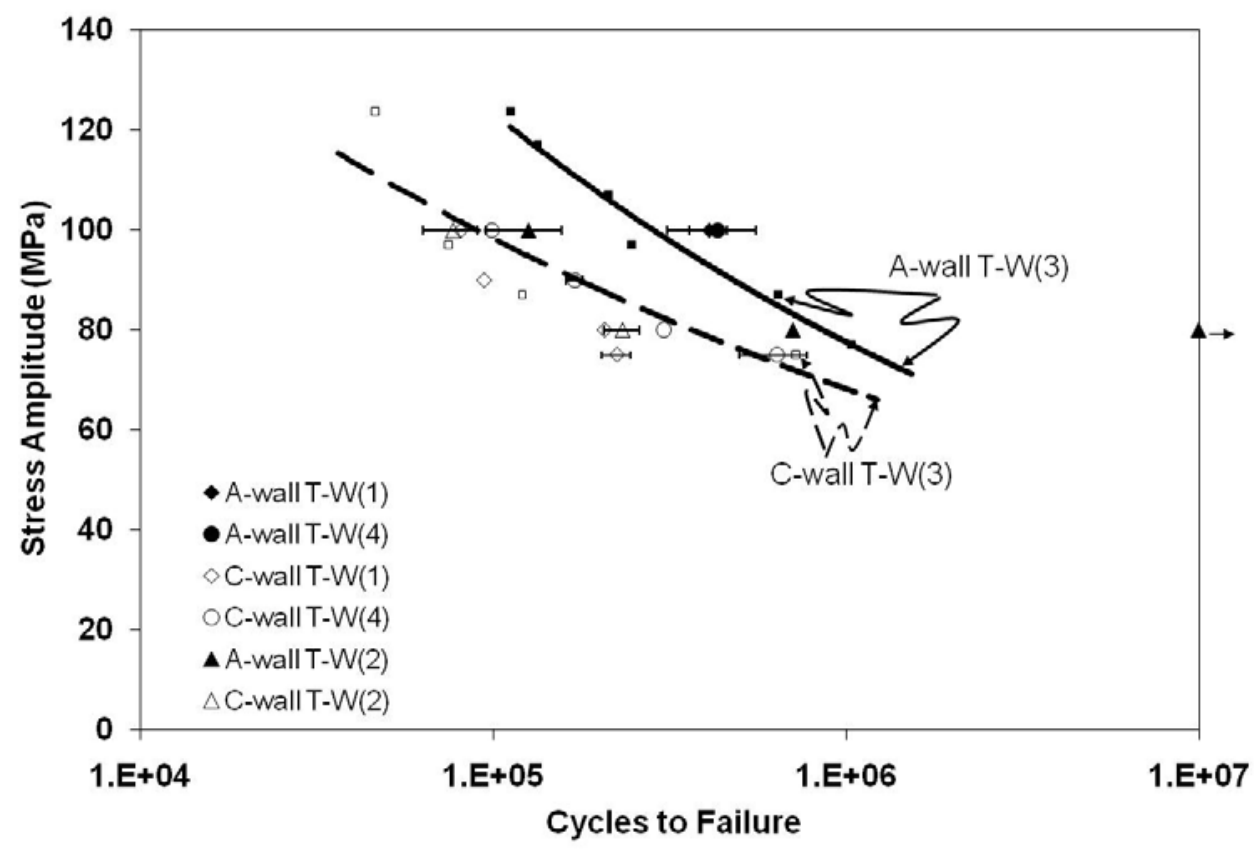

Figure 4-20. Fatigue data for AA6082 peak aged T-W specimens showing the effect of extrusion zones (error bars signify standard deviation)(T-W(3) data from Figure 4-13) 
The main thrust of these experiments was to investigate changes in fatigue behavior of specimens with moderate $(1-10 \mathrm{~mm})$ charge weld separation within the gauge section. Fatigue properties for these specimens are also plotted in Figure 4-20. Since, no trend in fatigue life as a function of charge weld separation within zone 2 was observed, the data plotted in Figure 4-20 correspond to average fatigue lives of specimens with charge weld separations between 0.25 and $8 \mathrm{~mm}$. For both the A and C wall, T-W(2) specimens exhibited a very minor drop in fatigue life when compared to T-W(3) specimens. Specimens containing charge welds, taken from the C wall, resulted in fatigue lives that corresponded to a drop in stress amplitude of approximately $5 \mathrm{MPa}$ at both the high stress amplitude of $100 \mathrm{MPa}$ and the lower amplitude of $80 \mathrm{MPa}$. This small difference in fatigue life could be contributed solely to scatter. In contrast to the $C$ wall specimens, the $T-W(2)$ specimens taken from the $A$ wall showed significantly lower fatigue lives at $100 \mathrm{MPa}$ stress amplitude and similar lives to $\mathrm{T}-\mathrm{W}(3)$ specimens at $80 \mathrm{MPa}$ with one specimen lasting $1 \times 10^{7}$ cycles.

Coring effects on fatigue life were studied by comparing mechanical properties of specimens taken from extruded material from the first and last meter of extruded material. This corresponds to the final billet material from both the first and second billets that were extruded. The mechanical properties, including high cycle fatigue life, of specimens taken from the first meter of material were slightly worse than specimens taken from the middle portion of the extruded product. The mechanical properties of zone 4 specimens were similar 
to zone 3 specimens. Coring would be expected from both zones 1 and 4, but differences were only observed in zone 1 specimens, this implies that coring under the extrusion press parameters for these materials does not appear to affect the tensile strength and fatigue behavior of hollow extrusions. Time did not allow further investigation into the actual reason for the lowered zone 1 properties. Tensile testing of as-quenched specimens from zones 1,3 and 4 could help explain the results, specifically if delayed quenching of zone 1 material is affecting the properties. Also, bulk chemical compositional analysis of material from zone 1,3 and 4 would be beneficial to determine if compositional differences between billets \#1 and \#2 exist.

Fatigue lives of AA6082 exhibited a small decrease when transverse specimens contain charge welds. Fatigue crack initiation, which dominates the life of the specimen in the high cycle regime, occurred on the surface for all specimens from every zone. In addition, when testing specimens taken transverse to the extrusion direction, cracks form at die line surface grooves. The effect of die line surface roughness on fatigue life has already been discussed.

Fatigue fracture surfaces of five specimens are provided in Figure 4-21. All five specimens had charge weld separations of approximately $5 \mathrm{~mm}$. In all images fatigue cracks initiated on the extruded surface and in all but one fracture surface (d) the presence of the charge weld is evident in the fracture surface. This implies that fatigue crack growth typically involves failure at the charge weld 
interface. High magnification images of the charge weld interface typically showed dimple type ductile failure, which implies overload failure along the interface instead of fatigue crack propagation. In Figures 4-21a\&e the fatigue cracks grow normal to the loading direction until the crack front reaches the charge weld. Once the charge weld is reached, the crack undergoes overload failure along the charge weld boundary. Following overload crack propagation long the charge weld, the specimen undergoes typical overload failure at $45^{\circ}$ relative to the loading direction. The fracture surface shown in Figure $4-21 b$ is slightly different than the two previously mentioned fatigue failures. The fatigue crack in 4-21b grew cyclically until the load could not be sustained, then underwent normal fatigue overload failure ( $45^{\circ}$ relative to loading direction), which intersected and followed the charge weld interface during a portion of overload failure. Figure $4-21 \mathrm{c}$ is similar to (a) and (e) except that some evidence of cyclic crack growth on both sides of the charge weld interface are evident. The failure at the charge weld interface was dimple type in this specimen as well, implying again rapid overload failure along the interface. Finally, the fracture surface in Figure 4-21d did not show the presence of the charge weld interface and failure occurred at the seam weld. Figure 4-22 provides an optical cross sectional image of the fractured specimen in Figure 4-21e. The fatigue crack growth process is clearly shown in Figure 4-22 with overload failure along the charge weld interface then oriented $45^{\circ}$ to the loading direction. 


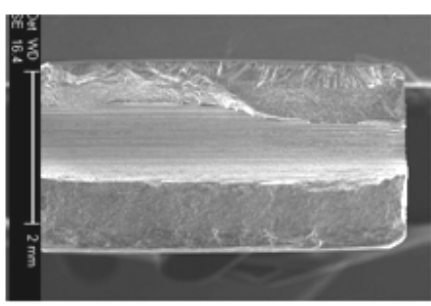

$$
\begin{gathered}
\text { C-wall } \\
\sigma_{\mathrm{A}}=80 \mathrm{MPa}
\end{gathered}
$$

174,117 cycles

a.

$1.30 \mathrm{~mm}$

C-wall

$\sigma_{\mathrm{A}}=80 \mathrm{MPa}$

243,552 cycles

b.

$1.30 \mathrm{~mm}$

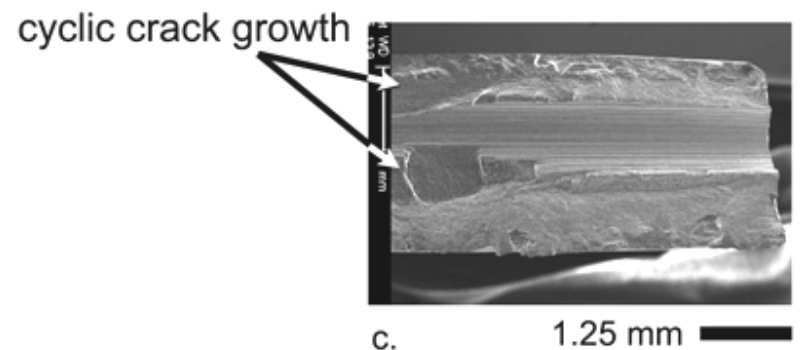

A-wall
$\sigma_{\mathrm{A}}=80 \mathrm{MPa}$
708,045 cycles

c.

$1.25 \mathrm{~mm}$

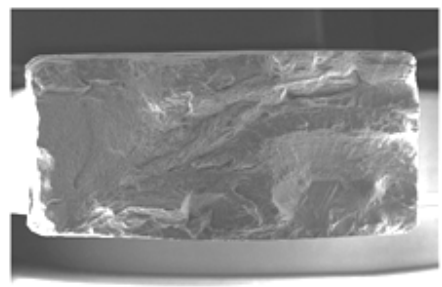

A-wall $\sigma_{\mathrm{A}}=100 \mathrm{MPa}$ 169,098 cycles

d.

$1.25 \mathrm{~mm}$

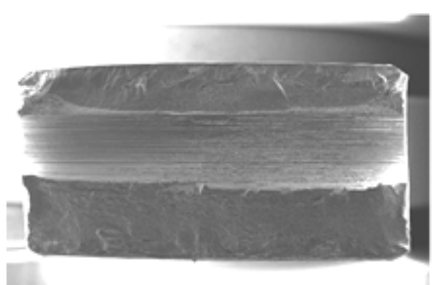

C-wall $\sigma_{\mathrm{A}}=100 \mathrm{MPa}$

57,530 cycles

e.

$1.30 \mathrm{~mm}$

Figure 4-21. SEM fracture analysis of several T-W(2) AA6082 specimens with charge weld separations near $5 \mathrm{~mm}$ 


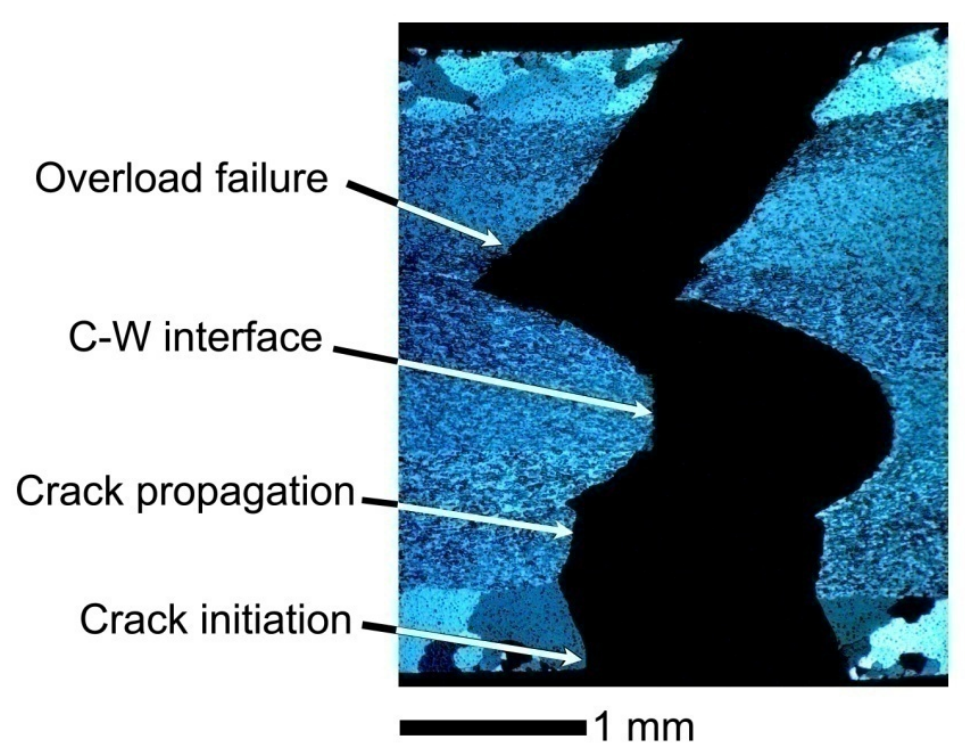

Figure 4-22. Optical image of cross section of $\mathrm{T}-\mathrm{W}(2)$ specimen $\left(\sigma_{\mathrm{a}}=100 \mathrm{MPa}\right.$, $\mathrm{N}_{\mathrm{f}}=5.7 \times 10^{4}$ ) (Figure 4-21e) showing typical fatigue failure with crack growth along charge weld interface

It appears that any decrease in fatigue lives for the AA6082 T-W(2) specimens can be explained by an increased rate of crack growth. Cracking may be accelerated by overload failure at the charge weld interface. The failure at the charge weld interface may be due to impurities (possibly oxides) on the weld surface or possibly linking of the segregated secondary constituent phase.

\subsection{Effect of fibrous core}

To determine the effect of the fibrous core on fatigue properties of the extruded material, several AA6082 specimens were ground and polished to remove or partially remove the surface recrystallized layer. By removing the surface recrystallized layer in the AA6082 alloy the fatigue properties of the fully fibrous microstructure can be compared with specimens retaining part or all of 
the recrystallized layer. Figure 4-23 shows the high cycle fatigue behavior of specimens polished to retain various amounts of the recrystallized surface layer. The lowest curve is the fit of as-extruded L-NW specimens (Figure 4-7). By removal of the surface recrystallized layer, the true benefits of a fibrous microstructure can be found. Similar experiments were first performed on AA6082 by Pedersen et. al. [3], who removed the recrystallized layer by machining cylindrical extrusions. An improvement of $\sim 20 \%$ in fatigue strength was observed by comparing the fully fibrous structure with the partially recrystallized structure. Experiments with flat extrusion specimens in this work yielded similar results, shown as data for $2 \mathrm{~mm}$ thick specimens (95\% Rx layer removed) in Figure 4-23. When the specimen was polished approximately 0.4 $\mathrm{mm}$ on each side, a twenty percent increase in fatigue run-out stress was observed (approximately equal to the increase observed by Pedersen). The 0.4 $\mathrm{mm}$ polish corresponds well to the recrystallized layer thickness, therefore only the interface between the fibrous and recrystallized layer remains and in some specimens the recrystallized layer is fully removed. 


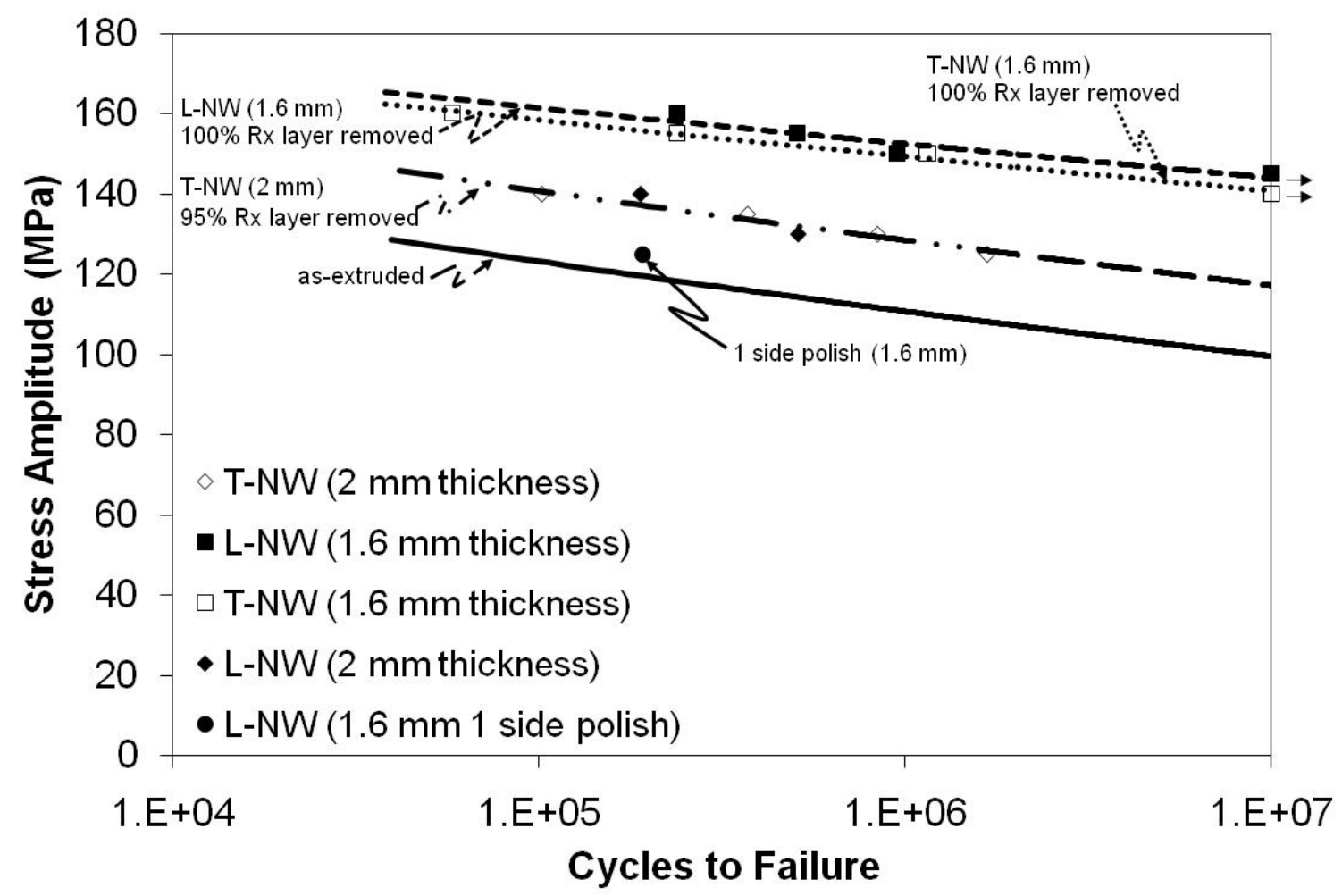

Figure 4-23. S-N curve showing effect of removing the surface recrystallized layer of the AA6082 alloy

Surprisingly, further polishing into the fibrous layer resulted in an increased improvement of the fatigue properties, as shown as the $1.6 \mathrm{~mm}$ data and power law curve fittings (100\% Rx layer removed) in Figure 4-23. The runout stress value of the $1.6 \mathrm{~mm}$ specimens are nearly $20 \mathrm{MPa}$ higher than that of the $2 \mathrm{~mm}$ specimens, even though they both maintain nearly a fully fibrous microstructure. To verify that the thickness of the $1.6 \mathrm{~mm}$ specimens (as opposed to the removal of recrystallized grains) was not the determining factor in the improved fatigue performance of those specimens, one specimen was polished to $1.6 \mathrm{~mm}$ only on one side. The life of this specimen was in reasonable agreement with results for the AA6082 as-extruded curve shown in Figure 4-23. 
Since the thickness of the specimen per se does not appear to affect the testing results, it is assumed that the improved properties are due to removal of the recrystallized layer.

Interestingly, as the recrystallized layer was removed, the tensile properties of the material changed very little. Table 4-3 shows both the static mechanical properties and fatigue properties of specimens with various amounts of as-extruded recrystallized layer. Yield and ultimate strengths of AA6082 specimens are all reasonably close regardless of the thickness of the surface recrystallized layer. Micro-hardness measurements through the cross section of a specimen were also obtained, and are shown in Figure 4-24. It is apparent that the hardness does not vary significantly across either the recrystallized or fibrous structure, which is consistent with the absence of any effect of recrystallized layer thickness on yield strength. In spite of the lack of difference in tensile properties, the fatigue properties tend to increase as the surface recrystallized layer is minimized and removed.

Table 4-3. Effect of microstructure on tensile and fatigue properties

\begin{tabular}{|c|c|c|c|c|c|c|c|c|}
\hline Sample & Microstructure & $\begin{array}{c}\mathbf{0 . 2 \%} \\
\text { Yield } \\
\text { (MPa) }\end{array}$ & $\begin{array}{c}\text { UTS } \\
(\mathbf{M P a})\end{array}$ & $\begin{array}{c}\text { Strain at } \\
\text { Failure } \\
\text { (\%) }\end{array}$ & $\begin{array}{c}\sigma_{\mathrm{a}} \text { at run } \\
\text { out } \\
(\mathbf{M p a})\end{array}$ & $\boldsymbol{b}$ & $\begin{array}{c}\sigma_{\mathrm{f}}^{\prime} \\
\mathbf{( M p a )}\end{array}$ & $\begin{array}{c}\text { Run-Out } \\
\text { I Yield }\end{array}$ \\
\hline $\begin{array}{c}6082 \mathrm{~L}-\mathrm{NW} \\
\text { as-extruded }\end{array}$ & Mixed & 291 & 323 & 19.0 & 98.0 & -0.0465 & 210 & 0.34 \\
\hline $\begin{array}{c}6082 \mathrm{~T} / \mathrm{L}- \\
\text { NW 2 mm }\end{array}$ & Mainly fibrous & 292 & 337 & 19.5 & 117.0 & -0.0399 & 223 & 0.40 \\
\hline $\begin{array}{c}6082 \mathrm{~T}-\mathrm{NW} \\
1.6 \mathrm{~mm}\end{array}$ & Fully fibrous & 296 & 330 & 17.5 & 140.0 & -0.0257 & 213 & 0.47 \\
\hline $\begin{array}{c}6082 \mathrm{~L}-\mathrm{NW} \\
1.6 \mathrm{~mm}\end{array}$ & Fully fibrous & 293 & 330 & 19.5 & 145.0 & -0.0249 & 215 & 0.49 \\
\hline
\end{tabular}




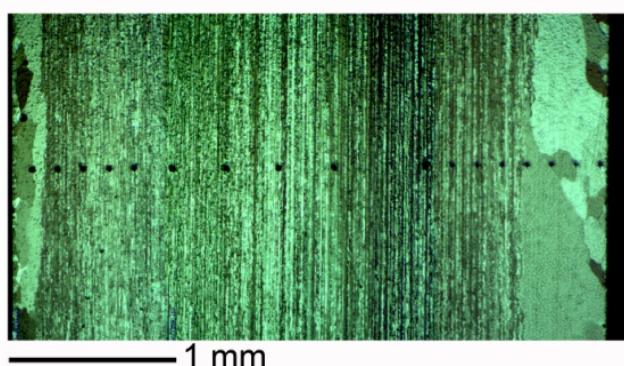

a.

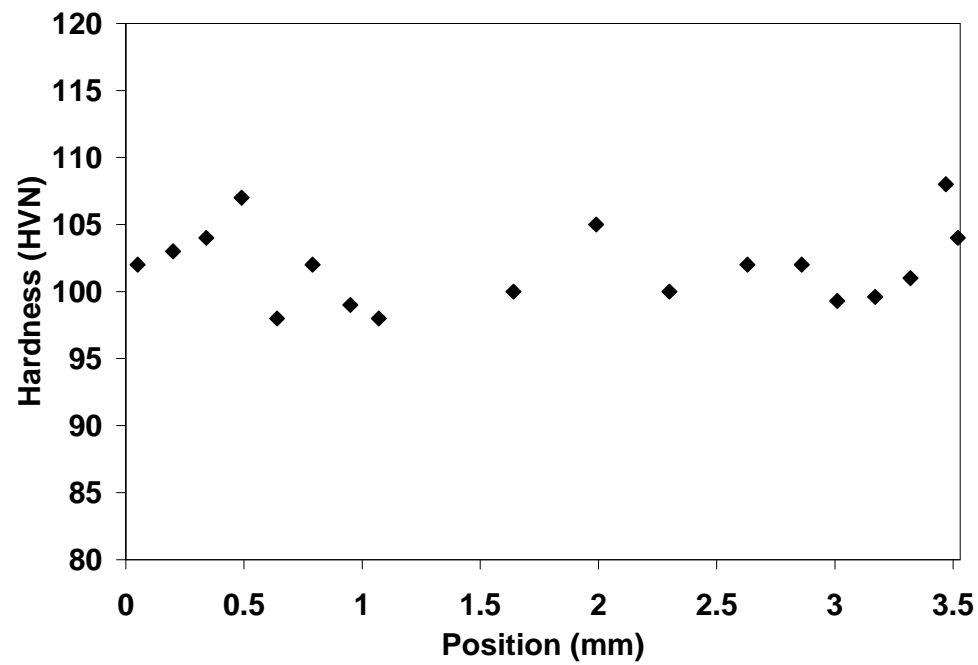

b.

Figure 4-24. Microhardness results through D wall cross section a. indentations in cross section b. hardness through cross section

The last column in Table 4-3 shows the ratio of fatigue run-out stress (or endurance limit) to the yield strength. The ratio of run-out to yield stress for the 2 $\mathrm{mm}$ specimens was 0.40 , slightly higher than the 0.34 for the as-extruded specimens. It appears that the benefits of the fibrous microstructure on fatigue properties are somewhat realized in these specimens. As more of the specimen is thinned, the ratio increases from 0.4 for the $2 \mathrm{~mm}$ specimens to $0.47-0.49$ for 
the $1.6 \mathrm{~mm}$ specimens. At these sample thicknesses no recrystallized grains will be present in the AA6082 specimens.

Another interesting result from these experiments is that the maximum stresses applied to the specimen at the fatigue run-out stress limits for the 1.6 $\mathrm{mm}$ specimens were actually greater than the yield strength. This behavior has been observed by other researchers, but in general is something that does not typically occur in high cycle fatigue [86]. Visual examination of the specimen surface during fatigue testing did show macroplastic yielding in the specimen gauge section, although the amount of yielding was not measured with a strain gauge. Also, the specimens tested at the higher stress levels, $150 \mathrm{MPa}$ stress amplitude, correspond to maximum stress levels very close to the ultimate. These results imply that significant cyclic strain hardening may be occurring in the fibrous core structure, although cyclic stress-strain curves generated by Pedersen did not reveal significant strain hardening for peak aged fibrous AA6082 specimens [87]. Time limitations prevented further investigation of these results, but it would be interesting to perform strain control tests on the $1.6 \mathrm{~mm}$ specimens to explain the origin of these extremely high fatigue properties and verify that the results are not dependent on specimen thickness and testing equipment.

One other unexpected result was the similarity in properties between fully fibrous specimens taken longitudinal and transverse to the extrusion direction. The fatigue properties of L-NW and polished T-NW specimens with recrystallized 
surface grains are nearly the same; and with these results, it is apparent that even without the recrystallized layer the properties are relatively isotropic. Runout stresses for the $1.6 \mathrm{~mm}$ L-NW and T-NW specimens are within $5 \mathrm{MPa}, \mathrm{a}$ difference that is difficult to rationalize with the inherent scatter in fatigue data. Even if such a small difference in fatigue lives of T-NW and L-NW does exist, this small disparity is much lower than expected since the fibrous grains are so highly anisotropic in shape. The degree of $\beta$-fiber texture in extruded AA6082 plate, with a fibrous grain structure, has been shown to decrease from the center of the plate to surface [54], but gross anisotropy due to thinning of the specimen were not evident in tensile and fatigue tests.

Examination of the fracture surfaces of AA6082 specimens with and without recrystallized surface layers can assist in explaining the differences in fatigue properties. Figure 4-25 displays the fatigue fracture surface of a fully fibrous $1.6 \mathrm{~mm}$ L-NW specimen, which can be compared to the typical fatigue failure of as-extruded specimens with recrystallized layers in Figure 4-9. An obvious difference between the failure modes of fully fibrous and partially recrystallized specimens is the initial crack growth. Without the presence of the recrystallized surface layer, crack growth through the fully fibrous material develops beginning at the specimen surface. In contrast, for the partially recrystallized specimens, as shown in Figure $4-9 a \& c$, crack growth is originally transgranular within the recrystallized grains and then transitions to a more regular striated transgranular crack growth through the fibrous zone. The other 
main difference between fatigue failure in as-extruded and fully fibrous specimens is the crack initiation mechanism. For specimens with recrystallized surface layers the, initial crack has been shown to exist as a localized area of intergranular failure, whereas the fully fibrous specimens appear to initiate the fatigue crack at fibrous grain boundaries or sub-grain boundaries. Crack initiation at sub-grain boundaries in fibrous structures was reported by Pedersen et. al. [4]. Figure 4-25d shows a magnified image where a sub-grain oriented at a large angle to the tensile axis appears to have separated.

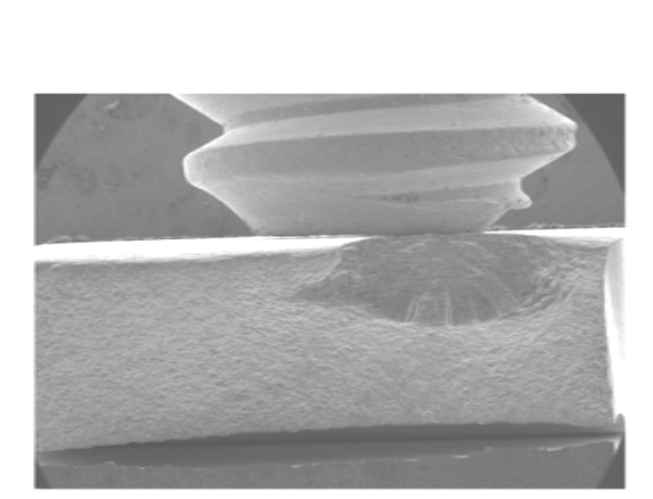

a.

$1 \mathrm{~mm}$

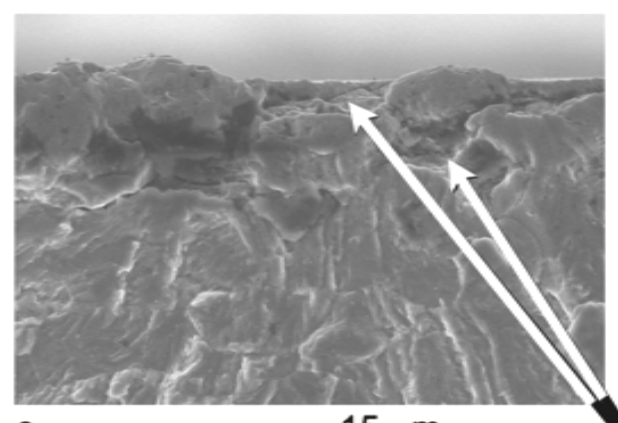

c.

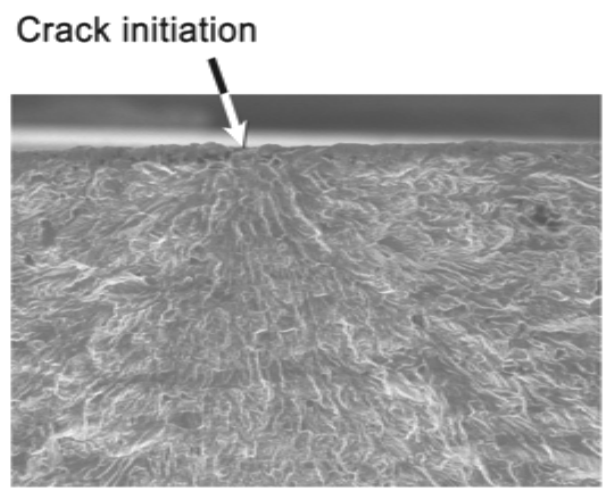

b.

75 um

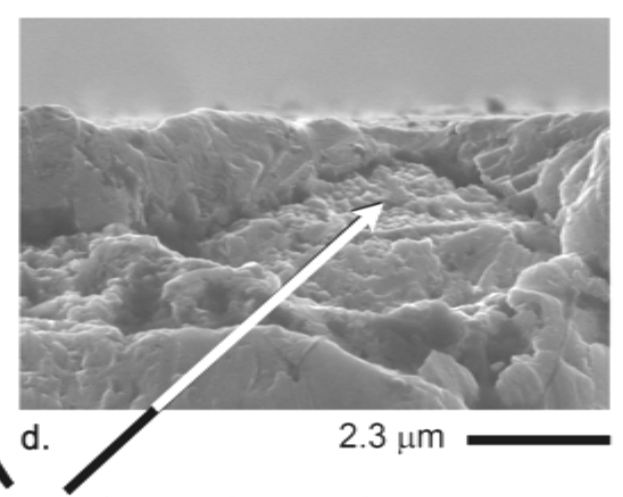

fibrous G.B. or sub-grain boundaries

Figure 4-25. Fatigue fracture surface of peak aged AA6082 fully fibrous (1.6 $\mathrm{mm}$ ) specimen $\left(\sigma_{\mathrm{a}}=160 \mathrm{MPa}, \mathrm{N}_{\mathrm{f}}=2.4 \times 10^{5}\right)$ a. macro-fractograph b. early crack growth c. $\mathrm{FCl}$ site d. magnified $\mathrm{FCl}$ site 
There is a significant amount of work presented in the literature addressing the relationship between grain size and fatigue properties. Although much of the research has been performed on more equiaxed structures than those of the fibrous AA6082 alloy studied here, some of the basic principles relating improvements in high cycle fatigue behavior with reductions in grain sizes can be applied. Since fatigue crack initiation occurs due to localized plastic strain, fatigue endurance limits do not usually scale equally proportionally with grain size as macroscopic yield strength values do with, but Hall-Petch type relationships are generally applicable [88]. The slope of the Hall-Petch curve is typically steeper when modeling yield strength compared to fatigue endurance limits [88]. The effect of grain size and fatigue lives, specifically high cycle $\mathrm{FCl}$, is usually attributed to dislocation density differences, slip homogenization, grain boundary rotation and compatibility of grain elasticity's [89-91]. Liang and Laird have studied the effect of grain size on high cycle fatigue in high purity copper [90]. The fatigue endurance limit was higher in the fine grain material and they explained this difference by homogenization of slip leading to intergranular failure in coarse grain materials, as opposed to strain localization at persistent slip bands and transgranular failure of specimens with fine grains. The mechanism for Intergranular fatigue crack initiation during high cycle fatigue of the coarse grain specimens and some fine grain specimens was noted as being similar to that presented by Kim and Laird and mentioned in the Background section [7, 8]. 
Some researchers have also investigated the effect of grain size on fatigue crack growth thresholds [92-94]. Different materials appear to show mixed results on the effect of grain size on $\Delta \mathrm{K}_{\text {th }}$ values. Threshold values for a Cu-Al alloy were shown to decrease with increasing grain size, and this was more pronounced in alloys with higher aluminum concentrations [94]. The improvement in fatigue crack threshold was attributed to decreased stacking fault energy. On the other hand, $\Delta \mathrm{K}_{\mathrm{th}}$ values were shown to decrease with smaller grain sizes when examining ultra fine grained Al-Mg materials [93]. The increased rate of fatigue crack growth in the ultra fine grained materials was attributed to a lack of crack deflection at large grain boundaries.

Since the microstructure of the AA6082 alloy has a mixed microstructure with a majority of fine fibrous grains, $\sim 3 \mu \mathrm{m}$ in diameter, and a smaller number of 200-300 $\mu \mathrm{m}$ diameter surface grains, it is difficult to relate the fatigue life directly to a Hall-Petch type relationship. Removal of the recrystallized layer did not significantly improve the yield strength of specimens and therefore the improvement in fatigue life is not associated with increased strength due to grain size refinement. The fatigue life did however improve significantly when the entire specimen is comprised of fine fibrous grains. It is certainly likely that slip is more homogenous in the coarse surface grains, and cross slip may occur in localized surface grains oriented for easy glide slip, leading the intergranular failure at weak PFZs. Despite the fact that slip may be more localized in the fibrous grains or sub-grains, $\mathrm{FCl}$ occurred along those boundaries in 6 out of 8 
specimens that were examined in the SEM. It is likely that PFZs localize strain at grain boundaries and not persistent slip bands for both coarse and fine grain materials at high and low stress amplitudes. The improvement in fatigue behavior of fibrous structures may be most realized in early crack growth stages. Since the sub-grains in the fibers are much smaller than the recrystallized surface grains, the initial cracks that form due to boundary separation are much smaller in fibrous structures. Stage I crack tip stress intensities will be much lower for fibrous structures, resulting in much slower growth rates, regardless of improvements in $\Delta \mathrm{K}_{\text {th }}$ due to the refined grain sizes.

Previous research on fatigue of AA5754 sheet with an un-equiaxed grain structure and $\beta$-fiber texture showed anisotropy in fatigue lives but not tensile strengths between specimens taken $0^{\circ}, 45^{\circ}$ and $90^{\circ}$ with respect to the rolling direction [95]. The anisotropy was attributed to the orientation of the coarse second phase particles and not the grain structure and texture. A study by Viviani et. al. showed that yield strengths of specimen taken $0^{\circ}, 45^{\circ}$ and $90^{\circ}$ relative to the direction of extrusion of an AA6082 alloy with a $\beta$-fiber texture were similar, but specimens take at 30 and 60 degree angles had lower strengths [96]. The differences were attributed to specimen orientation relative to preferred textural orientations. Other researchers have shown various levels of anisotropy in fatigue crack growth, tensile properties and overall fatigue lives of aluminum extrusions with fibrous microstructures [97-101]. The lack of anisotropy in fatigue and tensile properties of specimens taken along the extrusion direction 
and $90^{\circ}$ relative to the extrusion direction in this study is most likely associated with the $\beta$-fiber texture, as explained by Viviani et. al.. It appears that the preferred slip orientations do not change significantly between these two orientations. Also, the grain aspect ratio does not affect the fatigue lives of L-NW or T-NW specimens, most likely due to grain boundary $\mathrm{FCl}$ at sub-grains and not separation along the entire fiber boundary.

\subsection{Heat treatment variations}

The precipitate strengthening trend for the AA6082 alloy at the temperature of $185^{\circ} \mathrm{C}$ was shown in Figure $4-1$. The peak aging time at this temperature corresponds to about $5 \mathrm{hr}$. This combination of heat treatment time and temperature was used for all fatigue specimens, except for those discussed here. Specimens aged for times longer and shorter than the peak aging time at $185^{\circ} \mathrm{C}$ and specimens aged at $175^{\circ}$ and $195^{\circ} \mathrm{C}$ for $5 \mathrm{hr}$ were tested to determine their effect on fatigue life.

High cycle fatigue results for specimens aged for times shorter and longer than $5 \mathrm{hr}$ at $185^{\circ} \mathrm{C}$ as well as those specimens aged for $5 \mathrm{hr}$ at $175^{\circ}$ and $195^{\circ} \mathrm{C}$ are provided as open symbols in Figure 4-26 along with the solid trend line representing the power law curve fit of the peak aged $5 \mathrm{hr}$ specimens at $185^{\circ} \mathrm{C}$ (Figure 4-7). The fatigue properties of the specimens aged at $175^{\circ}$ for $5 \mathrm{hr}$ show an improvement over the base line peak aged specimens at $185^{\circ} \mathrm{C}$, but all of the

other heat treatments yielded results that were either comparable or lower. The 
two dashed lines in Figure 4-26 represent the scatter band in fatigue life from the range of aging treatments.

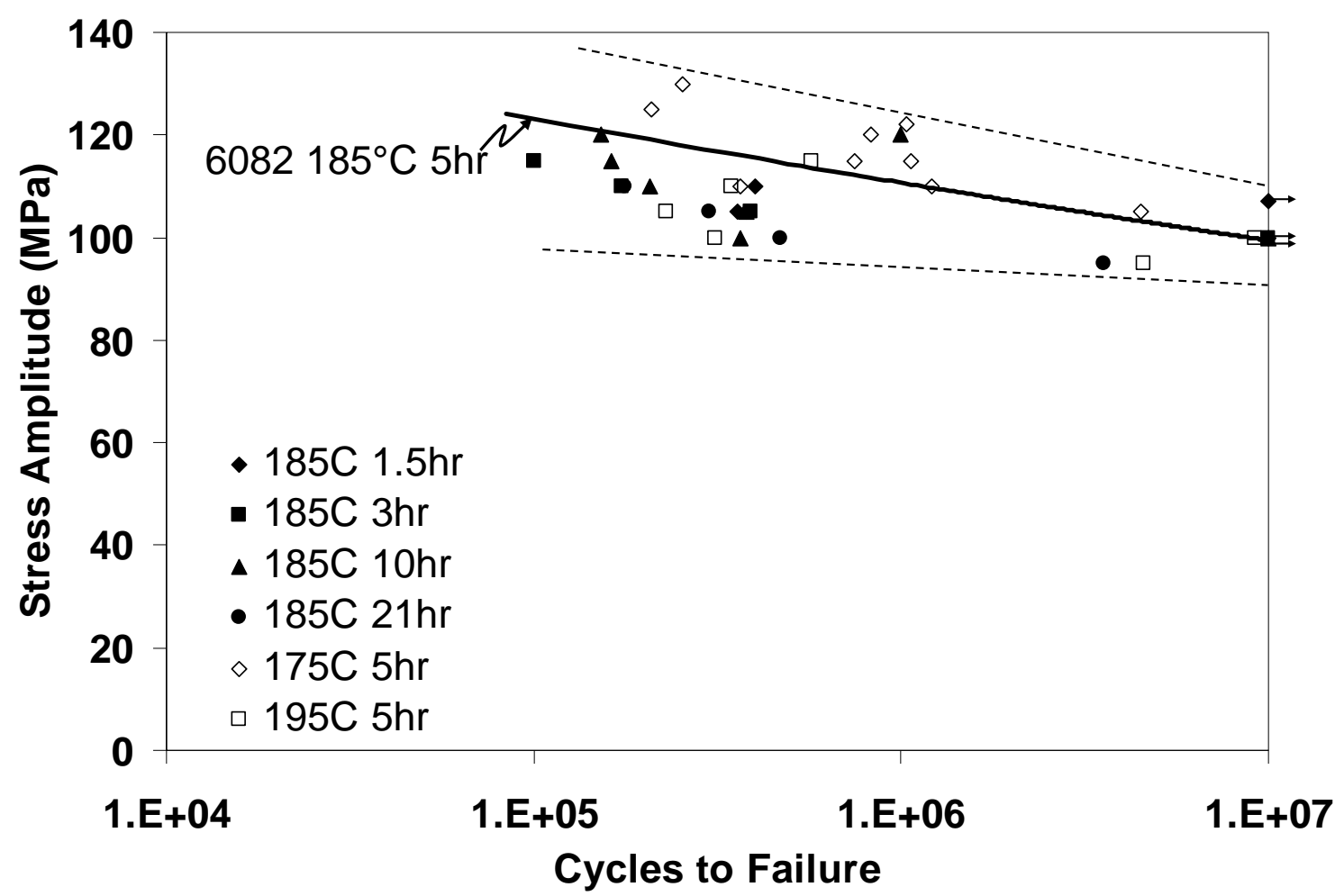

Figure 4-26. Fatigue lives of AA6082 L-NW specimens with different aging treatments

The differences between fatigue properties of the various aging treatments are significantly larger at the high stress levels than at the lower stress amplitudes. In the high cycle regime, the differences among the fatigue properties for the various heat treatments are reduced. One possible explanation for this trend is that more dislocation-precipitate interactions will occur as the stress is increased and as plasticity becomes more general within the gauge 
section. When stress levels are low enough, near run-out (endurance limit) values, the majority of the specimen gauge will undergo only elastic stresses, and slight difference in precipitate size should not drastically effect properties. Also, cyclic hardening and softening may occur more rapidly at higher stress amplitudes, leading to larger variations in fatigue properties. Pedersen has reported cyclic hardening until saturation in under-aged, and softening to saturation in over-aged, AA6082 specimens [87].

If the fatigue data from the various individual age hardening treatments are fit to a Basquin curve, the run-out stresses can be estimated by extrapolation and plotted against values of yield strength, as shown in Figure 4-27. The variation in endurance limit stress amplitude values ranged from 90 to $105 \mathrm{MPa}$, with the $21 \mathrm{hr} 185^{\circ} \mathrm{C}$ specimen being the lowest and the $5 \mathrm{hr} 175^{\circ} \mathrm{C}$ specimen the highest. The data is fit with a linear trend where estimates of fatigue run-out limit can be made based on yield strength. 


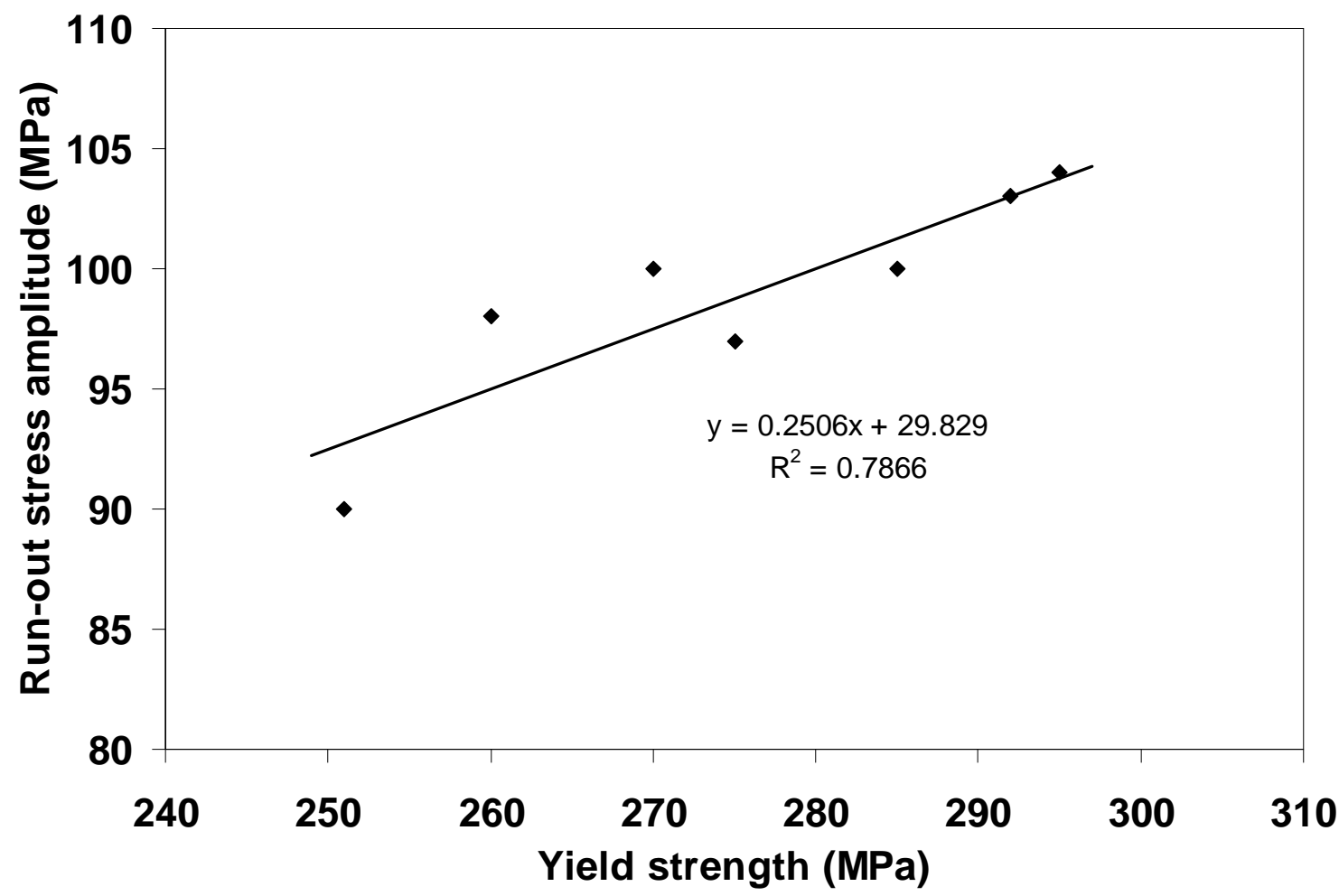

Figure 4-27. Relationship between yield strength and endurance limit for L-NW AA6082 specimens aged at different times and temperatures

\subsection{Effect of $\mathrm{NaCl}$ solution}

Stress-life curves for L-NW AA6082 specimens tested in air, distilled water and a 3.5wt $\% \mathrm{NaCl}$ solution are shown in Figure 4-28. The detrimental effect of testing in aqueous environments, specifically those containing chloride ions is clear. The stress levels corresponding to $1 \times 10^{6}$ cycles for the AA6082 air, water and salt fatigue tests are approximately 110, 95 and $50 \mathrm{MPa}$, respectively. During high cycle fatigue of metals $\left(<1 \times 10^{5}\right.$ cycles) initiation of fatigue cracks generally occupies more of the fatigue life of the specimen than does fatigue crack propagation $[6,18]$. For this reason, the decreases in fatigue life due to the exposure to aqueous solutions are probably attributed to more rapid crack 100 
initiation, although there are examples where the rate of crack growth in aluminum alloys will also increase when exposed to $\mathrm{NaCl}$ solutions $[102,103]$. The AA6082 T-W specimens tested in the salt solution (not shown in Figure 428) at 60 and $90 \mathrm{MPa}$ had fatigue lives of $4 \times 10^{5}$ and $8 \times 10^{4}$ cycles, respectively, corresponding well with the lives of L-NW specimens tested in the $\mathrm{NaCl}$ solution. This implies that neither the effects of orientation and associated stress concentrations due to die line grooves nor the effect of seam welds are significant when testing in the salt solution.

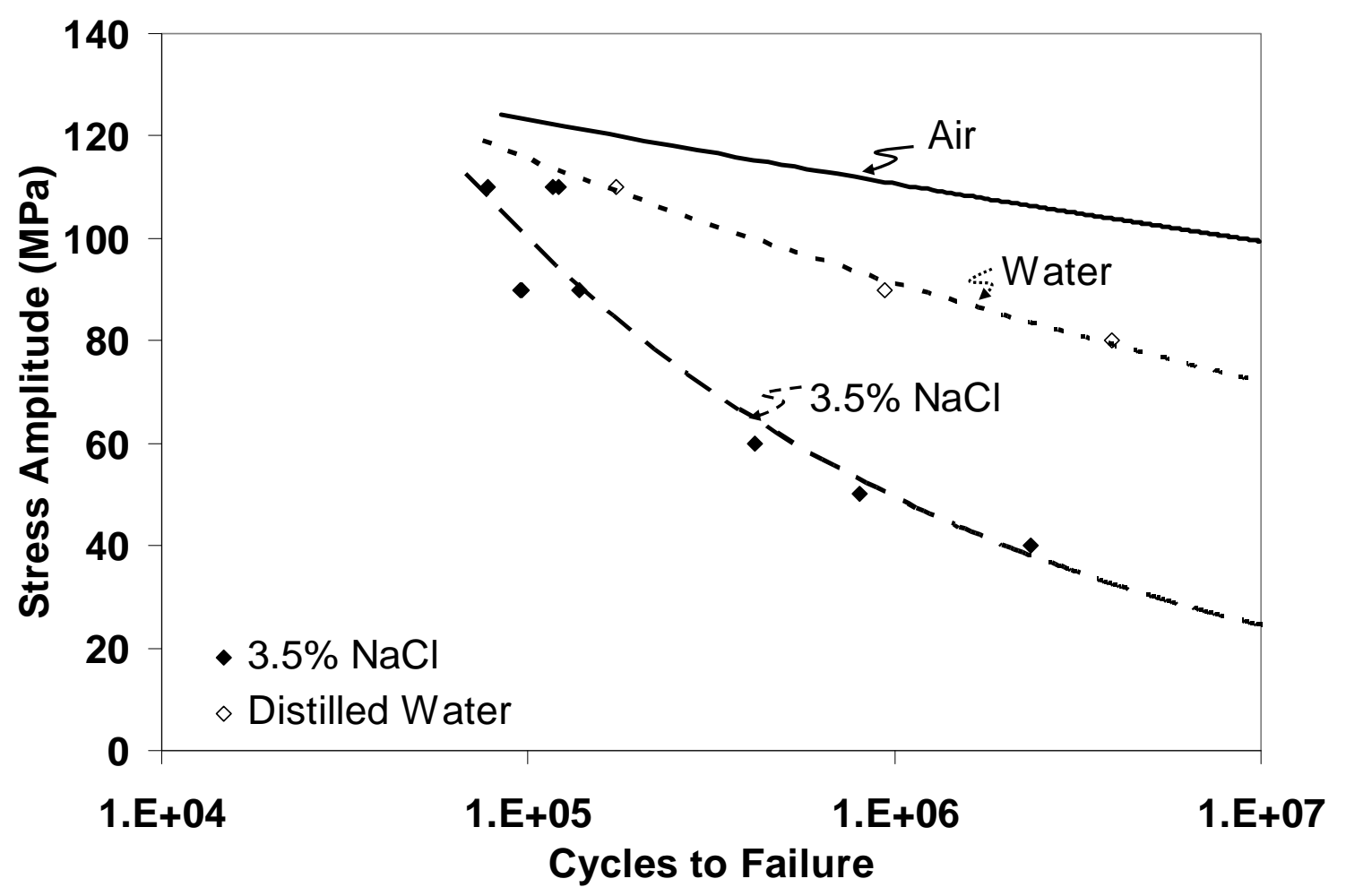

Figure 4-28. Effect of salt and distilled water solutions on fatigue lives of peak aged L-NW AA6082 specimens 
Fracture surfaces of selected fatigue specimens tested in the salt solution are shown in Figure 4-29 and are compared with one specimen tested in air, Figure 4-29a-c. In the first column of Figure 4-29, the macrographs shows typical fatigue failure where the white dot denotes the site of $\mathrm{FCl}$, which is followed by cyclic propagation of the crack until final overload fracture. Figure 4$29 \mathrm{~b}$ provides an image of higher magnification at the initiation site in 4-29a, showing clear evidence of intergranular separation. This intergranular separation mechanism, acting as the $\mathrm{FCl}$ site, was typical in specimens tested in air. The following images in the first column show macrographs of the fatigue damage of specimens exposed to the $\mathrm{NaCl}$ solution, starting with the higher stress amplitude (110 MPa) down to the lowest amplitude (40 MPa). As the stress amplitude is decreased the specimen is exposed to the salt solution for longer periods, and a noticeable difference in the location of initiation occurs at stresses lower than $110 \mathrm{MPa}$. The specimens tested at both 40 and $50 \mathrm{MPa}$ initiated the fatigue crack on the corner or milled face of the specimen, as opposed to the extruded face of specimens tested at higher stresses levels. Also, the initiation mechanisms (shown in more detail in column 2 of Figure 4-29) in the lower stress specimens are not as clearly intergranular separation, as in Figure 4-29e. It is likely though that fibrous grain boundaries or sub-grains may play a role in fatigue initiation when cracks start on the milled surface. 


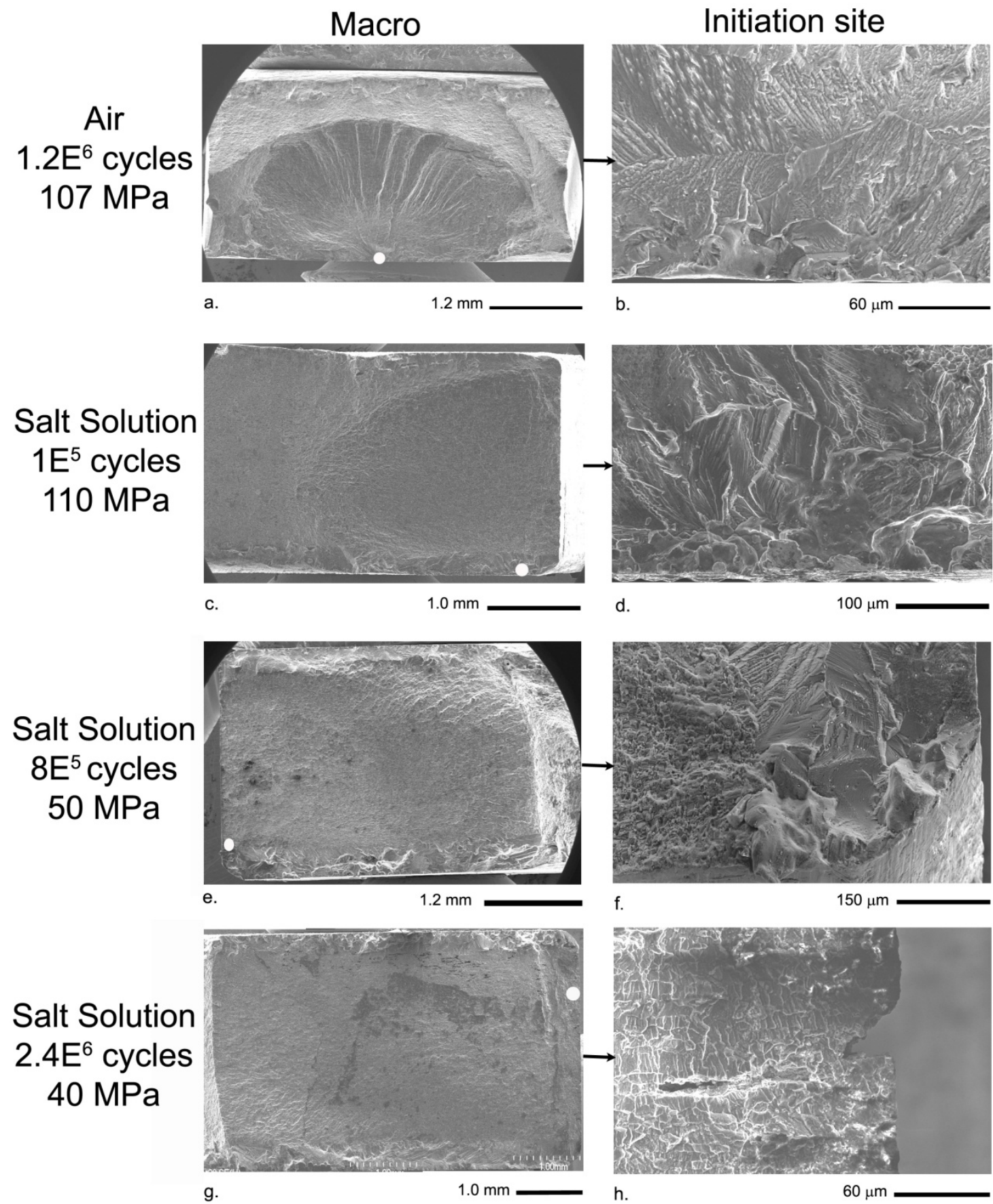

Figure 4-29. Scanning microscopy analysis showing fractographs of peak aged AA6082 L-NW tested in $\mathrm{NaCl}$ soluton. Column one shows macro-fractographs, highlighting initiation site (white dot). Column two provides higher magnification imaging at initiation site. 
Two specimens were tested at $60 \mathrm{MPa}$ with testing frequencies of 5 and $10 \mathrm{~Hz}$ (compared to typical $20 \mathrm{~Hz}$ for all other specimens) to examine the frequency dependence on corrosion-fatigue lives. The lives of specimens tested under at the three different frequencies were, $3.3 \times 10^{5}, 7.3 \times 10^{5}$ and $4.1 \times 10^{5}$ cycles, for 5, 10 and $20 \mathrm{~Hz}$, respectively. These results do not indicate a significant effect of frequency, and the range of results is typical of the inherent scatter in corrosion-fatigue testing. Reductions in frequency typically lead to reductions in corrosion-fatigue lives due to time dependant corrosion reactions $[103,104]$. For these experiments, frequencies between $5-20 \mathrm{~Hz}$ did not indicate a significant effect.

Two other tests were performed to evaluate the effect of the salt solution of fatigue performance. One specimen was held in the salt solution for 5 days, at a constant stress equivalent to the maximum stress (244 Mpa) of the specimens tested at the stress amplitude of $110 \mathrm{MPa}$. After five days without failure, the specimen was incrementally loaded to the failure stress, which was equivalent to the UTS of specimens tested in air. This suggests that whatever damage occurs during constant loading while exposed to the salt solution, does not significantly affect the tensile properties of AA6082.

A second specimen was held unloaded in the salt solution for 11.5 hours, which is equivalent to the life time of the $50 \mathrm{MPa}$ stress amplitude test at $20 \mathrm{~Hz}$. The as-extruded surfaces of fatigue specimens tested in air and in the $\mathrm{NaCl}$ solution at various stress amplitudes are shown in Figure 4-30. For comparison, 
the surface of the un-loaded specimen exposed to the salt solution is also shown in Figure 4-30d. At the highest stress level of $110 \mathrm{MPa}$ (Figure 4-30a) the exposure time was about 1.5 hrs, apparently only enough time for pitting to initially occur at the large second phase constituent particles. The $8 \times 10^{5}$ cycles to failure of the specimen tested at $50 \mathrm{MPa}$ (Figure 4-30c) provides adequate time to completely pit out the dispersoid phases near the grain boundaries at this stress level. After 36 hours $\left(2.4 \times 10^{6}\right.$ cycles $)$ all of the dispersoid and undissolved constituent particles have been pitted from the extruded surface (Figure 4-30e), exposing the grain boundaries below the surface. The unloaded specimen only shows pitting corrosion at the un-dissolved secondary constituent particles and grain boundaries are not typically exposed in Figure 4-30d. This is in contrast to the pitting of the dispersoid particles that occurred in the cyclically loaded specimen. These observations indicate that pitting corrosion is accelerated during fatigue loading of the specimen. This is probably due to the continual breakdown of the passive surface oxide layer in the vicinity of surface particles under cyclic straining in the $\mathrm{NaCl}$ solution. The breakdown of the oxide layer can lead to increased rates of anodic dissolution of the material immediately adjacent to constituent and dispersoid particles. Dissolution of aluminum at grain boundary particles is especially damaging. 


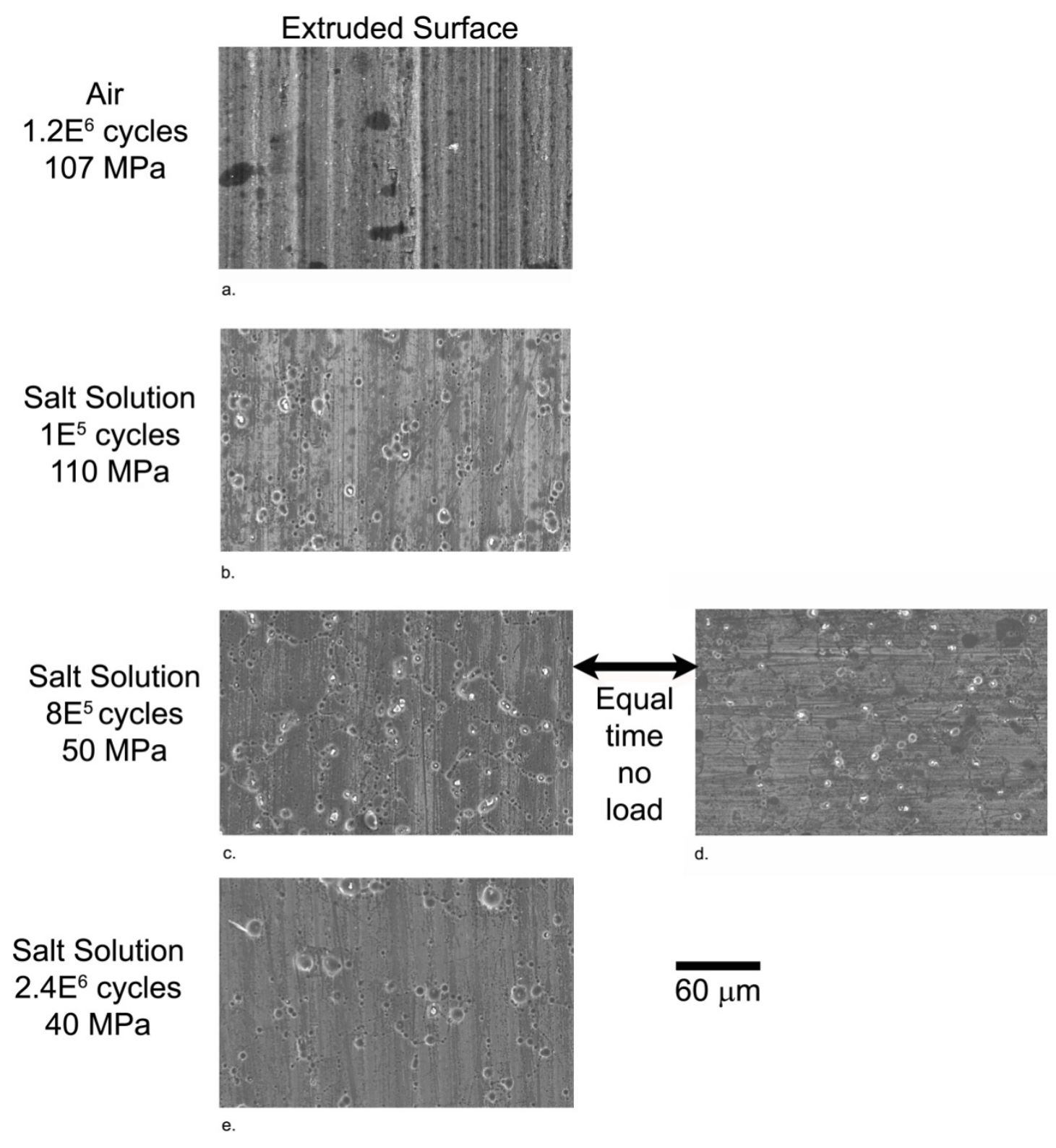

Figure 4-30. Pitting progression on the as-extruded surface of AA6082 specimens fatigue tested in air and $\mathrm{NaCl}$ solution $\mathbf{d}$. held for $11.5 \mathrm{hrs}$ at zero load in MTS machine 
A polarized light optical micrograph showing the cross section of the L-NW fatigue specimen tested at $\sigma_{a}=40 \mathrm{MPa}$ is provided in Figure 4-31. Here, several effects of the corrosion environment on the fatigue mechanism can be clearly identified. Near the fracture surface in Figure 4-31, there are two sites of localized attack on opposite surfaces. At both sites of localized attack, there is a large pit that forms, most likely due to corrosion adjacent to an agglomeration of dispersoids and/or secondary constituent particles. The formation of the large pits exposed grain boundaries that are near the surface, which led to intergranular corrosion attack. The initiation of fatigue cracking on the nearby fracture surface could easily have occurred as a result of similar pitting and intergranular attack. A similar corrosion mechanism has been reported on an unstressed AA6111 alloy with low copper concentration [28]. This corrosion mechanism seems to be amplified by the cyclic loading occurring during the fatigue tests, which leads to premature intergranular crack initiation and failure. The role of the salt solution and corrosive attack during Stage II fatigue crack propagation is also evident on the fracture surface cross section in Figure 4-31. Some corrosion occurred down the boundaries of the fibrous core grains, specifically on the right side of the fracture surface image. Since the stages of fatigue crack initiation and crack propagation were not independently studied, the exact role of corrosion for each stage in the fatigue process is not known, but it is expected that at such low stresses the fatigue crack initiation process was more severely affected. 


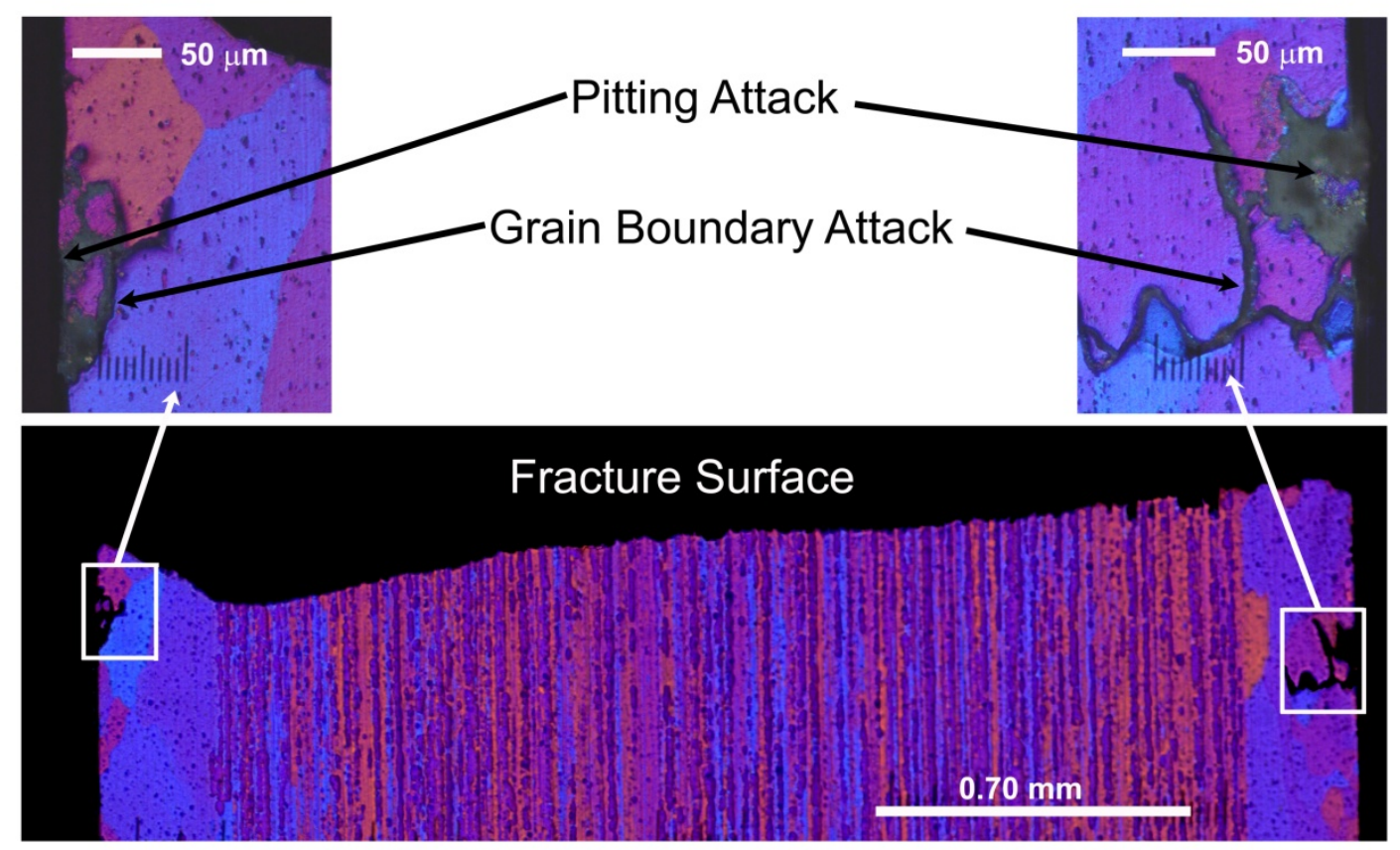

Figure 4-31. Polarized light image of cross-section of peak aged AA6082 L-NW specimen tested at $\left(\sigma_{\mathrm{A}}=40 \mathrm{MPa}, \mathrm{N}_{\mathrm{f}}=2.4 \times 10^{6}\right)$, showing localized pitting that exposed the grain boundaries to corrosion deep within the recrystallized surface layer

\subsection{Effect of elevated temperature}

Components in automobile engine compartments may reach moderately elevated temperatures; therefore, a study was performed to examine how the fatigue behavior of AA6082 changes at temperatures up to $150^{\circ} \mathrm{C}$. Both L-NW and T-W specimens were tested at the elevated temperature and fatigue lives of these specimens are compared to specimens tested in air in Figure 4-32. For LNW specimens, there is clearly a decrease in fatigue properties at the testing temperature of $150^{\circ} \mathrm{C}$. Modest decreases in fatigue lives are observed for specimens tested at the higher stress levels while more severe effects of 
temperature can be observed for L-NW specimens tested at low stress amplitudes. This observation implies a stronger temperature dependence on the number of cycles to initiate a fatigue crack. Comparing fatigue lives (using the power law curve fittings) at stress levels of 90 and $110 \mathrm{MPa}$, the lives of specimens tested under ambient air conditions are respectively, $\sim 22$ and $\sim 4$ times higher than those tested at $150^{\circ} \mathrm{C}$. Sharma, et. al. [15] have reported moderate more uniform decreases in fatigue lives of an Al-Li alloy tested at $150^{\circ} \mathrm{C}$

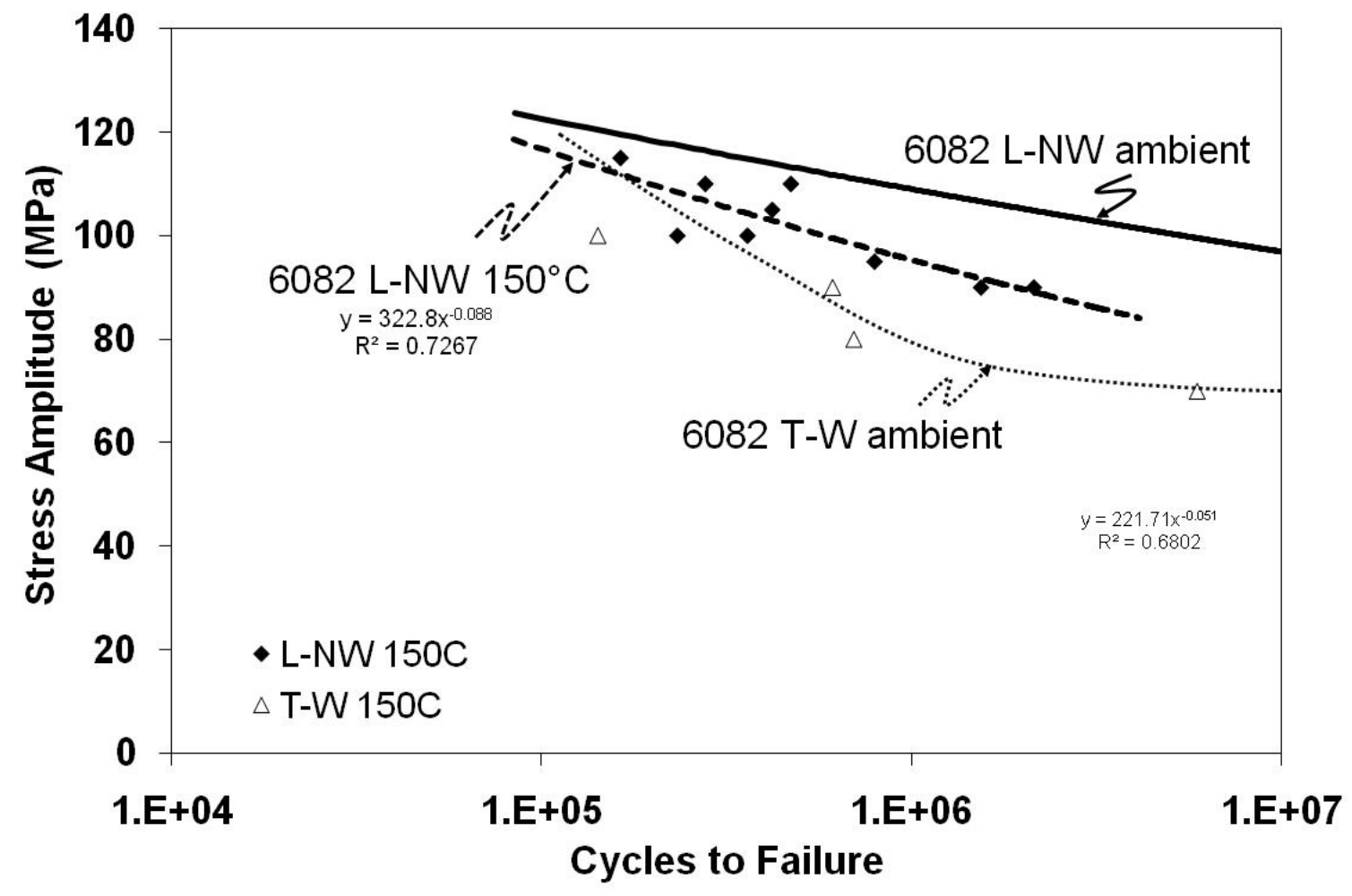

Figure 4-32. Fatigue behavior of peak aged AA6082 specimens tested at $150^{\circ} \mathrm{C}$ 
The limited number of $\mathrm{T}-\mathrm{W}$ specimens tested at $150^{\circ} \mathrm{C}$ were all taken from the A wall. In Figure 4-32, ambient temperature fatigue results from A wall specimens (Figure 4-13) are compared to elevated temperature fatigue lives. With the exception of the higher stress elevated temperature specimen, the fatigue behavior of the T-W specimens at the elevated temperature corresponds well to the curve fitting of the ambient $A$ wall fatigue data. Fatigue failures in the T-W specimens were not associated with the seam weld.

There are several variables associated with the microstructure and stress state that could be affected by the testing temperature, thereby, leading to premature fatigue failure during cyclic loading. Since these alloys are age hardenable, and are typically used in the peak aged condition, coarsening or transformation of the $\mathrm{Mg}-\mathrm{Si}$ precipitate phase could occur at elevated temperatures. At the moderate testing temperature of $150^{\circ} \mathrm{C}, 35^{\circ}$ below the aging temperature utilized, drastic changes in the precipitate structure are not expected. Fatigue strengths of specimens with different aging time and temperatures (section 4-9) showed little variation, even at temperatures greater than $150^{\circ} \mathrm{C}$. Increased segregation of impurities or changes in PFZ grain boundary structures could also influence fatigue properties tested at the elevated temperatures, but again the slow diffusion kinetics at these temperatures are not expected to make these effects significant. A temperature dependant factor that could play a role is the kinetics of oxidation at the surface of the specimens or at freshly exposed free surfaces where Stage I cracks appear. Oxidation could also 
affect the Stage II crack growth rate of specimens tested at the elevated temperatures. Enhanced plasticity and creep-fatigue interactions could concievably play a role in the fatigue failure of specimens tested at the elevated temperature, but the low temperature and relatively high frequency probably limit creep effects. Finally, one other factor to consider is the relaxation of residual stresses, specifically at the burnished specimen corners. These temperatures and testing times should be adequate for stress relaxation and this relaxation could result in $\mathrm{FCl}$ at corners, thus leading to increased scatter and, in some cases, lower fatigue lives.

Figures 4-33a-d show the fracture surface from a L-NW specimen tested to failure at $110 \mathrm{MPa}$, while Figures $4-33 \mathrm{e}-\mathrm{h}$ are from a specimen tested at the lower stress amplitude of $90 \mathrm{MPa}$. The specimen tested at the higher stress amplitude showed fatigue fracture behavior similar to those tested at ambient temperatures, with the crack initiating on the extruded surface and propagating uniformly from the nucleation site, approximately $90^{\circ}$ to the loading direction. Differences in fracture behavior could be observed under higher magnification at the initiation site, Figure $4-33 c \& d$. One small grain boundary can be seen at the initiation site, and the grain boundary itself shows the presence of an oxidation product (Figure 4-33d). The oxidation of the grain boundary may have assisted in activating crack growth from the initiation site. Oxidation products at separated grain boundaries has been attributed to lower fatigue lives in AA6061 and AA7074 aluminum tested in low cycle fatigue at elevated temperatures $[13,14]$. 
Another feature present on the fracture surface is the smooth transgranular feature on each side of the separated grain boundary, which appears to be a product of planar slip within the neighboring surface grains. This feature was rarely observed in specimens tested at ambient temperature and suggests that increased slip due to the thermal activation at higher temperatures may cause slip bands to become preferred over weakened grain boundaries as Stage I crack paths.
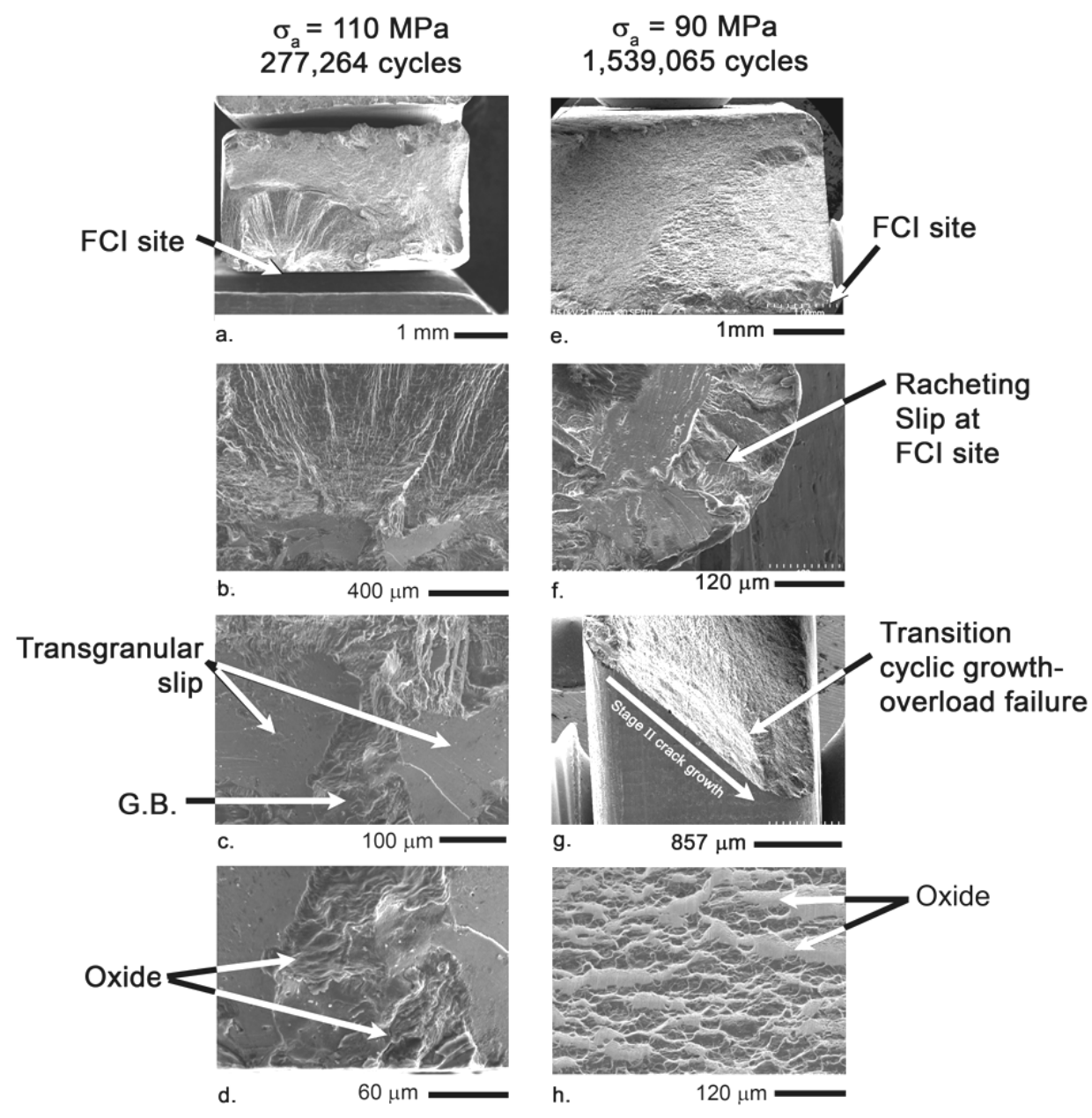

Figure 4-33. Fractographs of peak aged AA6082 L-NW specimens tested at $150^{\circ} \mathrm{C}$ a.-d. high stress amplitude, e.-h. low stress amplitude 
While the fracture behavior of specimens tested at higher stress amplitudes was generally similar to ambient air testing conditions, the fracture surface of the specimens tested at the lower stress amplitudes was quite different. Figure 4-33e-h show the fracture surface of a specimen tested at $\sigma_{a}=$ $90 \mathrm{MPa}$, a stress level that would have run-out at $1 \times 10^{7}$ cycles if tested in ambient conditions. Two main features are evident in the macro images of the fracture surfaces in Figures 4-33e\&g. The nucleation of the fatigue crack occurred on the corner and Stage II crack growth occurred on a plane at a $\sim 45^{\circ}$ angle relative to the tensile axis. Burnishing of the corners typically suppressed fatigue crack initiation at the corners of as-extruded specimens tested in ambient air. The residual stresses that were induced during the burnishing of the corners may have been relieved by the exposure to the elevated temperature. The lack of residual stress in the unconstrained corner grains leads to increased localized plastic slip and eventual crack nucleation at the corner. Since the residual surface stresses were not measured, this scenario was not verified, but the consistency in fatigue crack initiation at corners in low stressed elevated temperature tests, even for T-W specimens, does suggest the relaxation of surface stresses at corners. Juijerm et. al. have shown that surface residual compressive stresses induced by deep rolling solutionized AA6110 were reduced by over $150 \mathrm{MPa}$ through aging at $160^{\circ} \mathrm{C}$ for 12 hours [105]. The test temperature and fatigue lives of the specimens reported here for low stress amplitude tests correspond well to those studied by Juijerm. 
Stage II crack growth on planes where the shear stress was high $\left(\sim 45^{\circ}\right.$ relative to the loading direction) was observed only in specimens tested at elevated temperatures and low stress amplitudes. This relatively abnormal fatigue crack growth character has also been observed in elevated temperature fatigue testing of Al-Li alloys [15]. Another feature present on the fracture surface of Figure 4-33e was a large amount of oxidation (verified with EDS) within the Stage II crack region (magnified in Figure 4-33h). Oxidation at the crack tip could lower the resistance of the alloy to fatigue crack growth, leading to premature failure, but this effect should not play a significant role in overall fatigue life since the number of cycles required to grow a crack until overload failure occurs should be less significant when compared to the crack nucleation period.

The magnified crack initiation site on the corner of the specimen tested at the lower stress amplitude, Figures 4-33f, shows the same transgranular slip characteristics at the $\mathrm{FCl}$ site as the higher stressed specimen (Figure 4-33b-d). This transgranular slip occurred in a ratcheting fashion around the corner of the specimens and was characteristic of many of the low stress amplitude elevated temperature specimens. Oxidation product was also found at the $\mathrm{FCl}$ site on this specimen and could lower $\Delta \mathrm{K}_{\mathrm{th}}$ further reducing the fatigue life. 


\section{AA6063 RESULTS AND DISCUSSION}

\section{$5.1 \quad$ Heat treatment}

The precipitation hardening response of the AA6063 alloy at $185^{\circ} \mathrm{C}$ is provided in Figure 5-1. The trend is similar to that of AA6082, where peak strength occurs after about $5 \mathrm{hrs}$ of aging, and significant variations in strength are not observed between 5 and 9 hrs. All AA6063 specimens were heat treated at $185^{\circ} \mathrm{C}$ for $5 \mathrm{hrs}$. A comparison between peak aged tensile properties of L-NW and T-W AA6063 specimens are shown in Table 5-1. It is evident that tensile properties vary little between the two specimen types and it is further assumed that, as with the AA6082, significant differences in tensile properties are not expected between specimens from different locations and orientations within the extrusion profile.

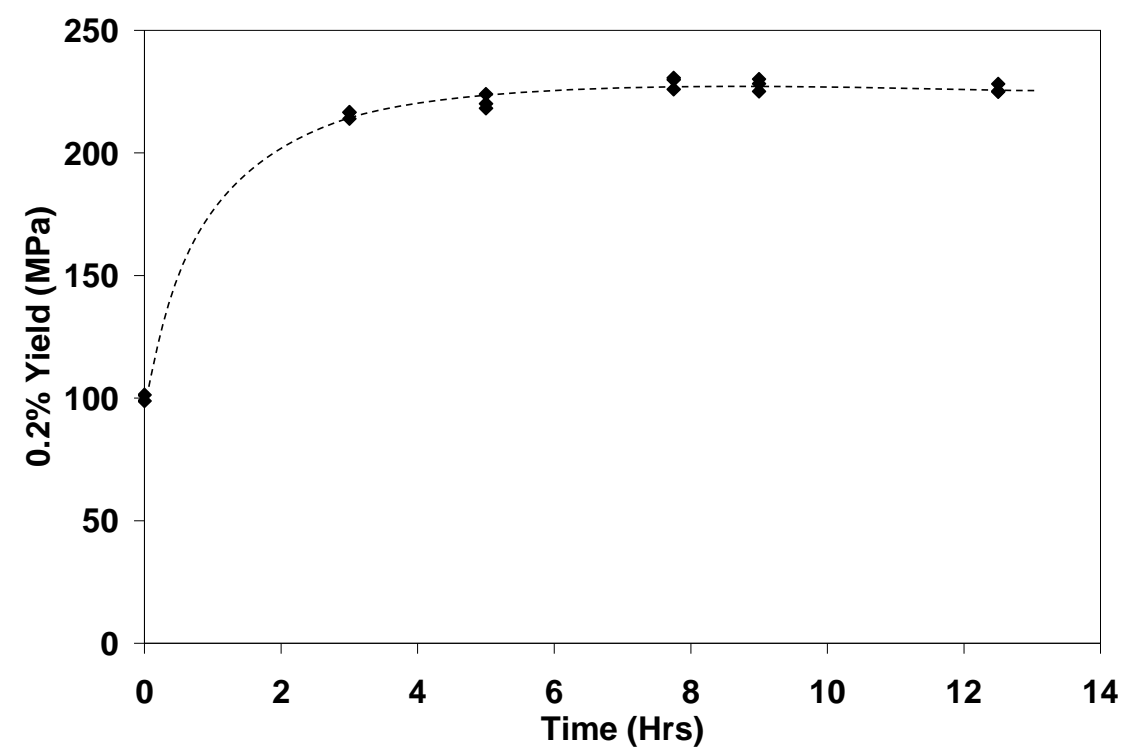

Figure 5-1. Aging response of $A A 6063$ at $185^{\circ} \mathrm{C}$ 
Table 5-1. Tensile properties of peak aged AA6063 L-NW and T-W specimens

\begin{tabular}{cccc}
\hline Specimen & $\begin{array}{c}\mathbf{0 . 2 \%} \text { Yield } \\
\text { Stress } \\
\text { (MPa) }\end{array}$ & UTS (Mpa) & $\begin{array}{c}\text { Fracture } \\
\text { Strain (\%) }\end{array}$ \\
\hline L-NW & 221 & 260 & 27 \\
T-W & 233 & 262 & 21 \\
\hline
\end{tabular}

\subsection{Heat treated microstructure}

An optical image of a typical AA6063 recrystallized extruded microstructure can be seen in Figure $5-2 a$. The recrystallized grain size is approximately $100 \mu \mathrm{m}$ and the texture is assumed to be cube type, similar to that reported previously for extruded AA6063 [37]. Recrystallization, in AA6063 extrusions, occurs across both seam and charge weld interfaces, making them difficult to distinguish in optical images, and therefore representative images of welds are not shown. A TEM image of the fine scale microstructure can be viewed in Figure 5-2b. A precipitate free zone of nearly $100 \mathrm{~nm}$ can be seen on each side of the boundary. The PFZ may be thicker in the AA6063 alloy, compared to AA6082, due to the increased amount of precipitation of the $\alpha$-AlFe-Si phase on the boundaries, which may have drained solute concentrations near the grain boundaries. The $\beta$ " precipitates can only be slightly resolved in Figure 5-2b, but they appear to be similar in size and distribution to those in the AA6082 alloy. 
G.B.

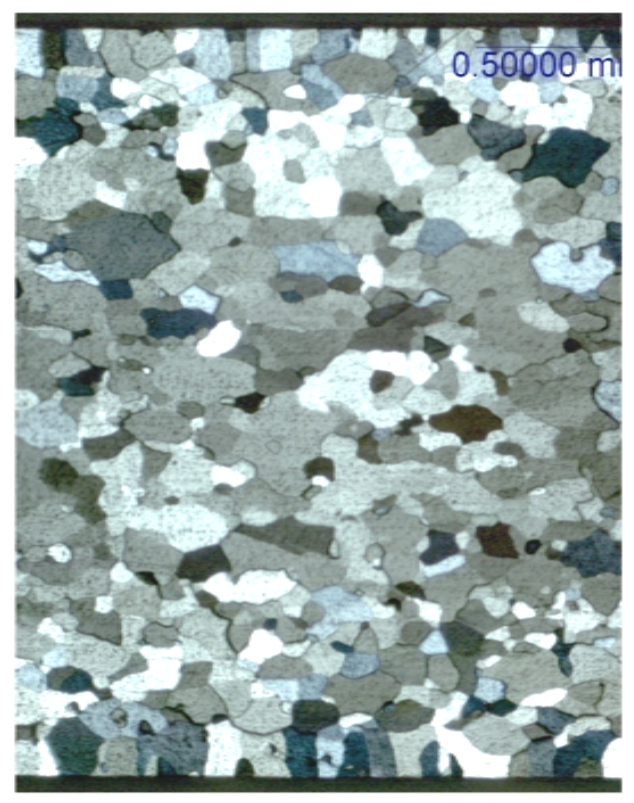

a.

$1 \mathrm{~mm}$

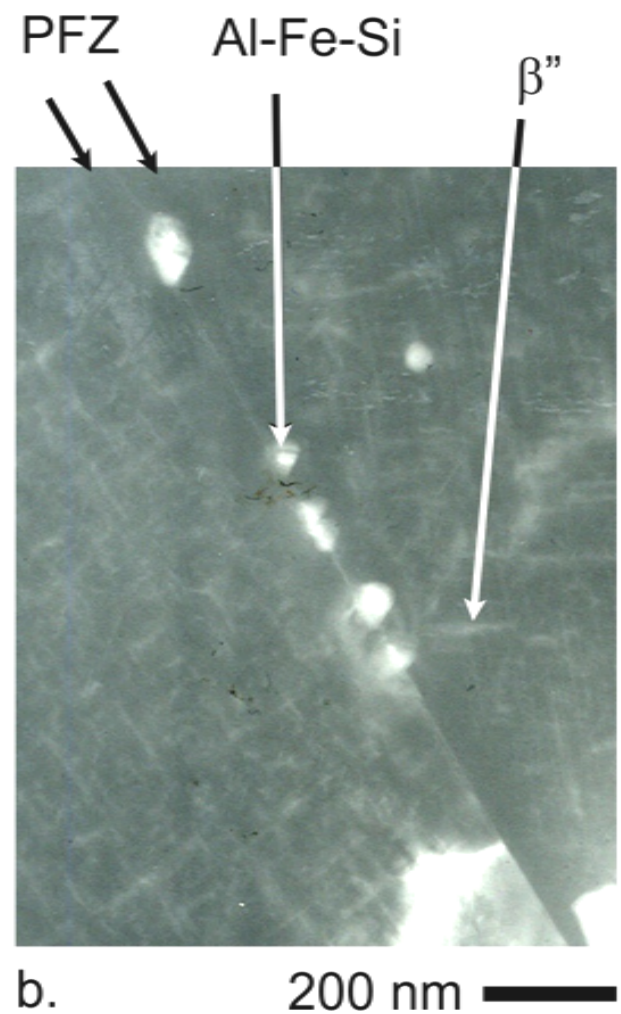

Figure 5-2. AA6063 microstructure a. optical microstructure of peak aged AA6063 specimen b. TEM image of peak aged AA6063 specimen (viewed in [110] aluminum zone axis)

\subsection{Surface roughness}

Surface roughness values taken from the AA6063 extruded profile are provided in Table 5-2. The trends in roughness are similar to the AA6082 extrusion, but the overall severity of the roughness is less for AA6063. The lower roughness most likely occurs due to the lower concentration of second phase particles. As with the AA6082 alloy, the highest roughness values occur for stylus scans across seam welds in the A and C walls, but unlike AA6082, the roughness on both $A$ and $C$ walls is similar. 
Table 5-2. Roughness of AA6063 extrusion profile walls

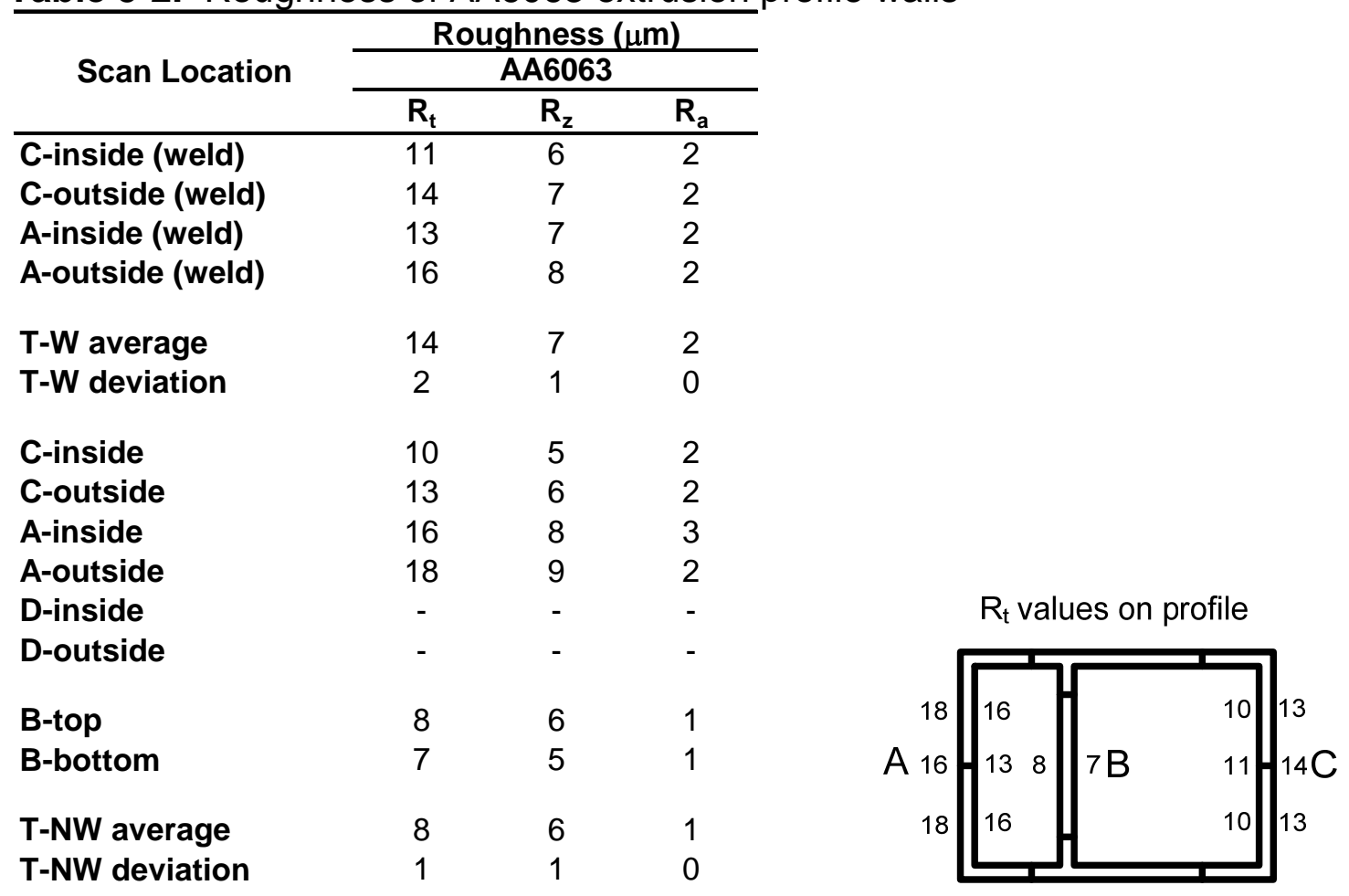

\subsection{Baseline fatigue (L-NW specimens)}

Figure 5-3 is an S-N curve for AA6063 L-NW specimens. The endurance limit for baseline L-NW AA6063 is near $80 \mathrm{MPa}$, nearly $20 \%$ below the value for the AA6082 alloy. This difference in the run-out stress amplitude is slightly lower than the corresponding $25 \%$ difference in yield strengths for the two alloys. The ratio of fatigue endurance limits $\left(\sigma_{a}\right)$ to yield stress for the two alloys are 0.37 and 0.34 for the AA6063 and AA6082 alloys respectively. Since the metastable $\mathrm{Mg}_{5} \mathrm{Si}_{4}$ precipitate hardening phase is similar for both alloys, the increased strength of the AA6082 alloy can be attributed mainly to its refined fibrous microstructure. The fibrous grains in AA6082 have diameters (normal to the 
extrusion direction) on the order of a few microns, whereas the grain size of the fully recrystallized AA6063 alloy is $\sim 100 \mu \mathrm{m}$. Even though there is a large difference in grain size between the recrystallized AA6063 alloy and the fibrous core of AA6082, the benefits of these fibrous grains are not fully realized in the AA6082 extrusion due to its recrystallized surface layer. The fatigue lives of the baseline L-NW AA6063 specimens are comparable to values reported by other researchers $[1,2,51,52]$.

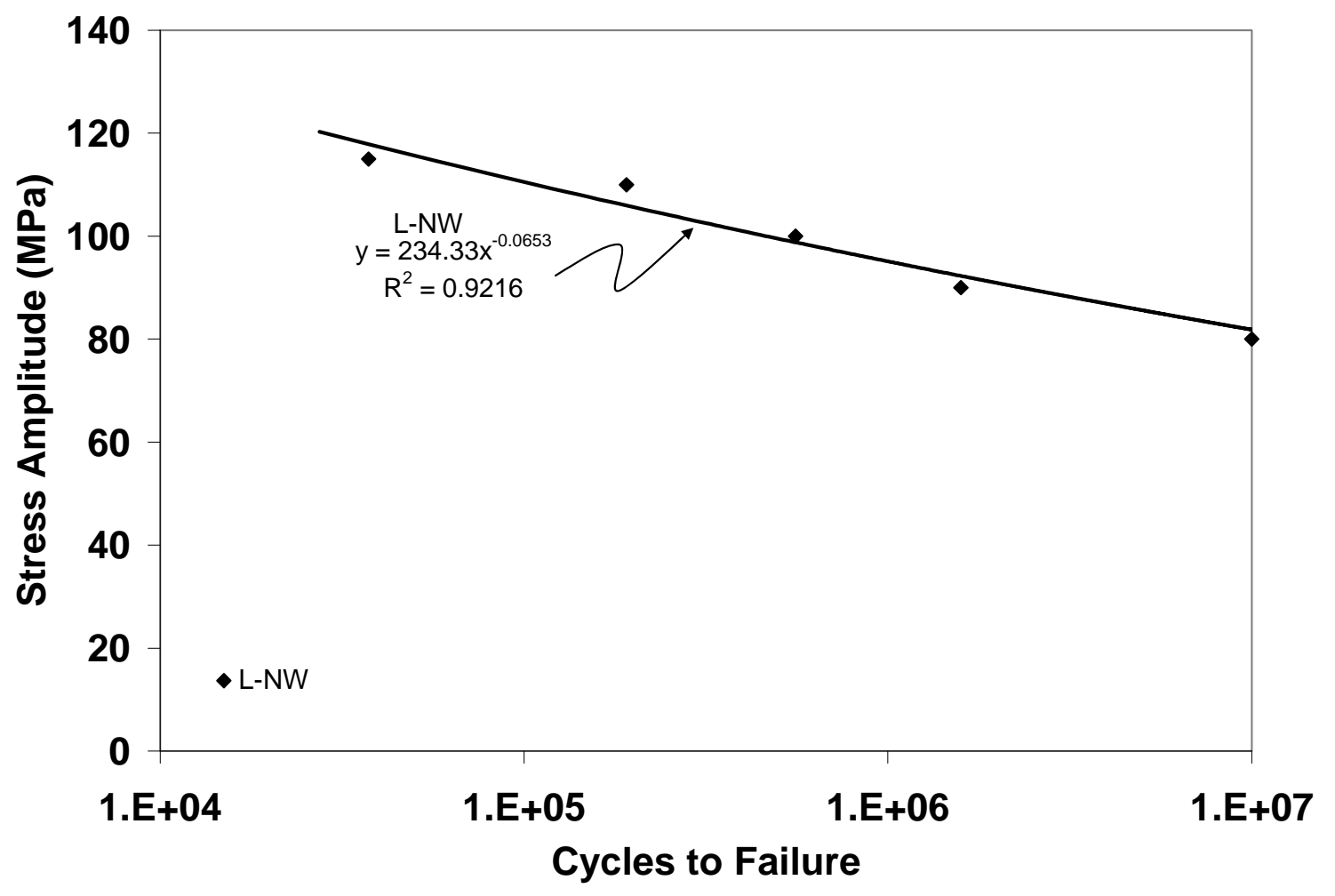

Figure 5-3. S-N curve for baseline peak aged L-NW AA6063 specimens 


\subsection{Effect of orientation/die lines on fatigue}

Fatigue lives of L-NW, 45-NW and T-NW AA6063 specimens are shown in Figure 5-4. Fewer data points were collected for these curves than for the corresponding AA6082 specimens, but the curve fittings are relatively good. The relationships shown for the AA6063 specimens in Figure 5-4 are similar to those for the AA6082 alloy in Figure 4-8. As the orientation of the specimens goes from longitudinal to transverse, the fatigue lives decrease, specifically in the high cycle, low stress, regime. The run-out stress amplitudes for L-NW, 45-NW and T-NW AA6063 specimens were near 80, 75, and $70 \mathrm{MPa}$, respectively. Although the fatigue lives of non-longitudinal AA6063 specimens were less than those for the corresponding longitudinal specimens, the orientation effects on specimens with as-extruded surfaces are much smaller for the AA6063 alloy than for AA6082. The rationale for the shortened fatigue lives of non-longitudinal specimen orientations for the AA6063 extrusion is similar to the rationale for the higher strength AA6082 alloy, and can most likely be attributed to die line

roughness. The lower roughnesses for the AA6063 specimens results in a correspondingly smaller decrease in fatigue life than for AA6082. 


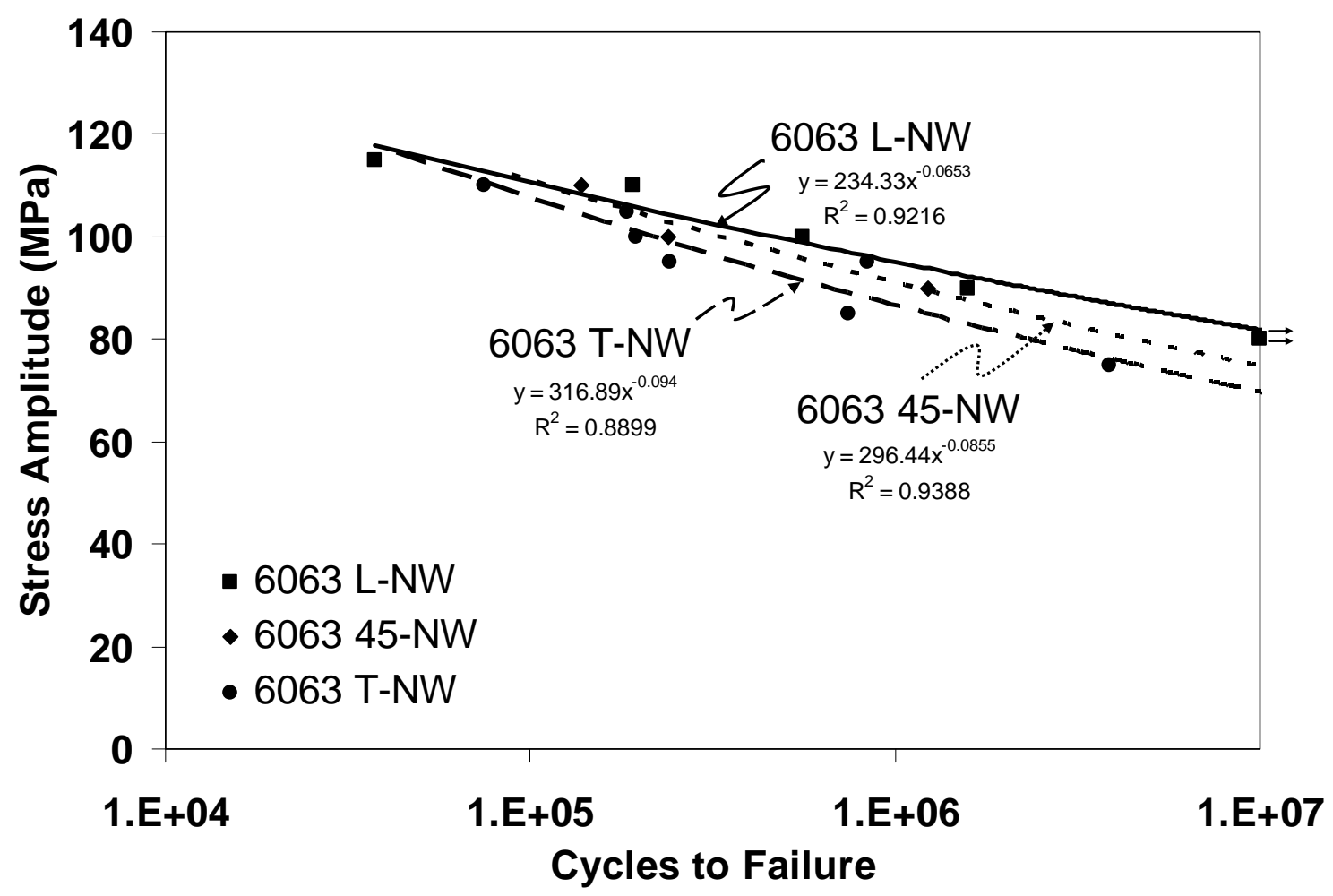

Figure 5-4. S-N curve for peak aged AA6063 L-NW,45-NW and T-NW specimen types

Interestingly, the fatigue lives of T-NW AA6063 specimens are very similar to those for T-NW AA6082 specimens. This is somewhat surprising since the tensile properties of AA6063 specimens are nearly $25 \%$ lower than for AA6082 specimens. The equivalency of fatigue lives of T-NW specimens for both alloys further supports the conclusion that die line surface features are playing an important role in fatigue crack initiation for T-NW specimens in the high cycle fatigue regime. 


\subsection{Effect of seam welds}

The effect of welds oriented $90^{\circ}$ and $45^{\circ}$ to the loading direction, for AA6063 specimens, are shown in Figure 5-5. As with the AA6082 extrusion, the properties of AA6063 specimens containing seam welds loaded at nonlongitudinal orientations was lower than specimens not containing welds. The rationale for this decrease is similar to that for the AA6082 alloy, specimens containing welds had an increased level of surface roughening, leading to premature crack initiation at localized stress concentrations. The main differences between the effects of seam welds on the AA6063 and AA6082 alloys is that variations in fatigue properties between the $A$ and $C$ wall do not exist for the AA6063 extrusions. This results from the negligible differences in roughness on different profile walls in the AA6063 extrusion. The fatigue lives of L-W AA6063 specimens were very similar to those of AA6063 L-NW specimens. As was the case for L-W AA6082 specimens, the scatter in fatigue lives of L-W AA6063 specimens was higher $\left(R^{2}=0.55\right)$ compared to L-NW AA6063 specimens $\left(R^{2}=0.92\right)$. 


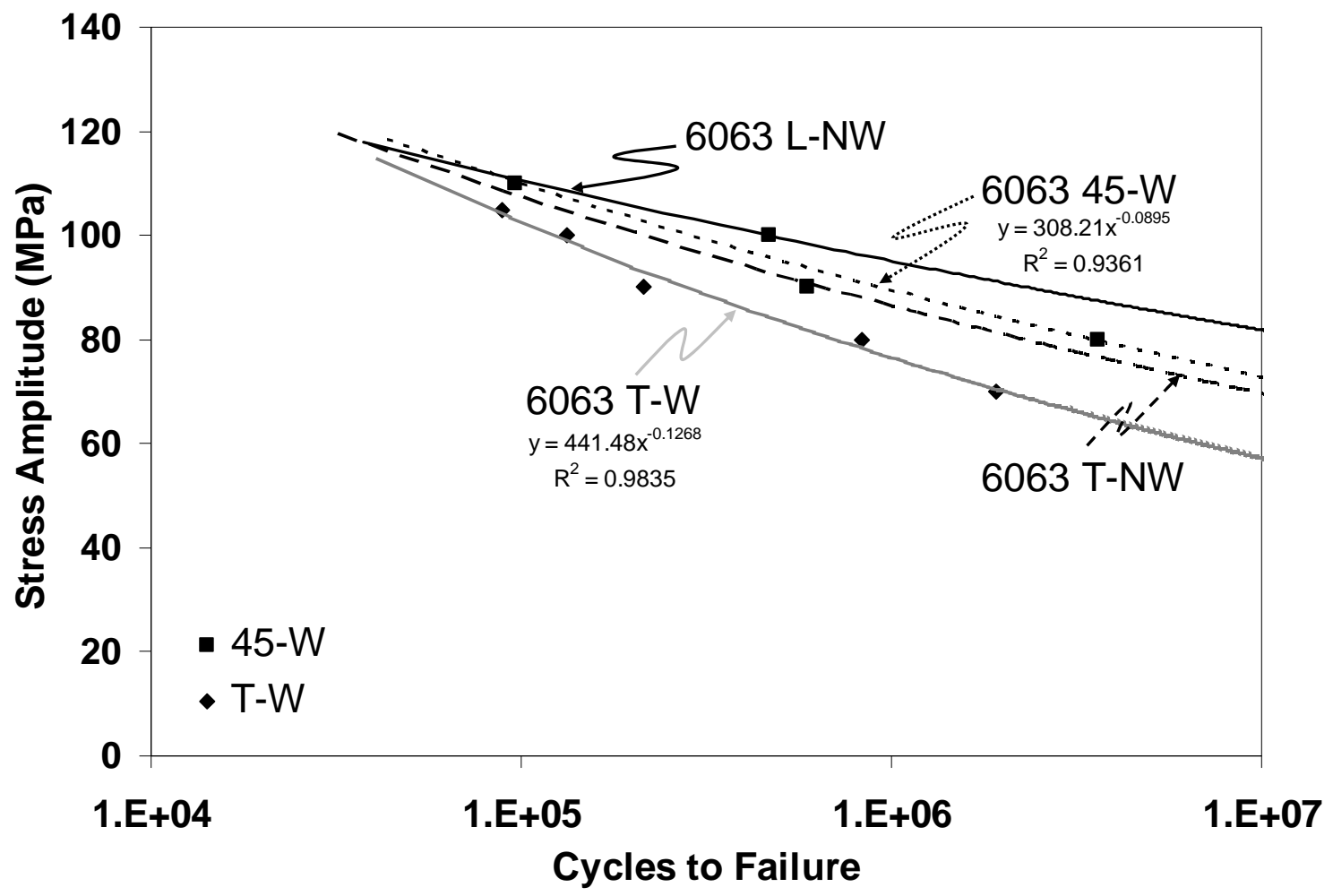

Figure 5-5. S-N curve for peak aged AA6063 45-W and T-W specimens

Fatigue fracture surfaces of L-NW and T-W AA6063 specimens are compared in Figure 5-6. The three stage fatigue process can be viewed in the macrographs in Figure 5-6a\&d. The crack initiation mechanism for L-NW specimens (Figure 5-6a-c), as with L-NW AA6082 specimens, is grain boundary separation. The initial fatigue crack boundary surfaces in the AA6063 alloy are typically larger in area than AA6082. The mechanism of $\mathrm{FCl}$ in non-longitudinal specimens (Figure 5-6d-f) is very similar to that observed for AA6082; with grain boundary initiation occurring at locations where surface grain boundaries are aligned preferentially along die lines. The number of AA6063 fracture specimens examined was 17 , and of those 17,14 exhibited intergranular separation at the 
initiation site and all transverse and $45^{\circ}$ specimens showed separation at die lines.
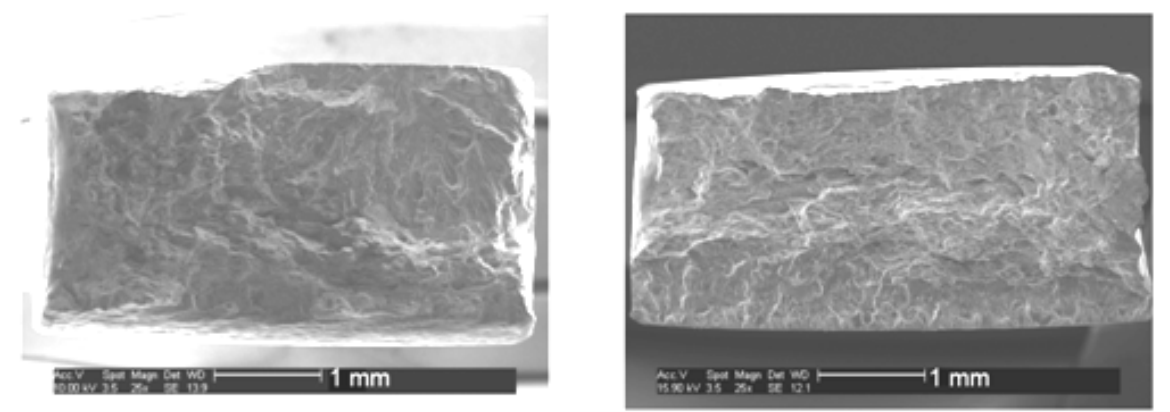

a.

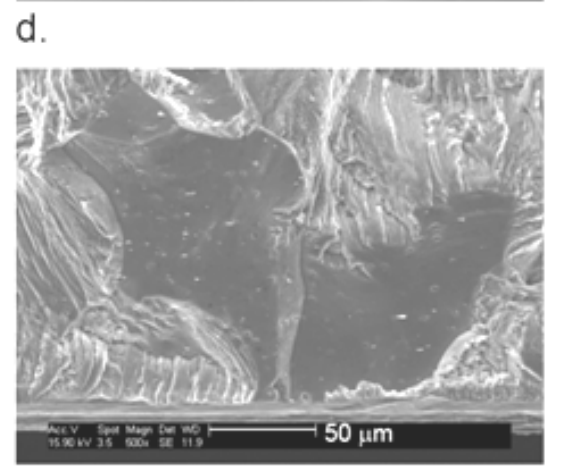

b.

e.
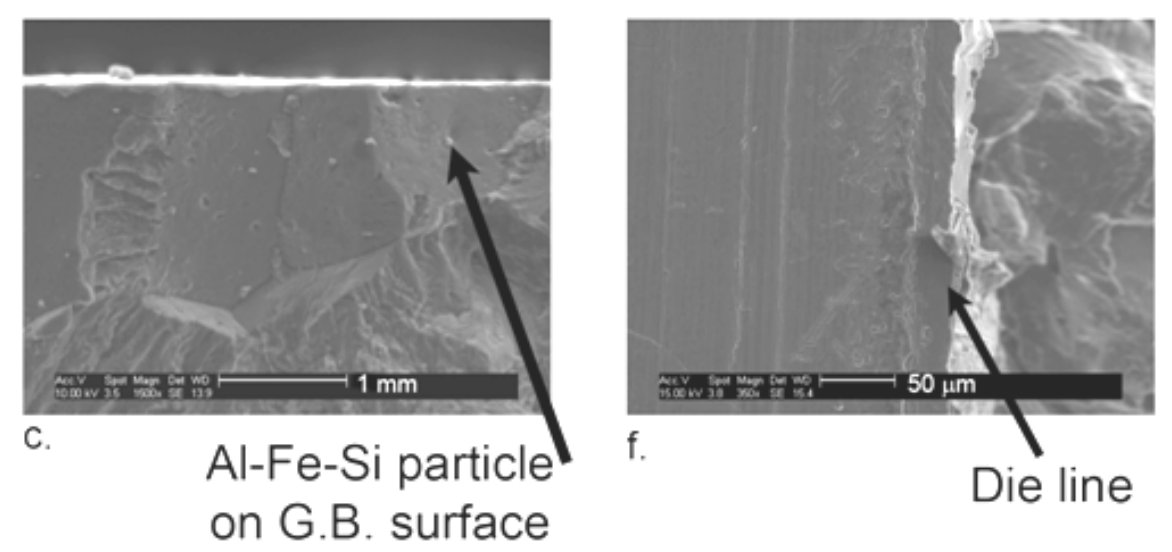

Figure 5-6. SEM fractographs showing fatigue failures in peak aged AA6063 alloy a.-c. Fracture surface of L-NW specimen $\left(\sigma_{a}=90 \mathrm{MPa} N_{f}=1.6 \times 10^{6}\right.$ cycles), d.-e. Fracture surface of T-W specimen $\left(\sigma_{a}=105 \mathrm{MPa} \mathrm{N} \mathrm{N}_{\mathrm{f}}=1 \times 10^{5}\right.$ cycles), $\mathbf{f}$. Fracture face of specimen in $\mathrm{d}$. and e. showing initiation at die line 
Fractographs from the 45-W specimen shown in Figure 5-7 assist in further clarifying the relationship between grain boundary failures at die line stress concentrations. This fatigue specimen was one of only a few specimens that had two stable crack initiation sites (Figure 5-7a). Higher magnification images at the two $\mathrm{FCl}$ sites, Figure 5-7b\&d, display the typical separated grain boundary surfaces found at nearly all $\mathrm{FCl}$ sites in this study. When examining the $\mathrm{FCl}$ sites from the extruded surfaces, Figure 5-7c\&e, a deep die line groove can be seen at both nucleation sites. In fact, the separated grain boundaries have surface boundaries that are aligned along the die line stress concentrations, i.e. $45^{\circ}$ relative to the loading direction. This can be compared to the surface grain leading to $\mathrm{FCl}$ of the $\mathrm{T}-\mathrm{W}$ specimen shown in Figure 5-6e\&f, where the surface boundary failed along the die line perpendicular to the loading direction. Secondary cracks shown in Figure 5-7f\&g also show surface grain boundary separation occurring when the boundary is aligned $45^{\circ}$ relative to the loading direction, also at a deep die line groove. 


\section{Initiation Sites}

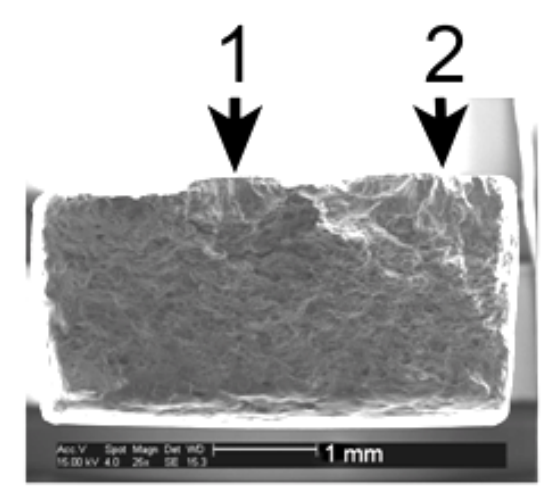

a.
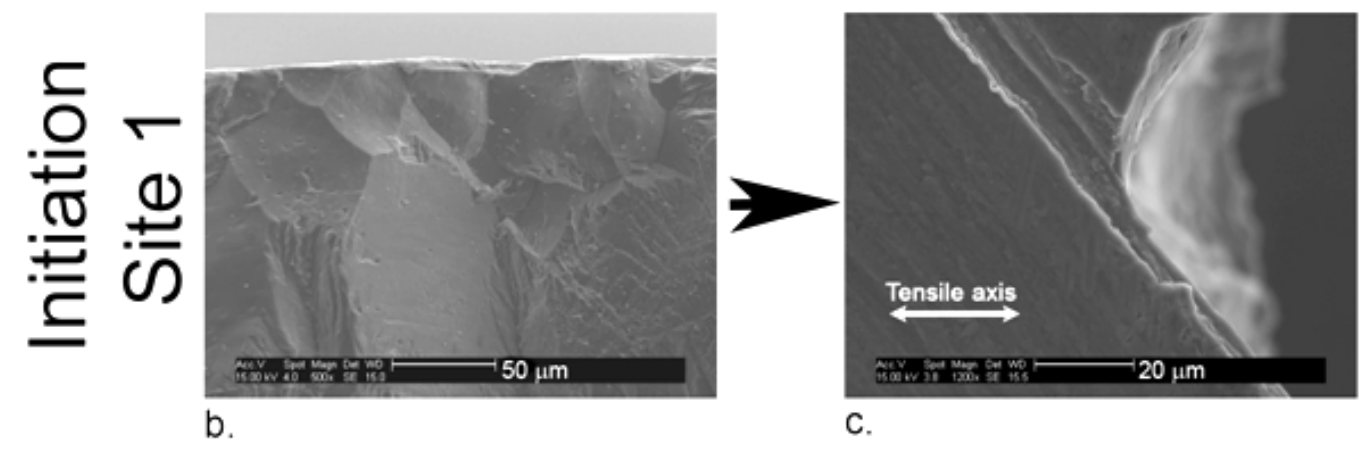

c.
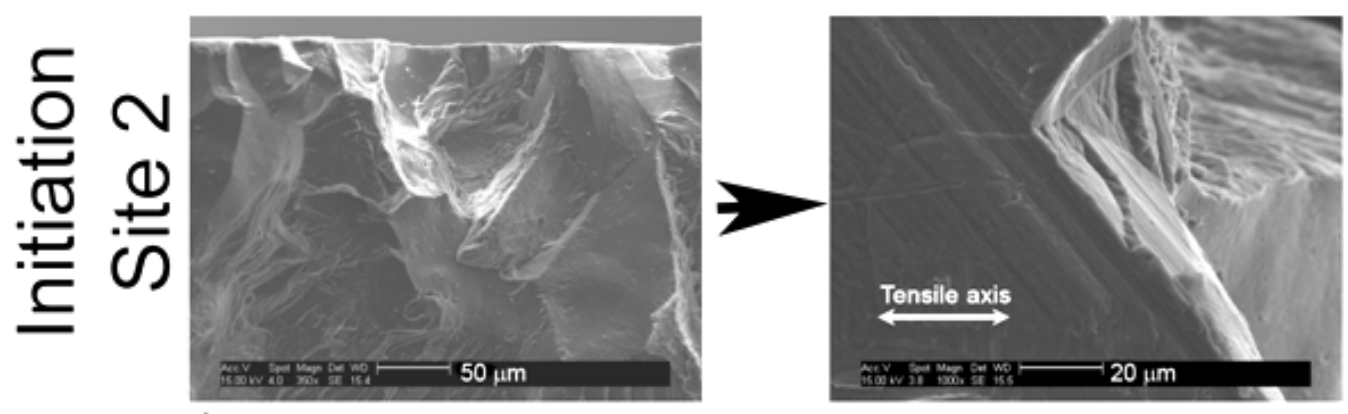

d.

e.
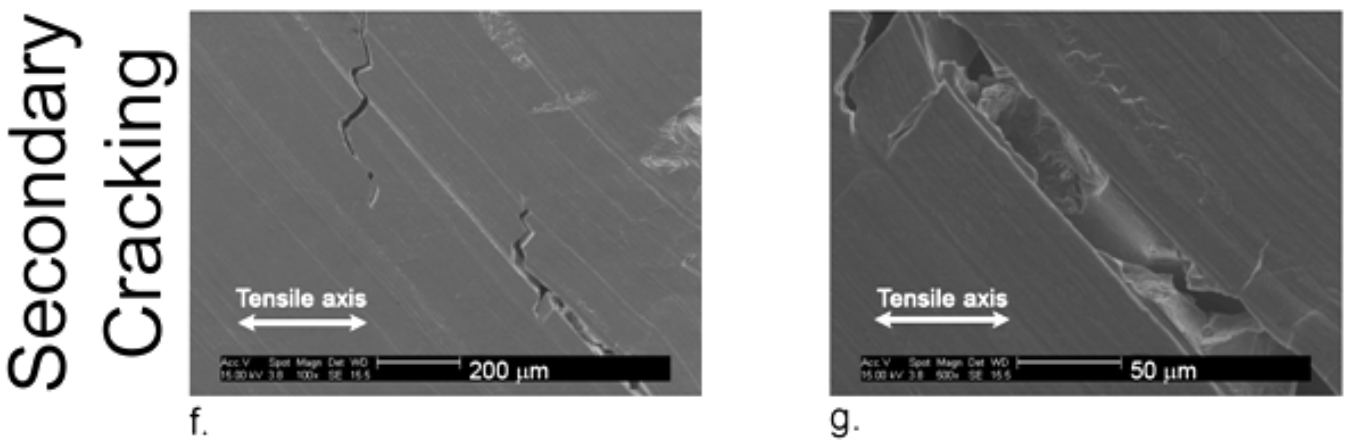

g.

Figure 5-7: SEM fractographs showing primary and secondary cracking at die lines of an AA6063 45-W specimen $\left(\sigma_{\mathrm{a}}=110 \mathrm{MPa}\right.$ and $\mathrm{N}_{\mathrm{f}}=1 \times 1$ 


\subsection{Effect of charge welds}

The tensile properties of transverse AA6063 specimens containing separated charge weld interfaces were similar to baseline specimens taken from zone 3 of the extrusion. The fatigue lives of longitudinal specimens containing charge weld separations was also similar to the baseline curve shown in Figure 5-3. Figure 5-8 is an S-N curve comparing fatigue data for T-W(3) AA6063 specimens (Figure 5-5) with fatigue lives of T-W(2) AA6063 specimens, containing moderately high charge weld separations $(1-8 \mathrm{~mm})$. There is a consistent drop in fatigue life at all three stress levels for specimens containing charge welds from zone 2. Fatigue failure of these specimens typically occurred outside the gauge section, within the shoulder; where some large die line grooves appeared to be present. Unlike T-W(2) AA6082 specimens, failure of the AA6063 specimens did not appear to be associated with the charge weld interfaces. Instead, an increase in roughness for the AA6063 T-W(2) specimens appears to be responsible for the decrease in fatigue lives. 


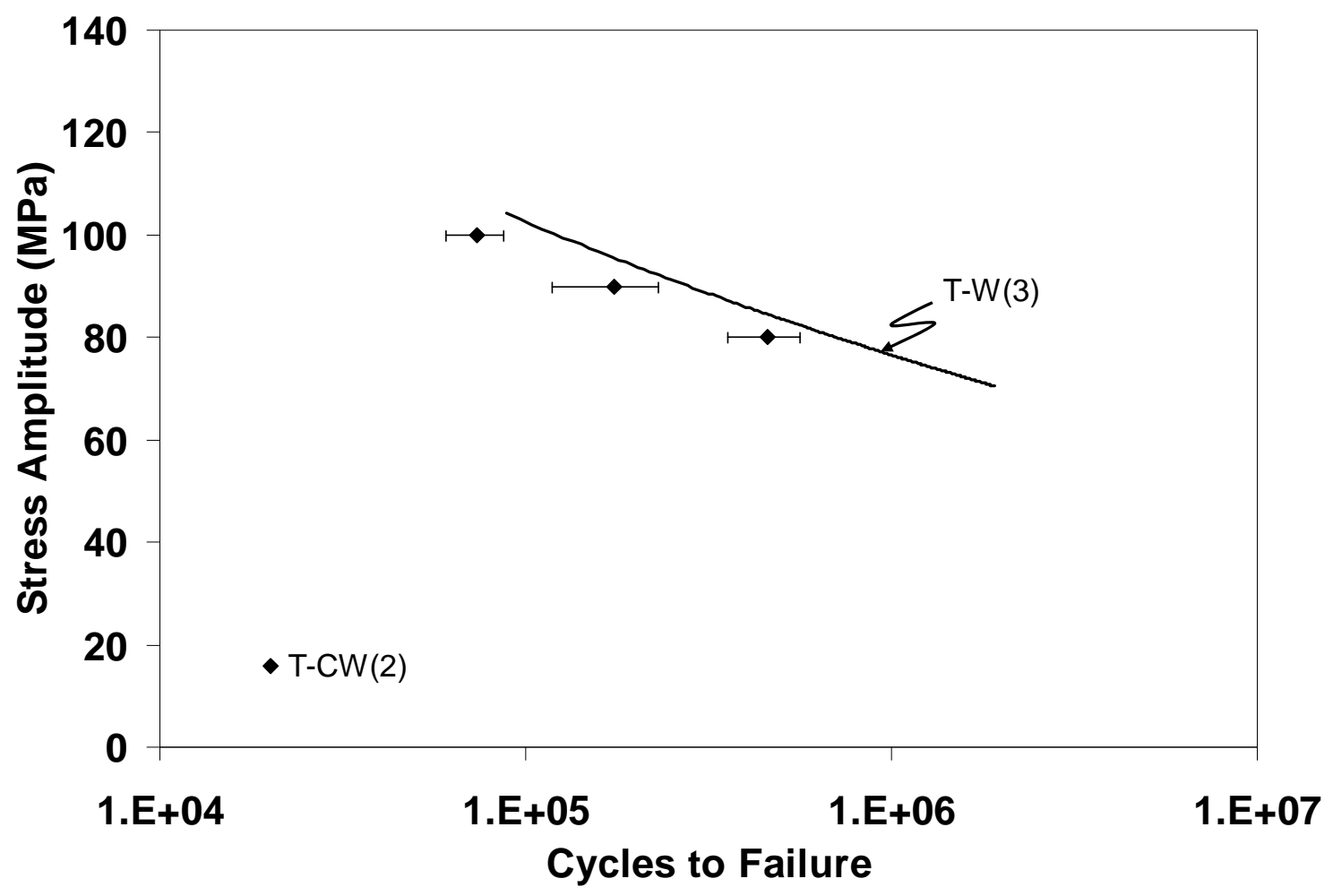

Figure 5-8. Fatigue behavior of peak aged AA6063 T-W(2) and T-W(3) specimens (T-W(3) curve from Figure 5-5)

\subsection{Effect of $\mathrm{NaCl}$ solution}

Figure 5-9 provides the S-N curves for air and salt solution fatigue tests performed on the AA6063 alloy. The stress level corresponding to $1 \times 10^{6}$ cycles to failure for the AA6063 specimens in air and salt solution are 95 and $50 \mathrm{MPa}$, respectively. This corresponds to a $47 \%$ drop in fatigue life, compared to a $54 \%$ for the AA6082 specimens test in the salt solution. Interestingly, the stress level corresponding to $\mathrm{N}_{\mathrm{f}}=1 \times 10^{6}$ cycles occurred at stress amplitudes of $50 \mathrm{MPa}$ for both alloys in the salt solution, even though this fatigue life corresponds to stress amplitudes of $110 \mathrm{MPa}$ and $95 \mathrm{MPa}$ for AA6082 and AA6063 specimens tested in air, respectively. The higher strength, AA6082 alloy appears to be more 
sensitive to the corrosive environment than its lower strength counterpart, AA6063. This can be explained by the lower concentration of constituent and dispersoid phases in the AA6063 alloy that are acting as sites of localized pitting on the surface and lead to exposure at grain boundaries.

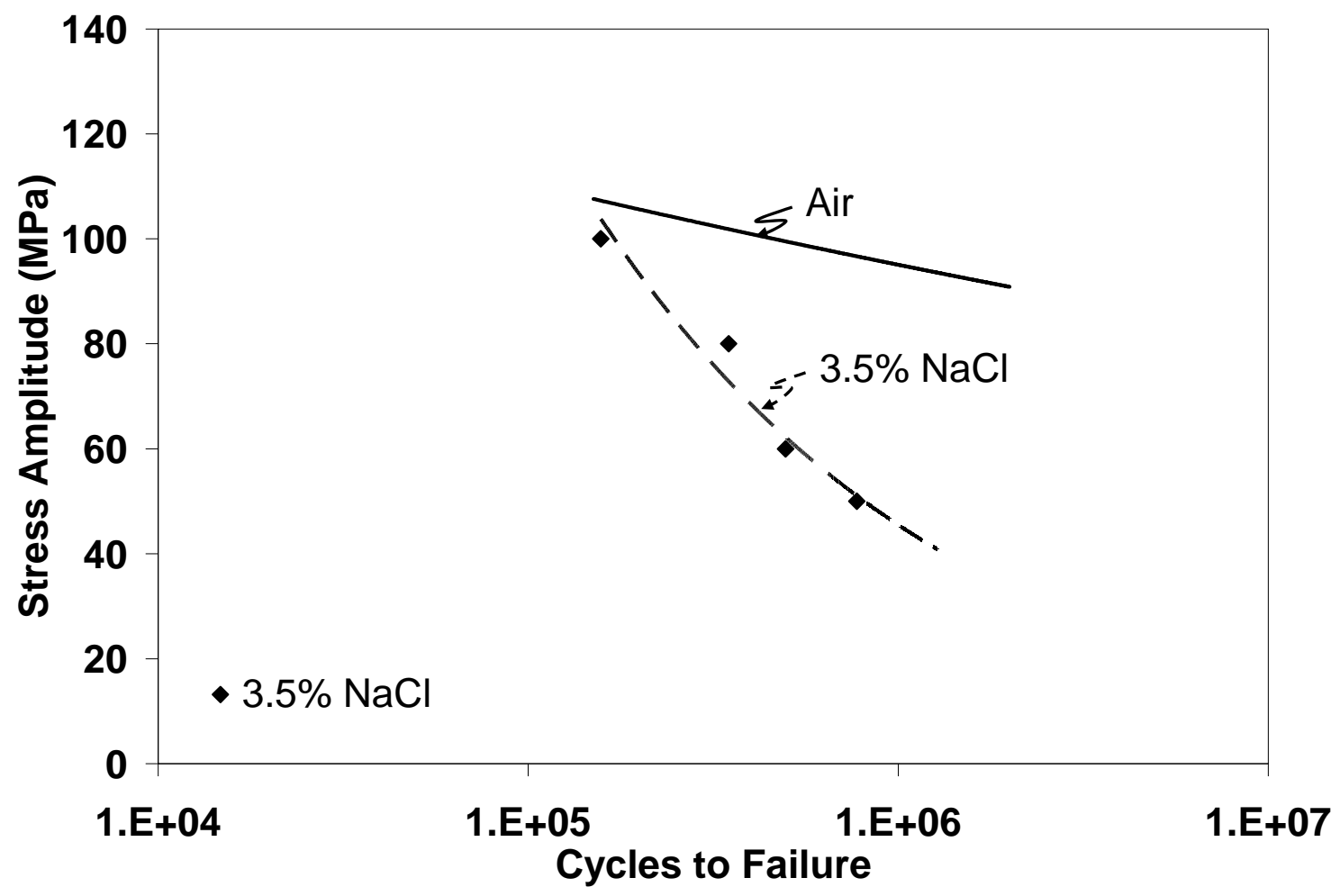

Figure 5-9. Stress-life curve of peak aged L-NW AA6063 specimens tested in air and $3.5 \mathrm{wt} \% \mathrm{NaCl}$ solution

Fractographs of AA6063 specimens tested in air and salt solution are shown in Figure 5-10. Each of these two specimens lasted for $\sim 5 \times 10^{5}$ cycles to failure, with this occurring at $\sigma_{\mathrm{A}}=100 \mathrm{MPa}$ when tested in air and at $60 \mathrm{MPa}$ in the salt solution. The fracture mode of the AA6063 alloy fatigue tested in air 
(Figure $5-10 a-b)$ is similar to that of the higher strength AA6082 alloy, with intergranular separation acting as the initial fatigue crack. Although fatigue crack initiation of both alloys typically occurs at grain boundaries, the fully recrystallized AA6063 alloy exhibited significantly more intergranular failure. AA6063 specimens (tested in air) showed intergranular cracking at both the initiation site and during crack propagation, as well as, some intergranular cracking during tensile testing, unlike the AA6082 specimens which typically only showed intergranular failure near the $\mathrm{FCl}$ site in fatigue specimens. Figure 5-10c\&d shows the failure of the specimen tested in the salt solution. The increased level of intergranular cracking in the salt solution can clearly be observed in these images. In fact, for nearly half of the crack propagation stage the mode of fatigue crack propagation for this specimen was intergranular (Figure 5-10c). Therefore, it appears that the corrosion-fatigue behavior of the AA6063 alloy is similar to the fatigue of the alloy in air, except that the intergranular failure mode is greatly facilitated by corrosion in the vicinity of the grain boundaries. 


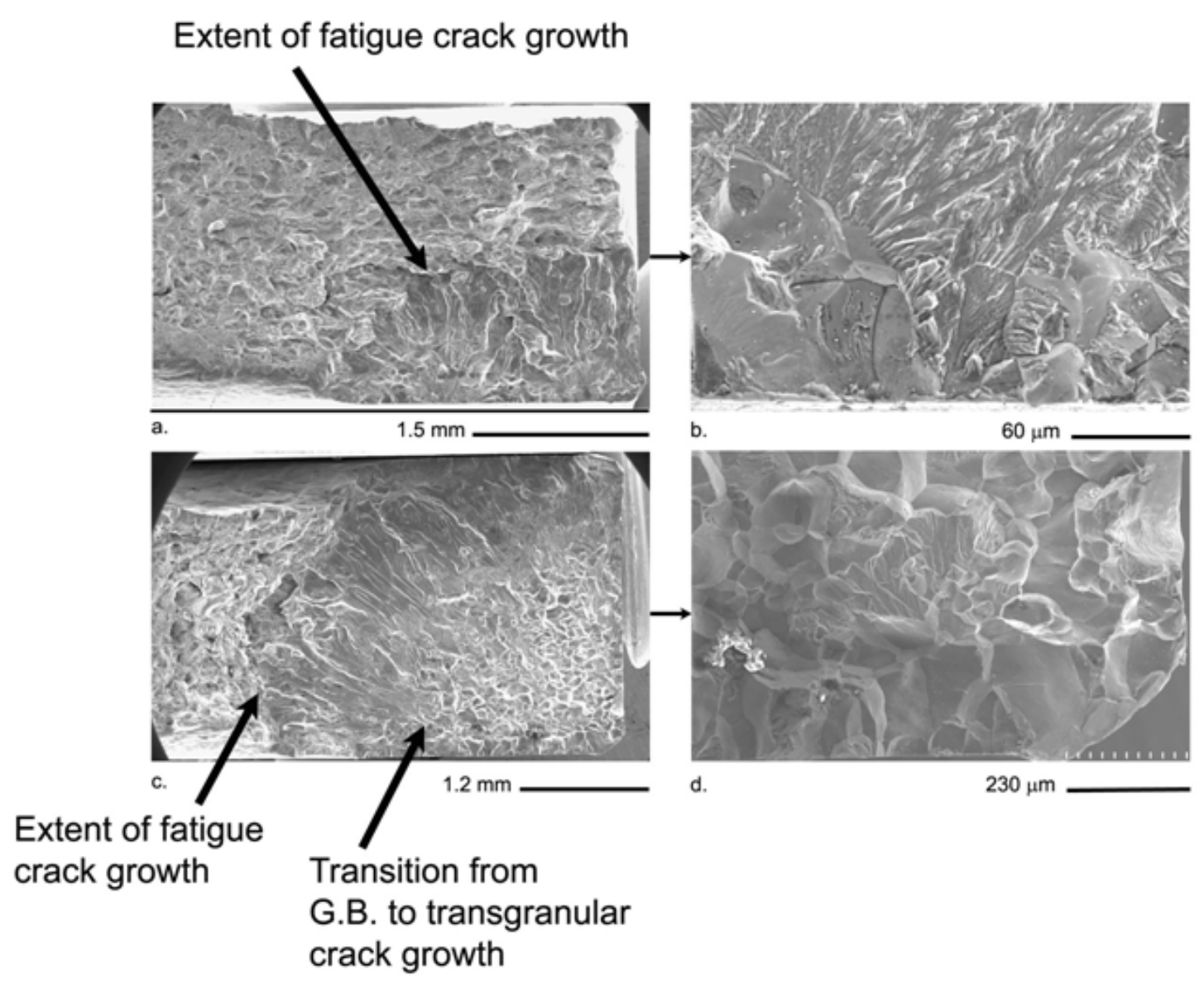

Figure 5-10. Scanning micrographs of fatigued L-NW AA6063 specimens tested in air ( $\mathbf{a} \& \mathbf{b}, \sigma_{\mathrm{a}}=100 \mathrm{MPa}, \mathrm{N}_{\mathrm{f}}=5 \times 10^{5}$ cycles) and in $\mathrm{NaCl}$ solution $\left(\mathbf{c} \& \mathbf{d}, \sigma_{\mathrm{a}}=\right.$ $60 \mathrm{MPa}, \mathrm{N}_{\mathrm{f}}=5 \times 10^{5}$ cycles). Images $\mathbf{b} \& \mathbf{d}$ show the locations of fatigue crack initiation

Clearly exposure to the aqueous environments, specifically the $3.5 \mathrm{wt} \%$ $\mathrm{NaCl}$ solution, during fatigue testing severely degrades the life of both the AA6082 and AA6063 alloys. The loss in fatigue life of these alloys is most likely the result of premature fatigue crack initiation due to localized grain boundary corrosion and facilitation of fatigue crack propagation along grain boundaries in preference to transgranular propagation, specifically at low stress amplitudes. 
The grain boundaries become exposed to corrosive attack at locations where localized pitting of dispersoid/constituent phases occurs. This mechanism of corrosive attack has been reported for similar AA6XXX alloys with low copper concentrations [28]. The corrosive attack is amplified by cyclic loading that leads to localized accumulation of cyclic strain and/or a continuous break down of the protective oxide film. 


\section{EFFECT OF ROUGHNESS ON RUN-OUT STRESS}

The detrimental effect of surface roughness on fatigue lives is well documented and there have been significant efforts to predict these effects [78$80,82,106,107]$. Many textbooks covering fatigue give mention to empirical models developed by Neuber and Peterson for predicting fatigue life reductions due to notch effects and stress concentrations [5, 12]. These models base predicted fatigue notch factors on the linear elastic stress concentrations, and are generally applicable only during high cycle fatigue testing, where the stress amplitude is low enough that the stress intensifications remain below the yield strength. A recent analysis by As et. al. took a similar approach, where instead of using empirical data for predicting $\mathrm{K}_{\mathrm{t}}$, FEA was used to predict stress concentrations from actual profilometer data on machined AA6082 surfaces [78].

This approach yielded reasonable predictions near run-out stress values and it was shown that the $\mathrm{FCl}$ typically occurred at notches with the highest stress intensifications about $10 \mu \mathrm{m}$ below the surface and not the highest surface stress concentration. This depth dependence could possibly be explained by the triaxial stress state below the surface.

Another approach to predicting fatigue lives of specimens with rough surfaces is through modeling of fatigue crack growth at the roots of surface asperities. Andrews and Sehitoglu developed a computer model to determine the time required to grow an intrinsic crack to a defined length, which was taken to signify failure under various surface roughness parameters [80]. This crack 
growth approach was shown to accurately predict the fatigue lives of steel specimens with two different roughnesses and the model was also shown to predict more scatter in fatigue results as the standard deviation of roughness values increased.

Taylor and Clancy examined the two different approaches, notch and fatigue crack growth, for modeling of fatigue lives of rough specimens [79]. It was shown that the notch approach was more suitable for surface roughness exhibiting high surface asperity heights, while low roughness values could be predicted better using the fatigue crack growth method. It should be noted that neither approach typically addresses possible effects of variations in surface chemistry, residual stresses, microstructures and hardness, all of which are critical intrinsic features that could affect fatigue crack initiation.

A simple FEA approach was used to approximate the effects of die line surface roughness on the fatigue properties of extruded AA6082 and AA6063 observed in this work. The die lines are modeled as notches with various depths related to the roughness parameter $\mathrm{R}_{\mathrm{t}}$.

\subsection{FEM Modeling}

Die line surface roughness was found to be a major contributor to loss in fatigue life of non-longitudinal specimens for both AA6082 and AA6063 alloys, therefore an FEM technique was used to model the effect of die lines on fatigue properties. The simplest way to model the effects of die lines is to utilize a static stress concentration factor to estimate low stress run-out (endurance limit) 
values. A rectangular notch, $125 \mu \mathrm{m}$ wide and extending across the gauge section was used to approximate the die lines in transverse and $45^{\circ}$ orientations. FEA was used to estimate the stress field for notches of depth ranging up to 70 $\mu \mathrm{m}$. The stress concentration factors for notched specimens were calculated as the maximum local stress divided by the nominal applied stress with FEA analysis. These results are plotted as a function of notch depth in Figure 6-1. As expected, the stress concentration factors increase with notch depth. The highest stress concentrations in the notched specimens occur at the corner of the notch root.

The calculated stress concentration factors in Figure $6-1$ for both $45^{\circ}$ and $90^{\circ}$ orientations were determined by dividing the local stress by the nominal stress, longitudinal to the loading direction. Fatigue crack initiation of longitudinal and transverse specimens typically occurred at grain boundaries that were roughly normal to the applied stress (Figures 4-9, 4-9, 4-15, 5-6). This Mode I crack type simplifies the analysis for longitudinal and transverse specimens since the longitudinal stresses (local and applied) are primarily responsible for the crack opening. Fatigue crack initiation in specimens taken $45^{\circ}$ relative to the extrusion direction appears to be more complicated with mixed Mode I (tensile) and Mode III (shear) cracking (Figure 5-7), where the initial cracks occurred at grain boundaries oriented along die lines. Shear stresses and shear microplasticity are known to play an important role in $\mathrm{FCl}$ and Stage I fatigue crack growth, while Mode I opening is generally considered most important in 
Stage II fatigue crack growth. The effective shear stresses complicate the FEA analysis of $45^{\circ}$ specimen orientations and determination of shear stress concentrations associated with these specimens is beyond the scope of this project. The use of longitudinal stresses may be somewhat justified though, since the initial crack along the die line, shown in Figure 5-7, appears to quickly transition to Mode I cracking, normal to the loading direction. The values for stress concentration as a function of notch depth of $45^{\circ}$ orientations, in Figure 61 , are all lower than those of transverse orientations. Also, the trend is more linear for the $45^{\circ}$ orientation.

Stress concentrations from actual die line profiles were also calculated by inputting profilometer scans into the modeling program. Scans from a $\mathrm{C}$ wall specimen (across the seam weld surface) and a B wall specimen were modeled with FEA and stress concentrations are plotted in Figure 6-1. The modeled C and B wall stress concentrations, when oriented transversely, generally agreed with the trend in stress concentration as a function of notch depth. 


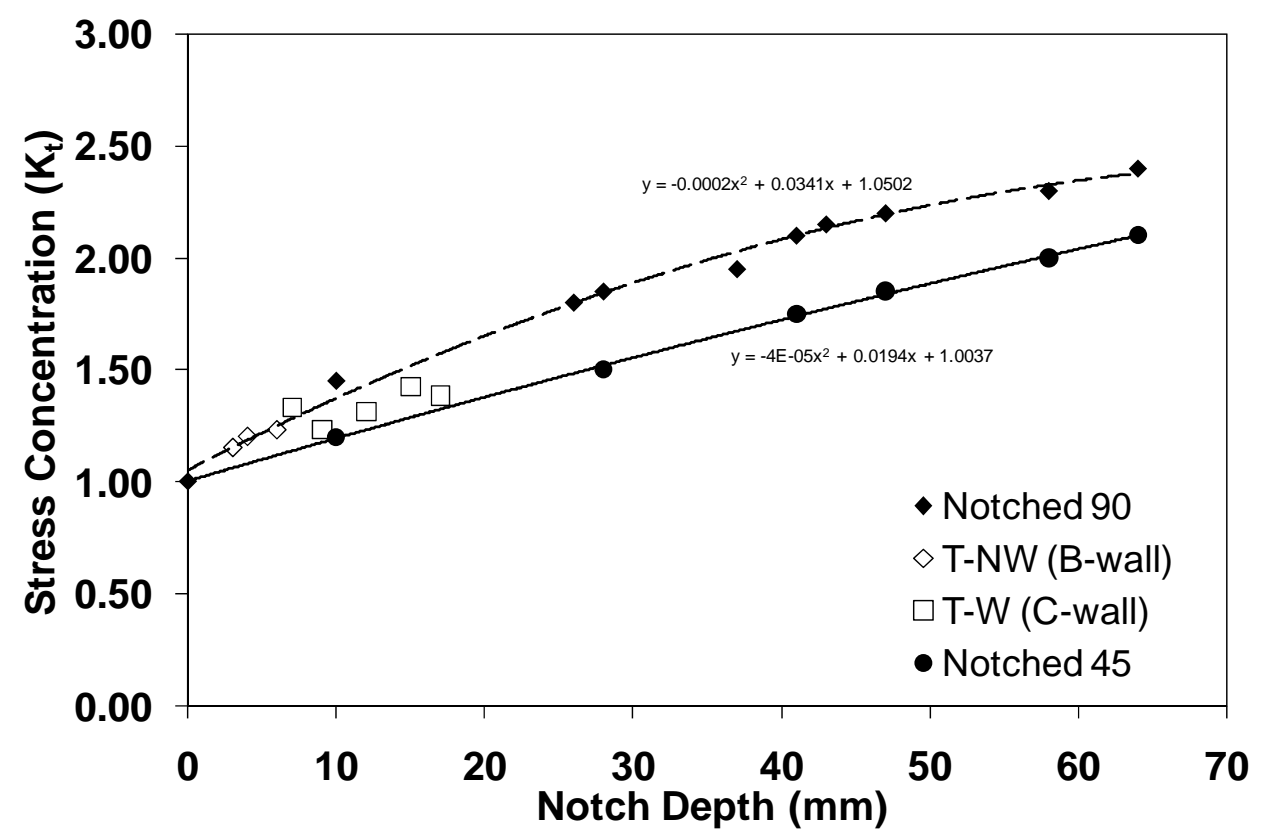

Figure 6-1. Static stress concentration as a function of notch/die line depth

Since the calculated stress concentrations for actual die line profiles agree reasonably well with the trend for rectangular notches in Figure 6-1, these curves were used to estimate the stress intensification for transverse and $45^{\circ}$ fatigue specimens of both AA6082 and AA6063 extrusions, where the roughness was known. The third column in Table 6-1 shows the averaged experimental roughness values for $\mathrm{T}-\mathrm{NW}, 45-\mathrm{NW}, \mathrm{T}-\mathrm{W}$ and $45-\mathrm{W}$ specimens from both extrusions. The stress intensity values for L-NW specimens was assumed to be unity, and the curve in Figure 6-1 was used to estimate the stress intensity due to die line roughness in the non-longitudinal specimens (column four). These stress intensity values were used along with the experimentally observed endurance limits for L-NW specimens to estimate endurance limits for the transverse and $45^{\circ}$ specimens ( $\mathrm{L}-\mathrm{W}$ endurance limit divided by $\mathrm{K}_{\mathrm{t}}$ ). The lower stress amplitudes 
associated with endurance limits should most nearly satisfy the assumptions associated with this strictly elastic stress analysis. Conversely, at moderate to high stress amplitudes where fatigue life depends more strongly on the applied stress amplitude, stress concentrations at deep die lines could induce sufficient plasticity to invalidate the use of this linearly elastic analysis in predicting localized stresses [12].

Table 6-1. Prediction of run-out stress values from profilometer roughness

\begin{tabular}{|c|c|c|c|c|c|c|}
\hline Alloy & $\begin{array}{l}\text { Specimen } \\
\text { Type }\end{array}$ & $R_{t}(\mu \mathrm{m})$ & $K_{t}$ & $\begin{array}{l}\text { Predicted } \\
\text { Limit (MPa) }\end{array}$ & $\begin{array}{l}\text { Experimental } \\
\text { Limit (MPa) }\end{array}$ & $K_{f}$ \\
\hline \multirow{4}{*}{ AA6082 } & L-NW & - & 1.00 & \multicolumn{2}{|c|}{99} & 1.00 \\
\hline & 45-W & 18.50 & 1.35 & 73 & 68 & 1.46 \\
\hline & T-NW & 10.80 & 1.40 & 71 & 70 & 1.41 \\
\hline & T-W & 18.50 & 1.61 & 61 & 70 & 1.41 \\
\hline \multirow{5}{*}{ AA6063 } & L-NW & - & 1.00 & \multicolumn{2}{|c|}{80} & 1.00 \\
\hline & 45-NW & 7.70 & 1.15 & 70 & 80 & 1.00 \\
\hline & 45-W & 13.68 & 1.26 & 64 & 73 & 1.10 \\
\hline & T-NW & 7.70 & 1.30 & 62 & 70 & 1.14 \\
\hline & $T-W$ & 13.68 & 1.48 & 55 & 60 & 1.33 \\
\hline
\end{tabular}

The predicted run-out stresses for T-NW and T-W specimens in column five of Table 6-1 are generally in good agreement with the experimentally observed values in column six for the AA6082 alloy, with the exception of the TW specimens. The endurance limit predictions for AA6063 specimens are all slightly lower than actual values. Linear elastic stress concentration factors are typically more conservative approximations in predicting run-out stress values, most likely due to intrinsic material properties and the volume of stress fields [12]. 
It appears though, that this method does provide a reasonably conservative first approximation for predicting fatigue lives of extrusions containing die line surface roughness.

This approximation is rather crude and significant improvements could be performed to more accurately predict the effect of surface roughness. The approach taken by As et. al. in modeling the stress concentrations associated with an actual surface may improve the predictive capabilities, compared to the present method of representing die lines as notches of consistent size and shape. Also, $\mathrm{FCl}$ in this study involved both grain boundary separation and die line stress concentrations. Statistical factors governing the spatial distribution of deep die lines and their spatial correspondence with grain boundaries intersecting the surface was not considered. Another source of error arises by the use of composite $R_{t}$ values of the inside and outside faces of the $A$ and $C$ wall, which were shown to vary considerably for the AA6082 alloy (Table 4-1). This roughness variation resulted in different fatigue endurance limits for the nonlongitudinal AA6082 fatigue specimens taken from the A and $C$ wall, shown in Figure 4-13. The shear stress contributions for $45^{\circ}$ orientations were not considered, and this is expected to further increase the error in the predicted runout stress values for these specimens.

The discrepancy between endurance limit predictions of the two alloys suggests that the situation may be more complex than a model based solely on stress intensification can predict. It would be interesting to take a fatigue crack 
growth approach similar to that of Andrews and Sehitoglu, since the assumption of intrinsic cracks is most likely satisfied by considering separated grain boundaries in AA6082 and AA6063. Using this method, both the effect of surface roughness and grain size on fatigue lives could be simultaneously studied. 


\section{CONCLUSIONS}

1. Surface roughness, resulting from die lines, contributes significantly to a reduction in fatigue life for both AA6082 and AA6063 specimens having non-longitudinal orientations. The greater die line roughness of the AA6082 specimens relative to AA6063 specimens results in more severe reductions in fatigue lives for transverse specimens.

2. Removal of die line surface features on transverse AA6082 specimens by polishing, while retaining most of the recrystallized surface layer, significantly reduced the differences between fatigue lives of longitudinal and transverse specimens. This implies a lack of microstructural anisotropy when surface recrystallized layers are present.

3. Removal of the recrystallized surface layer from AA6082 specimens, leaving only the fibrous core, results in fatigue strengths that are significantly higher than for the base line L-NW specimens. Maximum stresses for run-out specimens $\left(N_{f}=1 \times 10^{7}\right.$ cycles $)$ actually exceed the $0.2 \%$ offset yield stress. These fully fibrous specimens also exhibited little difference when tested in longitudinal and transverse orientations. Given the extreme microstructural anisotropy of these specimens, this insensitivity of fatigue performance to orientation is unexpected. 
4. Fatigue crack initiation for all specimen types typically involoved intergranular separation. This is most likely a result of lower strength grain boundary precipitate free zones, observed through TEM analysis. When die lines are oriented at either $45^{\circ}$ or $90^{\circ}$ to the loading direction, grain boundary separation at the crack initiation site occurs where surface grain boundaries are aligned along a die line stress concentration.

5. When testing transverse specimens with as-extruded surfaces, the presence of a seam weld in the gauge section further reduces the fatigue life of specimens when compared to transverse specimens without welds. This is mainly associated with increased die line surface roughness at seam weld locations. Removal of the surface roughness from transverse specimens with welds results in fatigue lives similar to longitudinal specimens without welds. This result implies that seam welds themselves do not affect high cycle fatigue life.

6. AA6082 Specimens with orientations transverse to the extrusion direction containing charge welds with interface separations between 0.25 and $8 \mathrm{~mm}$ result in a slight reduction in fatigue life. This reduction is associated with premature overload failure at charge weld interfaces. 
7. Small variations in aging time and temperature results in minor changes in precipitate size and distribution and yields slight changes in tensile properties. Differences in fatigue lives of specimens with aging variations correlate well with yield strength variations.

8. Fatigue specimens exposed to a $3.5 \% \mathrm{NaCl}$ solution during testing showed drastic reductions in fatigue lives for both alloys. The corrosion-fatigue behavior is associated with rapid pitting of secondary phases and exposure of grain boundaries to corrosion, leading to eventual premature fatigue crack initiation. The more highly alloyed AA6082 alloy showed greater susceptibility to corrosion-fatigue, which can be attributed to the higher density of secondary phases.

9. Fatigue testing of AA6082 specimens at an elevated temperature of $150^{\circ} \mathrm{C}$ showed a reduction in fatigue behavior of longitudinal specimens without welds. This reduction is mainly associated with residual stress relaxations at burnished corners and oxide generation at free crack surfaces. Transverse specimens with seam welds in the gauge, tested at $150^{\circ} \mathrm{C}$ and ambient temperatures, showed no differences in fatigue properties. 


\section{FUTURE WORK}

1. Since die lines were found to be quite detrimental to fatigue lives of specimens having non-longitudinal orientations, more work should be focused on minimizing roughness through extrusion parameters and alloying. The effect of die lines overrides both microstructural effects and seam and charge weld effects in high cycle fatigue.

2. The microstructure of $A A 6082$ extrusions with a recrystallized surface layer may not be the most suitable one for fatigue applications. This appears to result from the detrimental influence of the recrystallized grains on fatigue crack initiation. Specimens that were entirely fibrous exhibited excellent fatigue properties and a surprising absence of anisotropy in fatigue behavior. Additional fundamental study of fatigue crack initiation and propagation in fully fibrous microstructures would be useful in understanding these observations. From a more practical perspective, exploration of extrusion conditions that minimize or eliminate the recrystallized layer, and its influence on fatigue behavior would be very interesting.

3. More research into PFZ formation during extruding and fatigue initiation at grain boundaries in AA6XXX alloys would be useful.

4. The effects of exposure to salt solutions resulted in extensive degradation of fatigue properties in both alloys. The effect of testing frequency on fatigue behavior should be further examined, since 
mixed results on the dependency of frequency on fatigue lives were found in this study. 


\section{REFERENCES}

[1] Pedersen K, Segle P, Hagstrom J, Furu T, Ekstrom, HE. The effect of pre-strain on the fatigue life properties of AA6063 and AA6082. Aluminium 2004;80(6):747-752.

[2] White C, Andersen O, Bauger O, Furu T. Fatigue of extruded Al-Mg-Si alloys. In: Fatigue and durability - Fatigue of base materials Sunndalsora, NO: Hydro Aluminium R\&D Materials Technology, 2005.

[3] Pedersen K, Lohne $\mathrm{O}$, Helgeland $\mathrm{O}$. The effect of grain structure on fatigue life of age hardening aluminum alloys. Fracture and the role of microstructure, Vol. 2 Leoben, Austria, 1982, pp. 495-502.

[4] Pedersen K. Fatigue mechanism in an AlMgSi alloy. In: Fourth international conference on fatigue and fatigue thresholds, Vol. 1 Honolulu, HI, 1991, pp. 99-104.

[5] Suresh S. Fatigue of materials. New York, NY: Cambridge University Press, 1991.

[6] Courtney T. Mechanical Behavior of Materials. USA: McGraw-Hill Higher Education, 2000.

[7] Kim WH, Laird C. Crack nucleation and stage I propagation in high strain fatigue - I. Microscopic and interferometric observations. Acta Metallurgica 1978;26(5):777-787.

[8] Kim WH, Laird C. Crack nucleation and stage I propagation in high strain fatigue - II. Mechanism. Acta Metallurgica 1978;26(5):789-799.

[9] Neumann P. Cyclic deformation and crack initiation. Fatigue '87 Charlottesville, VA, 1987, pp. 3-22.

[10] Neumann P. Preferred locations for fatigue crack initiation. High Cycle Fatigue of Structural Materials Indianapolis, IN, 1997, pp. 145-155.

[11] Davidson DL, Tryon RG, Oja M, Matthews R, Ravi Chandran KS. Fatigue crack initiation in WASPALOY at 20 degrees C. Metallurgical and Materials Transactions A 2007;38A(13):2214-2225.

[12] Dowling NE. Mechanical Behavior of Materials. Englewood Cliffs, NJ: Prentice-Hall, Inc., 1993.

[13] Srivatsan TS, Anand S, Narendra N. Mechanisms governing deformation and damage during elevated-temperature fatigue of an aluminum-magnesium-silicon alloy. Journal of Materials Engineering and Performance 1997;6(2):187-198.

[14] Srivatsan TS. Mechanisms governing cyclic deformation and failure during elevated temperature fatigue of aluminum alloy 7055 . International Journal of Fatigue 1999;21(6):557-569.

[15] Sharma SC. Fatigue deformation characteristics of aged aluminium lithium alloys at elevated temperature. Materials Science Forum 1996;217-222(3):1355-1358.

[16] Genel K. The effect of pitting on the bending fatigue performance of high-strength aluminum alloy. Scripta Materialia 2007;57(4):297-300.

[17] Harlow DG, Wei RP. A probability model for the growth of corrosion pits in aluminum alloys induced by constituent particles. Engineering Fracture Mechanics 1998;59(3):305325.

[18] Wei RP, Harlow GD. Corrosion and corrosion fatigue of aluminum alloys: chemistry, micromechanics, and reliability. Air Force Office of Scientific Research, 1998.

[19] Zamber JE, Hillberry BM. Probabilistic approach to predicting fatigue lives of corroded 2024-T3. AIAA Journal (USA) 1999;37(10):1311-1317.

[20] Chlistovsky RM, Heffernan PJ, DuQuesnay DL. Corrosion-fatigue behaviour of 7075-T651 aluminum alloy subjected to periodic overloads. International Journal of Fatigue 2007;29(9-11):1941-1949.

[21] Dervenis CP, Meletis El, Hochman RF. Corrosion fatigue of Al-Li alloy 2090. Materials Science and Engineering A 1988;102(2):151-160.

[22] Ebtehaj K, Hardie, D, Parkins RN. Environment sensitive fracture of Al-Si-Mg alloy 6082. British Corrosion Journal 1989;24(3):183-188.

[23] Elboujdaini M, Shehata MT. Stress corrosion cracking and corrosion fatigue of 5083 and 6061 aluminum alloys. Microstructural Science 1997;25:41-49. 
[24] Haase I, Nocke K, Worch H, Zouhar G, Tempus G. An investigation of the fatigue behaviour of aluminium alloy AA 6013 T6 in a corrosive medium. Praktische Metallographie 2001;38(3):119-137.

[25] Eckermann F, Uggowitzer PJ, Schmutz P. Influence of composition and roughness on localized corrosion of Al-Mg-Si alloys characterized by microelectrochemistry. Materials Science Forum 2006;519-521(1):635-640.

[26] Minoda T, Yoshida $\mathrm{H}$. Effect of grain boundary characteristics on intergranular corrosion resistance of 6061 aluminum alloy extrusion. Metallurgical and Materials Transactions $A$ 2002;33A(9):2891-2898.

[27] Shaw BA, McCosby MM, Abdullah AM, Pickering HW. The localized corrosion of Al 6XXX alloys. In: JOM, Vol. 53, 2001, pp. 42-46.

[28] Shi A, Shaw BA, Sikora E. The role of grain boundary regions in the localized corrosion of a copper-free 6111-like aluminum alloy. Corrosion 2005;61(6):534-547.

[29] Svenningsen G, Larson MH, Walmsley JC, Nordlien JH, Nisancioglu K. Effect of artificial aging on intergranular corrosion of extruded AlMgSi alloy with small Cu content. Corrosion Science 2006;48(12):1528-1543.

[30] Yamaguchi K, Tohma K. Effect of $\mathrm{Zn}$ addition on intergranular corrosion resistance of AlMg-Si-Cu alloys. 6th international conference on aluminum alloys, Vol. 3 Toyohashi, Japan, 1998, pp. 1657-1662.

[31] Park JO, Paik CH, Huang YH, Alkire RC. Influence of Fe-rich intermetallic inclusions on pit initiation on aluminum alloys in Aerated $\mathrm{NaCl}$. Journal of Electrochemical Society 1999;146(2):517-523.

[32] Braun R. Investigation on microstructure and corrosion behaviour of 6XXX series aluminium alloys. Materials Science Forum 2006;519-521(1):735-740.

[33] Burleigh TD, Rennick RC, Bovard FS. Corrosion potential for aluminum alloys measured by ASTM G 69. Corrosion 1993;49(8):683-685.

[34] Metals Hanbook 9th Edition. Metals Park, OH: American Society for Metals, 1979.

[35] HydroAluminium. Profile Specifications UK. 2006.

[36] Parson N, Barker S, Shalanski A, Jowett CW. Control of grain structure in Al-Mg-Si extrusions. Eight International Aluminum Extrusion Technology Seminar, Vol. 1 Orlando, FL, 2004, pp. 11-22.

[37] Pedersen KO, Lademo OG, Berstad T, Furu T, Hopperstad OS. Influence of texture and grain structure on strain localisation and formability for AIMgSi alloys. Journal of Materials Processing Technology 2008;200(1-3):77-93.

[38] Sweet ED, Caraher SK, Danilova NV, Zhang X. Effects of extrusion parameters on coarse grain surface layer in 6XXX-series extrusions. Eight International Aluminum Extrusion Technology Seminar, Vol. 1 Orlando, FL, 2004, pp. 115-126.

[39] van Geertruyden W, Misiolek WZ, Wang PT. Analysis of peripheral coarse grain recrystallization in 6XXX aluminum alloy extrusion. Eight International Aluminum Extrusion Technology Seminar, Vol. 1 Orlando, Fl, 2004, pp. 107-113.

[40] Birol Y. The effect of processing and Mn content on the T5 and T5 properties of AA6082 profiles. Journal of Materials Processing Technology 2006;173:84-91.

[41] Blind JA, Martin JW. The effect of dispersoids on the micromechanisms of crack extension in Al-Mg-Si alloys. Journal of Materials Science 1983;18(4):1224-1234.

[42] Busby AK, Edwards L, Martin JW. Effect of aging and dispersoid content on tensile properties of Al-0.6Mg-1Si alloys. Materials Science and Technology 1986;2(4):363-367.

[43] Edwards L, Busby AK, Martin JW. Effect of aging and dispersoid content on fatigue crack growth in Al-Mg-Si alloys. Materials Science and Technology 1986;2(8):823-828.

[44] Edwards GA, Stiller K, Dunlop GL, Couper MJ. The precipitation sequence in Al-Mg-Si alloys. Acta Metallurgica 1998;46(11):3893-3904.

[45] Jacobs $\mathrm{MH}$. The structure of the metastable precipitates formed during ageing of an AlMg-Si alloy. Philosophical Magazine 1978;26(1):1-13.

[46] Lutts A. Pre-precipitation in Al-Mg-Ge and Al-Mg-Si Acta Metallurgica 1961;9:577-586. 
[47] Marioara CD, Nordmark H, Andersen SJ, Holmestad R. Post-b" phases and their influence on microstructure and hardness in 6XXX Al-Mg-Si alloys. Journal of Materials Science 2006;41(2):471-478.

[48] Thomas G. The ageing characteristics of aluminium alloys. Journal of the Institute of Metals 1961-62;90:57-63.

[49] Shercliff HR, Ashby MF. A process model for age hardening of aluminium alloys. Acta Metallurgica 1990;38(10):1787-1812.

[50] Shuey RT, Suni JP, Tiryakioglu M. A comparison of aging models on alloy 6061. Materials Forum 2004;28:118-123.

[51] Jiang DM, Hong BD, Lei TC. Fatigue fracture behavior of an underaged Al-Mg-Si alloy. Scripta Materialia 1990;24(4):651-654.

[52] Jiang DM, Hong BD, Lei TC, Downham DA, Lorimer GW. Influence of aging condition on tensile and fatigue fracture behaviour of aluminium alloy 6063. Materials Science and Technology 1991;7(11):1010-1014.

[53] Bjerkaas H, Fjeldbo SK, Roven HJ, Hjelen J, Chiron R, Furu T. Study of microstructure and texture evolution using in-situ EBSD investigations and SE imaging in SEM. Materials Science Forum 2006;519-521(1):809-814.

[54] Furu T, Vatne HE. Texture evolution during extrusion of flat AA6060 and AA6082 aluminium profiles. Materials Science Forum 1998;273-275:403-410.

[55] Nanninga N, White C, Furu T, Anderson O, Dickson R. Effect of orientation and extrusion welds on the fatigue life of an Al-Mg-Si alloy. International Journal of Fatigue 2008;20(9):1569-1578.

[56] Shastry CR, Levy M, Joshi A. The effect of solution treatment temperature on stress corrosion susceptibility of 7075 aluminium alloy. Corrosion Science 1981;21(9):673-688.

[57] Field DP, Weiland H, Kunze K. Intergranular cracking in aluminum alloys. Canadian Metallurgical Quarterly 1995;34(3):203-210.

[58] Porter DA, Easterling KE. Phase transformations in metals and alloys. Cheltenham, UK: Nelson Thornes, Ltd, 2001.

[59] De Haas M, van Scherpenzeel, SM, De Hosson, JThM. Grain boundary segregation and precipitation in aluminium alloy AA6061. Materials Science Forum 2006;519-521:467-472.

[60] De Hass M, De Hosson, JThM. Grain boundary segregation and precipitation in aluminium alloys. Scripta Materialia 2001;44(2):281-286.

[61] Misra RDK, Balasubramanian TV, Chakravorty CR. On the correlation of grain boundary segregation behaviour and solute-vacancy interactions in aluminium-lithium alloys. Transactions of the Indian Institute of Metals 1987;40(2):161-169.

[62] Radmilovic V, Taylor C, Lee Z, Tolley A, Mitlin D, Dahmen U. Nanoindentation properties and the microstructure of grain boundary precipitate-free zones (PFZs) in an AlCuSiGe alloy. Philosophical Magazine 2007;87(21):3905-3919.

[63] White C. Recent developments concerning segregation and fracture at grain boundaries. Journal of Vacuum Science and Technology A 1986;4(3):1633-1637.

[64] Cottignies L, Ehrstrom JC, Pillet G, Cialti F. Fatigue behaviour of subscaled specimens and full size welded and non welded AA6082 profiles. International converence on Fatigue of Welded Components and structures Senlis, France, 1996, pp. 199-207.

[65] Gunger S, Edwards L. Effect of surface texture on the initiation and propagation of small fatigue cracks in a forged 6082 aluminium alloy. Materials Science and Engineering $A$ 1993;A160(1):17-24.

[66] Yang HS. Effect of chemistry, extrusion speed and temperature, die design on recrystallized layer thickness in extruded aluminum alloy 6061. Seventh International Aluminum Extrusion Technology Seminar; Shaping the Future of Aluminum Extrusion Technology Chicago, IL, 2000, pp. 371-380.

[67] Akeret R, Strehmel W. Control of metal flow in extrusion dies. Fourth International Aluminum Extrusion Technology Seminar, Vol. 2 Chicago, IL, 1988, pp. 357-367. 
[68] Akeret R. Extrusion welds-quality aspects are now center stage. 5th International Aluminum Extrusion Technology Seminar, Vol. 1 Chicago, IL, 1992, pp. 319-336.

[69] Donati L, Tomesani L. The effect of die design on the production and seam weld quality of extruded aluminum profiles. Journal of Materials Processing Technology 2005;164165:1025-1031.

[70] Donati L, Tomesani L., Minak G. Characterization of seam weld quality in AA6082 extruded profiles. Journal of Materials Processing Technology 2007;191(1-3):127-131.

[71] Valberg $\mathrm{H}$. Extrusion welding in aluminium extrusion. International Journal of Materials And Product Technology 2002;17(7):497-556.

[72] van Rijkom J, Bolt PH, Weeke D. A review of new approaches and technologies in extrusion welds related to the background of existing knowledge. Seventh International Aluminum Extrusion Technology Seminar Chicago, IL, 2000, pp. 249-260.

[73] Loukus A, Subhash G, Imaninejad M. Mechanical properties and microstructural characterization of extrusion welds in AA6082-T4. Journal of Materials Science 2004;39(21):6561-6569.

[74] Johannes V, Jowett, CW, Dickson RF. Transverse weld defects. Sixth international aluminum extrusion technology seminar, Vol. 2 Chicago, IL, 1996, pp. 89-94.

[75] Clode MP, Sheppard T. Formation of die lines during extrusion of AA6063. Materials Science and Technology 1990;6(8):755-763.

[76] Takai T, Takatsuji N, Matsuki K, Tokizawa M, Murotani K, Morita H. Effect of Si content on surface quality of extruded Al-Mg2Si system alloys. Materials Science and Technology 1998;14(4):328-332.

[77] Tokizawa M, Takatsuji N. Effects of the die condition and billet composition on the surface characteristics of the extruded 6063 aluminum alloy. Transactions of the Japan Institute of Metals 1988;29(1):69-79.

[78] As SK, Shallerud B, Tveiten BW, Holme B. Fatigue life prediction of machined components using finite element analysis of surface topography. International Journal of Fatigue 2005;27(10-12):1590-1596.

[79] Taylor D, Clancy OM. The fatigue performance of machined surfaces. Fatigue and Fracture of Engineering Materials and Structures 1991;14(2-3):329-336.

[80] Andrews S, Sehitoglu $\mathrm{H}$. A computer model for fatigue crack growth from rough surfaces. International Journal of Fatigue 2000;22(7):619-630.

[81] Mura T, Tanaka K. Dislocation dipole models for fatigue crack initiation. Mechanics of Fatigue Washington, D.C., 1981, pp. 111-131.

[82] Tanaka K, Mura T. A micromechanical theory of fatigue crack initiation from notches. Mechanics of Materials 1982;1(1):63-73.

[83] ASTM Standard E 466. "Standard practice for conducting force controlled constant amplitude axial fatigue tests of metallic materials". ASTM International: West Conshohocken, PA.

[84] Basquin $\mathrm{OH}$. The exponential law of endurance tests. Proceedings of the ASTM 1910;10:625-630.

[85] Landgraf RW. The resistance of metals to cyclic deformation. In: Achievement of High Fatigue Resistance in Metals and Alloys PHILADELPHIA, PA: American Society for Testing and Materials, 1970, pp. 3-36.

[86] Wang M, Kassner ME. Tensile and fatigue properties of aluminum alloy sheet 6022 . Journal of Materials Engineering and Performance 2002;11(2):166-168.

[87] Pedersen K. Cyclic deformation of an extruded AlMgSi alloy. Fatigue 87', Vol. 1 Charlottesville, VA, 1987, pp. 103-112.

[88] Thompson A. The comparison of yield and fatigue strength dependence with grain size. Scripta Materialia 1971;5(10):859-863.

[89] Keller R, Zielwinski W, Gerberich WW. On the onset of low-energy dislocation substructures in fatigue: grain size effects. Materials Science and Engineering $A$ 1989;A113(1-2):267-280. 
[90] Liang F, Laird C. Control of intergranular fatigue cracking by slip homogeneity in copper I: effect of grain size. Materials Science and Engineering A 1989;A117(1-2):95-102.

[91] Morrison D, Moosbrugger JC. Effects of grain size on cyclic plasticity and fatigue crack initiation in nickel. International Journal of Fatigue 1997;19(1):S51-S59.

[92] Golos K, Osinski Z. The effect of the grain size on the threshold stress intensity range. Fatigue 93': 5th international conference on Fatigue and FAtigue Thresholds, Vol. 1 Montreal, Quebec, Canada, 1993, pp. 531-536.

[93] Hanlon T, Kwon YN, Suresh S. Grain size effects on the fatigue response of nanocrystalline metals. Scripta Materialia 2003;49(7):675-680.

[94] Higo Y, Pickard C, Knott JF. Effects of grain size and stacking fault energy on fatiguecrack-propagation thresholds in Cu-Al aluminium alloys. Metal Science 1981;15(6):233240.

[95] Li J, Wen XY, Man CS, Zhai T. Fatigue of continuous cast AA5754 Al alloy sheet. Materials Science and Technology 2007;23(3):324-332.

[96] Viviani L, Caglioti G, Albertini G, Ceretti M, Fiori F, Rustichelli F. Texture and mechanical anisotrpy of $6082 \mathrm{Al}$ alloy samples subjected to extrusion and rolling. Materials Science Forum 1996;217-222(1):653-658.

[97] Cerney I, Oceanasek V, Hnilica F. Problems of fatigue crack growth in strongly anisotropic Al-alloys. Key Engineering Materials 2003;251-252:61-72.

[98] Cerney I, Oceanasek V, Hnilica F. An evaluation of fatigue crack growth and affecting mechanisms in Al-alloys with strongly oriented microstructure. Eighth International Conference on Assessment and Control of Damage and Fracture Mechanics Crete, Greece, 2004, pp. 103-112.

[99] Ocenasek V, Sperlink K, Zuna P, Macek K. Heterogeneity and anisotropy of mechanical and fatigue properties of high-strength aluminum extrusions. ICAA-6: 6th International Conference on Aluminium Alloys, Vol. 3 Toyohashi, Japan, 1998, pp. 1313-1318.

[100] Ocenasek V, Cieslar M. Fatigue inhomogeneity and anisotropy of age-hardenable Al-Alloy extrusions. Kovove Materialy 2003;41(5):313-324.

[101] Sperlink K, Ocenasek V, Macek K. Effect of forming and tretment parameters on mechanical and fatigue properties of Al-Li extrusions. Third Symposium on Hot Deformation of Aluminum Alloys III as held at the 2003 TMS Annual Metting San Diego, CA, 2003, pp. 541-549.

[102] Lin CS, Krams WE. Corrosion fatigue crack growth rate of aluminum-lithium alloy sheet and its weldmet. New Methods for Corrosion Testing of Aluminum Alloys San Francisco, CA, 1990, pp. 117-131.

[103] Ryder DA, Lynch SP. The effect of environment and frequency on crack nucleation. Stage I and Stage II crack growth in two aluminium zinc magnesium alloys. The Influence of Environment on Fatigue London, UK, 1977, pp. 21-26.

[104] Lin CK, Chou J-C. Effects of mean stress and loading frequency on the corrosion fatigue behavior of a high strength aluminum alloy in different tempers. 14th International Corrosion Congress Cape Town, South Africa, 1999.

[105] Juijerm P, Altenberger I, Scholtes B. Influecne of ageing on cyclic deformation beehavior and residual stress relaxation of deep rolled as-quenched aluminium alloy AA6110. International Journal of Fatigue 2007;29(7):1374-1382.

[106] Huang Q, Xin Ren J. Surface integrity and its effects on the fatigue life of the nickel-based superalloy GH33A. International Journal of Fatigue 1991;13(4):322-326.

[107] Maiya PS. Geometrical characterization of surface roughness and its application to fatigue crack initiation. Materials Science and Engineering A 1975;21(1):57-62. 